WÍLERSON VENCESLAU CALIL

DETERMINAÇÃo DE FATOR DE CORREÇÃO PARA CÁLCULO DE PERDAS MAGNÉTICAS EM NÚCLEOS DE TRANSFORMADORES DE POTÊNCIA PELO MÉTODO DE ELEMENTOS FINITOS 
WÍLERSON VENCESLAU CALIL

\title{
DETERMINAÇÃO DE FATOR DE CORREÇÃO PARA CÁLCULO DE PERDAS MAGNÉTICAS EM NÚCLEOS DE TRANSFORMADORES DE POTÊNCIA PELO MÉTODO DE ELEMENTOS FINITOS
}

\author{
Dissertação apresentada à Escola \\ Politécnica da Universidade de São \\ Paulo para obtenção do título de Mestre \\ em Engenharia
}




\title{
WÍLERSON VENCESLAU CALIL
}

\section{DETERMINAÇÃO DE FATOR DE CORREÇÃO PARA CÁLCULO DE PERDAS MAGNÉTICAS EM NÚCLEOS DE TRANSFORMADORES DE POTÊNCIA PELO MÉTODO DE ELEMENTOS FINITOS}

\author{
Dissertação apresentada à Escola \\ Politécnica da Universidade de São \\ Paulo para obtenção do título de Mestre \\ em Engenharia \\ Área de Concentração: \\ Sistemas de Potência \\ Orientadora: Dra. Viviane Cristine Silva
}


Este exemplar foi revisado e alterado em relação à versão original, sob responsabilidade única do autor e com a anuência de seu orientador.

São Paulo, 29 de abril de 2009

Assinatura do autor

Assinatura do orientador

\section{Calil, Wílerson Venceslau}

Determinação de fator de correção para cálculo de perdas magnéticas em núcleos de transformadores de potência pelo método de elementos finitos / W.V. Calil. -- ed. rev. -- São Paulo, 2009.

119p.

Dissertação (Mestrado) - Escola Politécnica da Universidade de São Paulo. Departamento de Engenharia de Energia e Automação Elétricas.

1. Transformadores e reatores 2. Método dos elementos finitos 3. Aço elétrico I. Universidade de São Paulo. Escola Politécnica. Departamento de Engenharia de Energia e Automação Elétricas II. t. 
Aos meus pais, aos meus irmãos e à Paola, pelo incentivo, compreensão e apoio. 


\section{AGRADECIMENTOS}

Aos meus pais, Fátima e Wilerson, pelo exemplo de vida e apoio em todos os momentos. Pais muito dedicados que desde cedo não mediram esforços para me fornecer o maior legado que alguém pode receber: o estudo.

À minha orientadora, professora Dra. Viviane Cristine Silva, pela ajuda durante todas as fases de elaboração desta dissertação, pela orientação, dedicação, paciência e competência técnica.

Ao Dr. José Carlos Mendes, da ABB, pelo forte incentivo, colaboração, motivação ao estudo, direcionamentos e discussões oportunas, desde o início da minha carreira como engenheiro.

Aos meus professores Dr. José Roberto Cardoso, Dr. Luiz Lebensztajn e Dr. Silvio Ikuyo Nabeta, pelas sugestões e comentários durante o desenvolvimento deste trabalho, e aos colegas do LMAG, pelo constante auxílio e estímulo.

À ABB Asea Brown Boveri e aos meus colegas de trabalho, pelas discussões oportunas.

À Paola Miranda do Nascimento pelo amor, carinho, momentos de felicidade e motivação, por estar sempre presente nos momentos cruciais deste trabalho e por tornar a minha vida mais plena.

À minha irmã Adriana e ao meu irmão Wendel que sempre elevam minha autoestima e me apóiam nos momentos difíceis.

Por fim, agradeço às demais pessoas que, direta ou indiretamente, contribuíram na execução deste trabalho. 
Nada é tão maravilhoso que não possa existir, se admitido pelas leis da Natureza.

(Michael Faraday) 


\section{RESUMO}

Este trabalho apresenta uma proposta para cálculo da correção do fator de construção de núcleos de transformadores de potência, devido à influência das perdas na região das juntas magnéticas. Esse fator permite corrigir o valor de perdas em vazio no núcleo, obtido das curvas do fabricante das chapas de aço-silício, e sua determinação, até o momento, tem sido baseada, sobretudo, em estimativas empíricas e estatísticas. A correção proposta para esse fator é baseada no cálculo das perdas magnéticas na região das juntas, cálculo esse obtido a partir de uma simulação computacional do transformador pelo Método de Elementos Finitos. Com esse fator de correção, foi possível melhorar a precisão do cálculo de perdas em vazio, aproximando-o mais dos valores experimentais. Foram estudados dois tipos de juntas magnéticas, com e sem step-lap, e três dimensões de entreferro; em seguida, foi analisada a influência desses parâmetros no fator de construção. As simulações foram realizadas por um programa comercial que utiliza o Método de Elementos Finitos em duas dimensões.

Palavras-chave: Transformadores de potência, Método dos elementos finitos, aço elétrico, juntas de núcleo. 


\section{ABSTRACT}

This work presents a suggestion to calculate a correction factor of building factor in a core of power transformers, due to influence of losses in the magnetic junctions. This factor allows correcting the value of no load loss in the core, obtained from steel manufacturers, and their determination, up to now, it has been based, especially, in empirical and statistics estimates. The correction suggested to this factor is based in magnetic losses calculations in junction region, calculation which was obtained from a computer simulation of the transformer by Finite Element Method. Having this correction factor, could the accuracy of the calculation of no load loss, be improved, setting of the experimental value closer. Two types of magnetic joints, with and without step-lap, and three of gap were studied; then, it was examined the influence of these parameters in the building factor. The simulations were run by commercial software which uses finite element method in two dimensions.

Keywords: Power Transformers, Finite Element Method, Electric Steel, Junctions. 


\section{LISTA DE ILUSTRAÇÕES}

Figura 1.1 - Exemplo de utilização de transformadores num sistema elétrico [70]...20

Figura 1.2 - Núcleo magnético de transformador com destaque para as regiões das

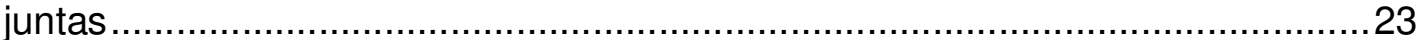

Figura 1.3 - Junta step-lap do núcleo de um transformador de potência..................24

Figura 1.4 - Perfis das juntas non-step-lap - V1 e step-lap V2 ...............................25

Figura 2.1 - Exemplo de configuração de núcleo, indicando em azul as regiões de

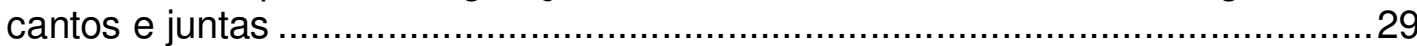

Figura 2.2 - Juntas com step-lap (superior) e sem step-lap (inferior) [23] ................33

Figura 3.1 - Construção de lâmina de aço para núcleos magnéticos com $\alpha$ no plano

da laminação [64] ............................................................................. 40

Figura 3.2 - Cristal cúbico exibindo anisotropia cristalina $(\vec{B}=\mu \cdot \vec{H}) \ldots \ldots \ldots \ldots \ldots \ldots \ldots . . . . . . .11$

Figura 3.3 - Seção transversal da lâmina do núcleo.....................................46

Figura 3.4 - Composição de núcleo com chapas em corte de 90 na junta: as flechas

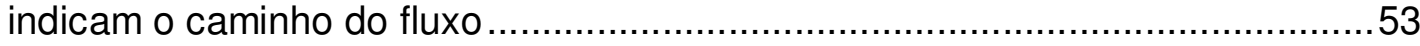

Figura 3.5 - Composição de núcleo com chapas em corte de 45ํㅡas juntas: as fechas indicam o caminho do fluxo ................................................................53

Figura 3.6 - Detalhe do corte representando a junta de núcleo padrão à direita e

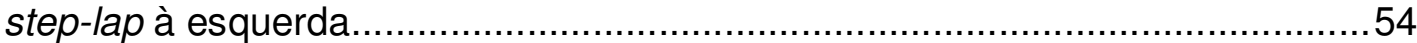

Figura 3.7 - Gráfico de perdas no núcleo versus custo de fabricação [64] ..............56

Figura 3.8 - Gráfico de perdas no núcleo versus custo de fabricação; determinação do ponto de otimização [64]

Figura 4.1 - (a) Modelo geométrico para simulação do trecho de núcleo (azul) e bobina de excitação (marrom). (b) Detalhe aumentado da interface com a condição periódica e a direção do fluxo magnético

Figura 4.2 - Malha de elementos finitos do modelo da Fig. 4.1 ...........................64

Figura 4.3 - Bloco de material laminado e bloco equivalente homogeneizado .........65

Figura 4.4 - Modelo para a simulação do núcleo homogeneizado ..........................66

Figura 4.5 - Vista do núcleo do transformador..................................................67

Figura 4.6 - Configuração para análise com condição de contorno de Dirichlet nãohomogênea

Figura 5.1 - Carta de cores da distribuição de induções no domínio de estudo, obtida da simulação por elementos finitos: representação de chapas e sua isolação. No detalhe, escala do valor das induções em $T$

Figura 5.2 - Carta de cores da distribuição de induções no domínio de estudo, obtida da simulação por elementos finitos: representação do núcleo por material homogeneizado. No detalhe, escala do valor das induções em T ....................71

Figura 6.1 - Exemplo de juntas de transformadores estudadas: (a) Junta Padrão sem step-lap. (b) Junta com step-lap - V2 [67] ......................................... 74

Figura 6.2 - Núcleo com juntas indicando linha para o traçado da indução. A carta de cores fornece o módulo da distribuição de induções....................................75

Figura 6.3 -Indução magnética axial no interior de uma chapa de aço-silício para indução de média 1,0T calculada pela simulação

Figura 6.4 -Indução magnética axial no interior de uma chapa de aço-silício para indução média de 1,0T de [24]

Figura 6.5 - Perda em função da indução a $60 \mathrm{~Hz}$ (valores interpolados e experimentais). 
Figura 6.6 - Comparação entre os fatores de correção para dois tipos de juntas ....80

Figura 6.7 - Indução em juntas sem step-lap - V1 - com 1,00mm de entreferro e 1,77 T de indução nominal

Figura 6.8 - Indução em juntas step-lap - V2 com 1,00mm de entreferro e 1,77T de

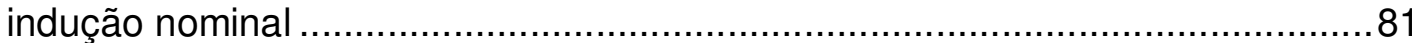

Figura 6.9 - Fator de correção para junta V1, sem step-lap, e vários valores de entreferro 82

Figura 6.10 - Fator de correção para junta step-lap V2 e vários valores de entreferro83 Figura 7.1 - Vista frontal e superior de um núcleo de transformador trifásico com três colunas e sem retorno

Figura 7.2 - Indução em núcleo de transformador trifásico, com detalhe para a região das juntas magnéticas no pacote central

Figura 7.3 - Divisão de um núcleo trifásico em diferentes regiões para cálculo de perdas. As regiões em azul correspondem àquelas das juntas no pacote central88

Figura 7.4 - Fator médio de correção, estimado através do valor de indução média obtido do banco de dados

Figura 7.5 - Screenshot do aplicativo desenvolvido para cálculo de FCR e FC corrigido.

Figura 7.6 - Screenshot do aplicativo com os resultados da situação 1 ..................92

Figura 7.7 - Screenshot do aplicativo com os resultados da situação 2 ...................93

Figura 7.8 - Screenshot do aplicativo com os resultados da situação $3 \ldots \ldots \ldots \ldots \ldots \ldots . . .93$

Figura 7.9 - Fator de redução do grau de empirismo do FC para diversas configurações de juntas. 


\section{LISTA DE TABELAS}

Tabela 3.1 - Perdas específicas máximas de aço para núcleos laminados a frio e laminados a quente [64]

Tabela 6.1 - Indução de pico versus perda magnética fornecida pelo fabricante a $60 \mathrm{~Hz}[69]$

Tabela 6.2 - Perdas (Valores numéricos e semi-analíticos) ……………………....78

Tabela 6.3 - Área de superfície de contato entre chapas de aço-silício ....................84 


\section{LISTA DE ABREVIATURAS E SIGLAS}

$\begin{array}{ll}\text { ABB } & \text { Asea Brown Boveri } \\ \text { EF } & \text { Entreferro } \\ \text { EI } & \text { Tipo de núcleo de transformador } \\ \text { FC } & \text { Fator de construção } \\ \text { FCR } & \text { Fator de correção } \\ \text { FE } & \text { Fator de empacotamento (ou empilhamento) do núcleo } \\ \text { FFL } & \text { Fator de fabricação local } \\ \text { FM } & \text { Fator de manuseio das chapas } \\ \text { GO } & \text { Chapa de aço-silício de grãos orientados } \\ \text { MEF } & \text { Método numérico de elementos finitos } \\ \text { SST } & \text { Single Sheet Tester: aparelho utilizado na caracterização de perdas }\end{array}$




\section{LISTA DE SÍMBOLOS}

\begin{tabular}{|c|c|}
\hline $\overrightarrow{A_{1}}$ & vetor potencial magnético na superfície 1 \\
\hline $\overrightarrow{A_{2}}$ & vetor potencial magnético na superfície 2 \\
\hline AJ & altura da janela \\
\hline$A_{\text {juntas }}$ & área das juntas \\
\hline AN & altura total do núcleo \\
\hline$A_{\text {total }}$ & área total do núcleo \\
\hline$a \%$ & taxa de juros correspondente à média anual \\
\hline$\Delta L$ & variação da dimensão do grão \\
\hline$\vec{B}$ & vetor indução magnética \\
\hline$B_{m}$ & indução máxima \\
\hline$B_{\max }$ & indução máxima \\
\hline$B_{\text {pico }}$ & indução magnética de pico \\
\hline$d$ & preço da energia \\
\hline$D_{n}$ & diâmetro nominal do núcleo \\
\hline$e$ & espessura total das chapas \\
\hline$\varepsilon$ & fator de empacotamento ou empilhamento \\
\hline$f$ & Freqüência \\
\hline$f_{\text {perdas }}(x)$ & função de perda \\
\hline FF & distância entre eixos das colunas do núcleo \\
\hline$F_{\text {junta }}$ & fator da área da junta, com relação à área total do núcleo \\
\hline$G_{F e}$ & massa do ferro \\
\hline$\vec{H}$ & vetor intensidade de campo magnético \\
\hline$H_{c}$ & força coerciva \\
\hline$I_{\text {excitação }}$ & corrente de excitação \\
\hline$i_{p}$ & corrente elétrica no primário \\
\hline$i \%$ & taxa da inflação média anual \\
\hline$k_{\text {Anomalas }}$ & coeficiente de perdas anômalas \\
\hline
\end{tabular}




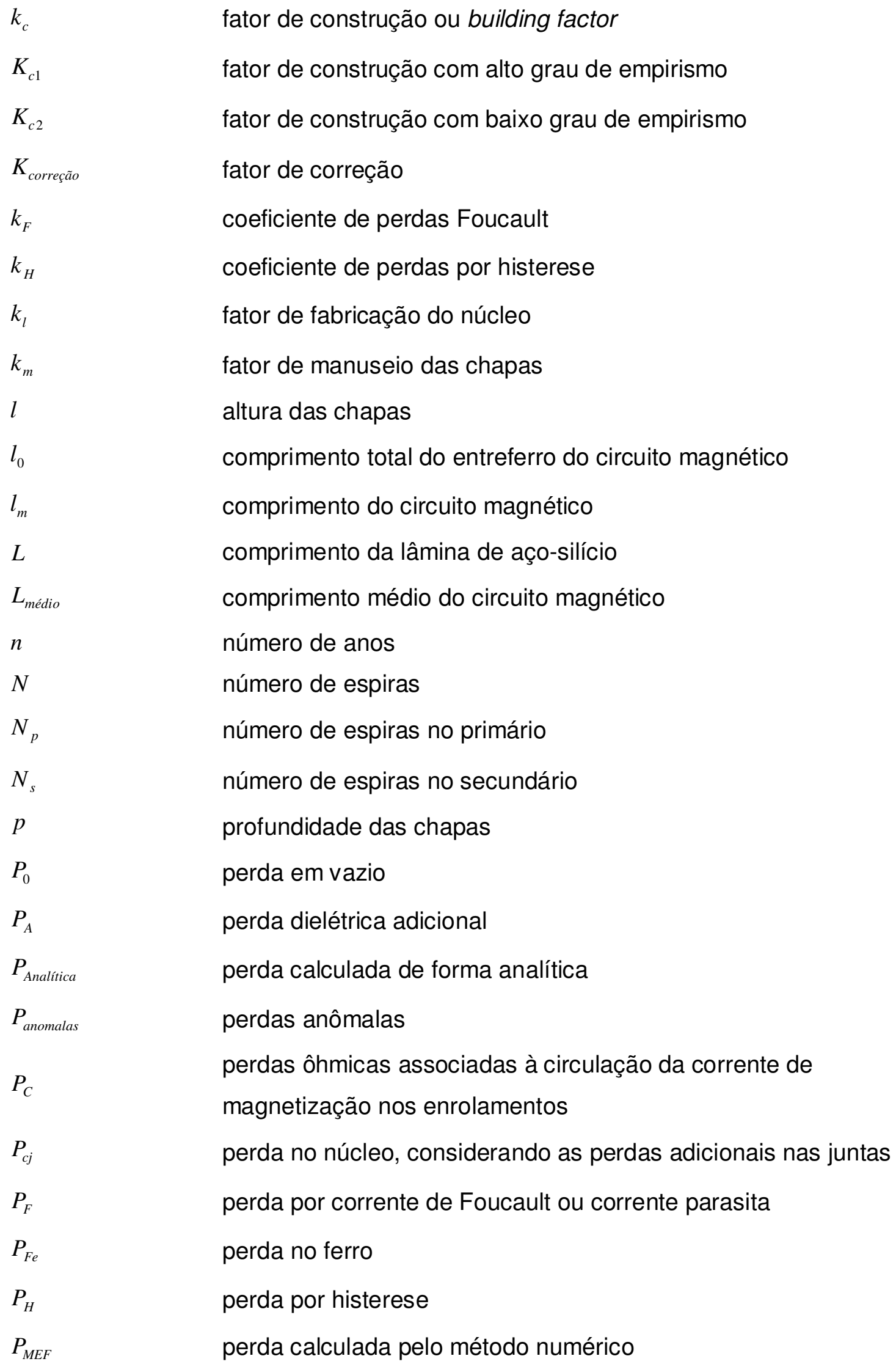




\begin{tabular}{|c|c|}
\hline$P_{\text {semi-analitico }}$ & perda calculada de forma semi-analítica \\
\hline$P_{t}$ & perda total \\
\hline$p \%$ & taxa anual de aumento do preço da energia \\
\hline$\Re_{0}$ & relutância do entreferro \\
\hline$\Re_{F e-S i}$ & relutância do núcleo de aço-silício \\
\hline$R_{F C}$ & fator de redução do fator de correção \\
\hline$s$ & fator multiplicativo \\
\hline$S$ & seção magnética efetiva do núcleo \\
\hline$t$ & espessura efetiva do material magnético \\
\hline$t_{\text {isolação }}$ & espessura da camada de isolação \\
\hline$\mu$ & permeabilidade magnética \\
\hline$\mu_{0}$ & permeabilidade magnética no vácuo \\
\hline$\mu_{f}$ & permeabilidade magnética de material linear \\
\hline$\mu_{f x}$ & $\begin{array}{l}\text { permeabilidade magnética de material linear na direção da } \\
\text { laminação }\end{array}$ \\
\hline$\mu_{F e-S i}$ & permeabilidade magnética do aço-silício \\
\hline$\mu_{n}$ & permeabilidade magnética na direção normal às lâminas \\
\hline$\mu_{t}$ & permeabilidade magnética na direção tangencial às lâminas \\
\hline$[\mu]$ & tensor de permeabilidade \\
\hline Vol & volume útil do material laminado \\
\hline$v_{s}$ & tensão no secundário \\
\hline$W_{t}$ & energia total \\
\hline$[W]$ & perda específica estabelecida pelas chapas a determinadas \\
\hline$k g$ & freqüência e indução \\
\hline$x$ & perda magnética \\
\hline$x$ & montante de dinheiro \\
\hline$y$ & coeficiente de Steinmetz \\
\hline$\gamma_{F e}$ & densidade específica do ferro \\
\hline$\gamma_{v}$ & densidade específica do volume \\
\hline$\sigma$ & condutividade do material \\
\hline
\end{tabular}




$\begin{array}{ll}\sigma_{f} & \begin{array}{l}\text { condutividade para material com permeabilidade magnética } \\ \text { linear } \\ \sigma_{f x}\end{array} \\ \sigma_{n} & \begin{array}{l}\text { condutividade para material com permeabilidade magnética } \\ \text { linear na direção da laminação }\end{array} \\ \sigma_{t} & \text { condutividade na direção normal às lâminas } \\ {[\sigma]} & \text { condutividade na direção tangencial às lâminas } \\ \phi & \text { tensor de condutividade } \\ \delta & \text { fluxo magnético } \\ \alpha & \text { profundidade de penetração de onda } \\ & \text { ângulo de desvio a partir da direção de laminação }\end{array}$




\section{SUMÁRIO}

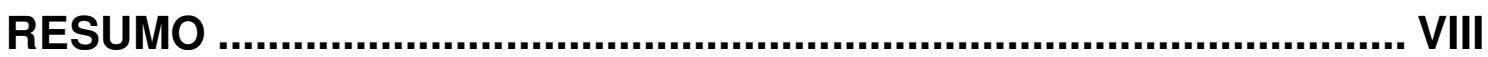

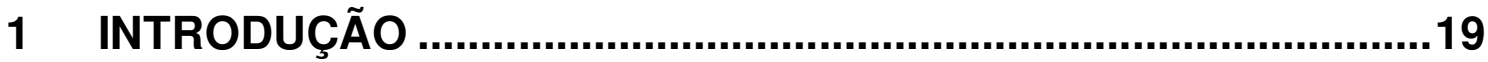

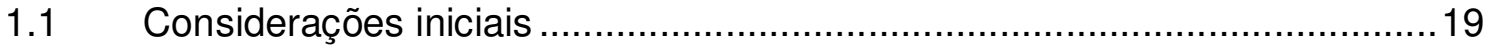

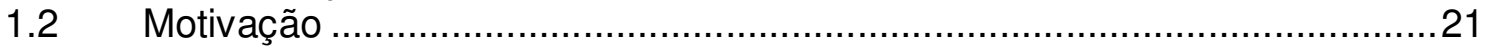

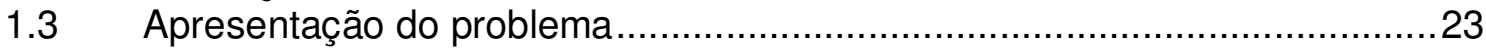

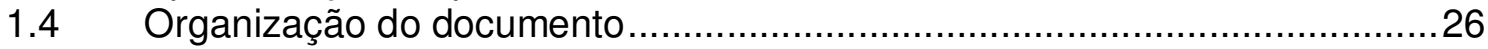

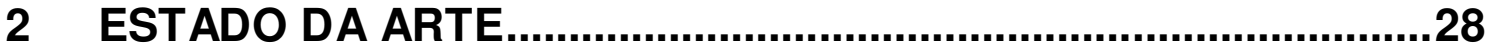

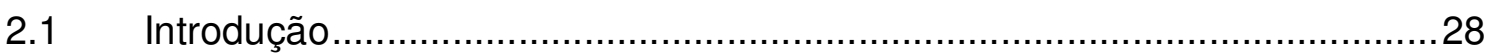

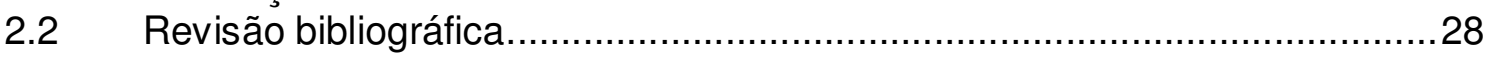

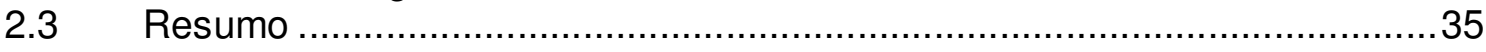

3 PERDAS NO NÚCLEO DO TRANSFORMADOR ..........................36

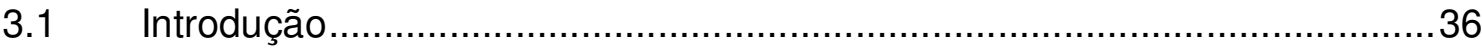

3.2 Materiais para núcleo de transformadores...............................................36

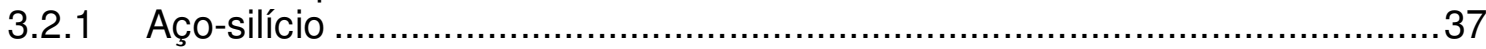

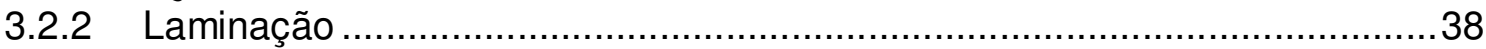

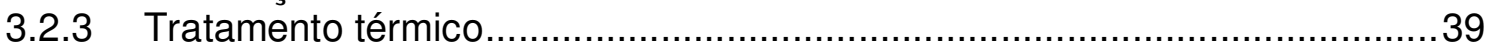

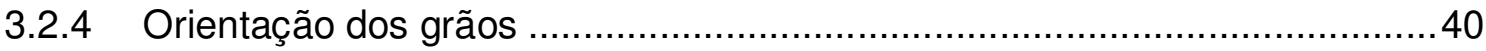

3.2.5 Anisotropia cristalina ..................................................................... 41

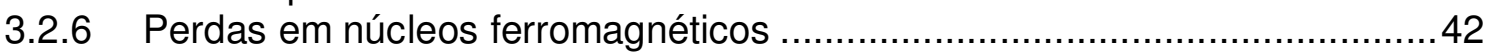

3.3 Perdas por histerese................................................................... 44

3.4 Perdas por correntes parasitas ou Foucault ..........................................46

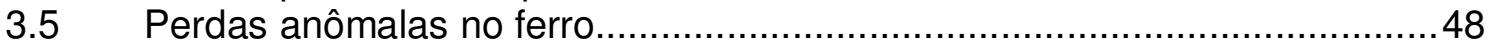

3.6 Perdas totais no núcleo ferromagnético ……....................................... 48

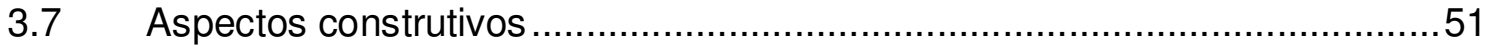

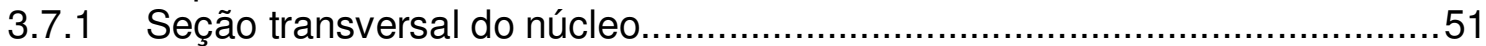

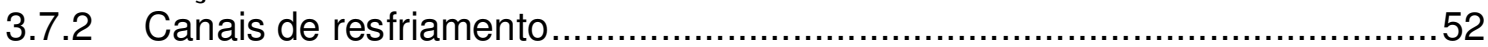

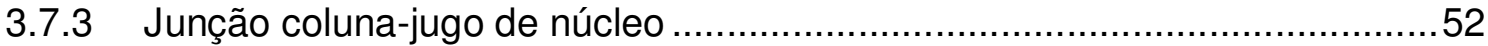

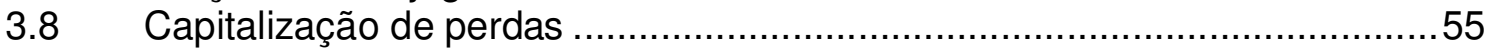

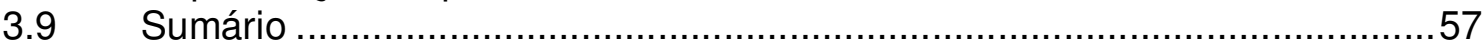

4 METODOLOGIAS E METAS .....................................................58

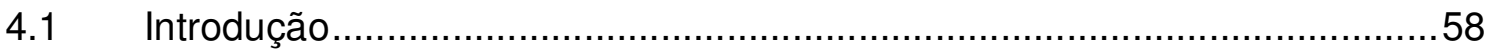

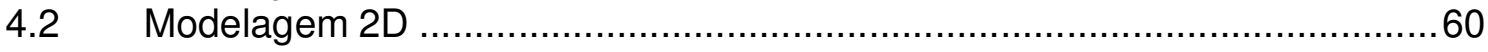

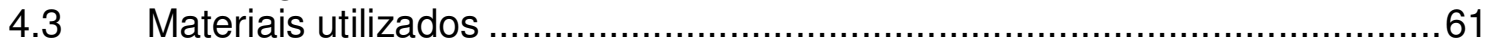

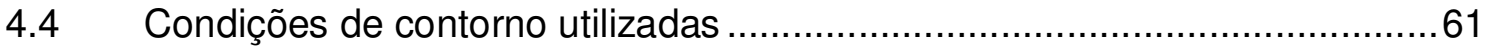

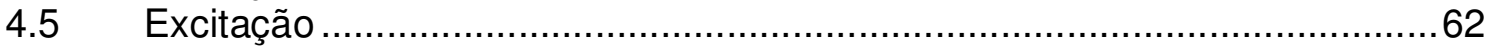

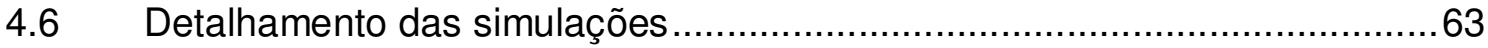

4.6.1 Chapas e espiras em contato com limite de contorno e condição de contorno

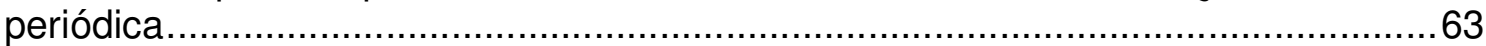

4.6.2 Homogeneização do núcleo …………….......................................65

4.6.3 Imposição de fluxo através de condição de Dirichlet não-homogênea ..........67

5 SIMULAÇÕES REALIZAD AS ...................................................70

5.1 Chapas em contato com limite de contorno e com condição de contorno

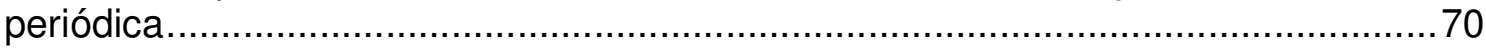

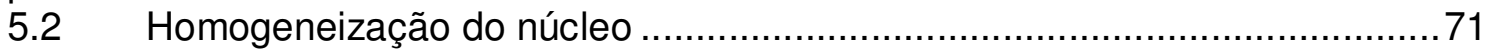


5.3 Imposição de fluxo através do vetor potencial magnético não-homogêneo 72

6 APLICAÇÕES E RESULTADOS PRELIMINARES .73

$6.1 \quad$ Modelagens realizadas..................................................................... 74

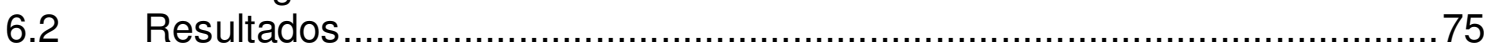

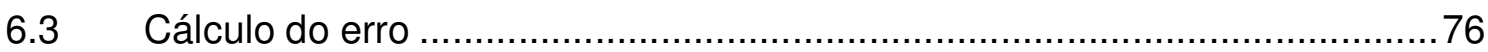

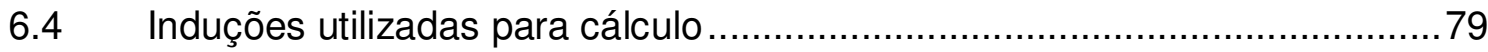

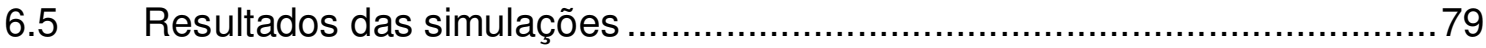

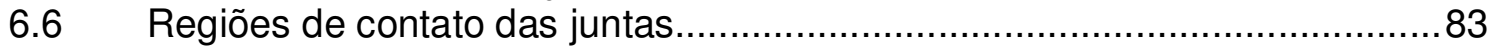

$7 \quad$ VALORES DE PERDAS MEDIDAS ...........................................85

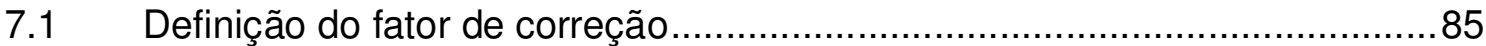

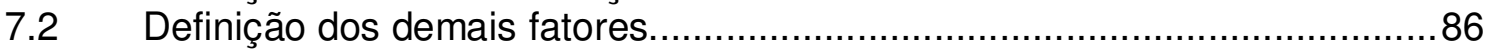

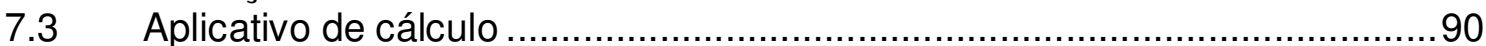

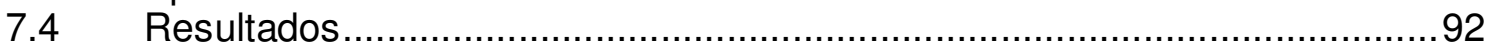

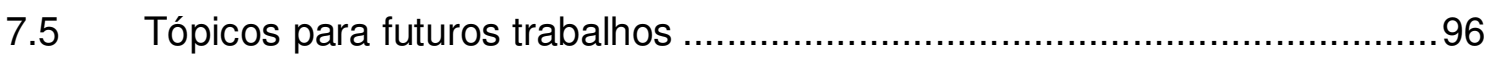

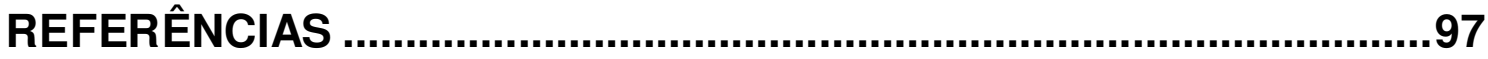

APÊNDICE A - PROPRIEDADES DOS MATERIAIS E CONFIGURAÇÃO DO PROGRAMA ................................................104 APÊNDICE B - CÁLCULO DAS PROPRIEDADES FÍSICAS PARA NÚCLEO HOMOGÊNEO .............................................................110 ANEXO A - CÁLCULO DE CAPITALIZAÇÃO DE PERDAS EM VAZI0113 


\section{INTRODUÇÃO}

\section{$1.1 \quad$ Considerações iniciais}

A descoberta da eletricidade representou um grande marco para o desenvolvimento da humanidade, culminando no seu estudo na criação da Engenharia Elétrica.

De acordo com relatórios de 2007 do Ministério de Minas e Energia (ano base 2006), entre 1974 e 2006, a capacidade instalada de geração de energia elétrica no Brasil teve crescimento maior que 2,2GW por ano. Com o aumento da demanda dos grandes centros urbanos e pela incapacidade de se gerar energia elétrica nas suas proximidades, foi necessária a utilização de um equipamento elétrico estático e de baixas perdas para elevar e reduzir a tensão, além de viabilizar a transmissão de energia elétrica para médias e longas distâncias.

O transformador foi inventado no final do século XIX e, desde então, a cada ano são publicados vários artigos sobre esse equipamento, provenientes das mais diferentes áreas técnicas às quais se aplica.

Transformadores estão presentes ao longo do sistema elétrico e isso tem motivado a existência de diversos estudos sobre perdas magnéticas, relacionados a esses equipamentos. A seguir, é ilustrada, na forma de diagrama unifilar, a diversidade de sua utilização dentro do sistema elétrico típico. 


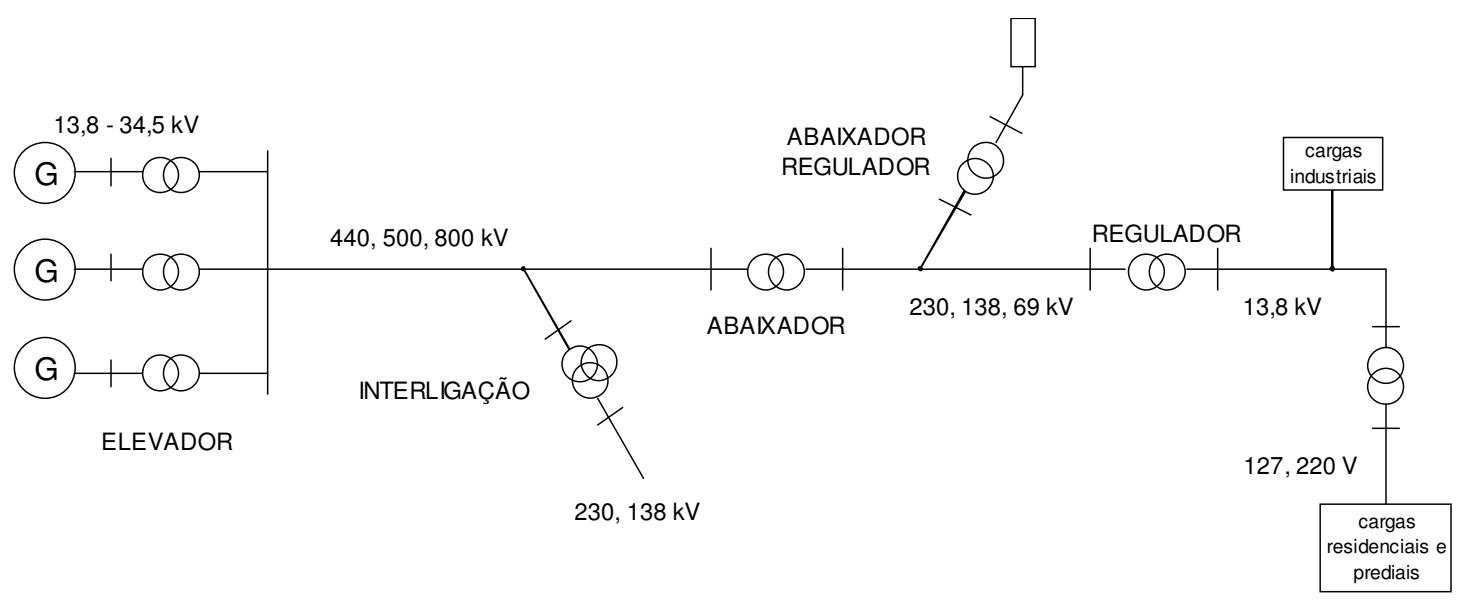

Figura 1.1 - Exemplo de utilização de transformadores num sistema elétrico [70]

Desde o desenvolvimento comercial dos transformadores, no início do século $\mathrm{XX}$, inúmeras teorias e modelos foram desenvolvidos para explicar os fenômenos encontrados. Até meados do século XIX, a comunidade científica não demonstrava interesse em modelagem dos materiais magnéticos; o que só passou a acontecer a partir da década de 80 , devido à crise energética iniciada nos anos 70 . No final da década de 90, houve outra crise energética no Brasil e agora, neste século, está tomando proporções mundiais. A comunidade científica está cada vez mais preocupada com o aquecimento global e isso contribui para aumentar o interesse em reduzir perdas, custos, consumo de energia e comercialização de crédito de carbono.

A preocupação em reduzir gastos energéticos, as leis governamentais e ambientais e a concorrência entre empresas que procuram melhorar o rendimento de seus equipamentos e diminuir custos com segurança e aumentar a confiabilidade estão proporcionando uma grande aproximação entre o setor industrial e o setor de pesquisa.

As concessionárias de energia elétrica e as indústrias consumidoras também são grandes interessadas em estudos e pesquisas para redução de custos, aumento de confiabilidade e vida útil de seus equipamentos, bem como redução dos custos com manutenção, tempo médio entre falhas e revitalização do parque de transformadores.

Os transformadores de potência são equipamentos do sistema elétrico que têm um alto valor agregado em materiais como aço-silício, aço-carbono, óleo, cobre e 
celulose. O núcleo magnético do transformador de potência não é a parte do transformador que está sujeita ao maior número de falhas, mas, na maioria das vezes, é uma parte que necessita ser otimizada, pois agrega cerca de $30 \%$ do custo final do produto.

\subsection{Motivação}

O conhecimento das perdas em transformadores de potência é de extrema importância para o planejamento do sistema elétrico de potência, do fluxo de potência e da tarifação.

Como apenas $1 \%$ do volume mundial de aço produzido, atualmente, é utilizado por suas propriedades magnéticas e, desse valor, apenas $15 \%$ é usado em transformadores (os aços chamados de grão-orientado - GO), investimentos em pesquisas e processos de produção de materiais, com menores perdas específicas para o núcleo, têm sido bastante investigados pela Engenharia Metalúrgica.

A Engenharia Elétrica estuda os aspectos construtivos dos equipamentos eletromagnéticos, para que seja possível minimizar a massa, de acordo com as premissas iniciais.

O melhoramento constante da tecnologia - devido a ferramentas modernas de simulações eletromagnéticas, térmicas e mecânicas através de métodos numéricos, e a materiais com melhores propriedades físicas e maior qualidade no processo de fabricação - reduziu, nas últimas quatro décadas, aproximadamente $20 \%$ da massa total de um transformador de potência. Desse valor, 35\% corresponde à redução da massa do núcleo durante o mesmo período devido aos novos métodos de prensagem das chapas, redução da resistência interlaminar, rebarbas nos cortes da chapas, melhores métodos de cálculo e maior entendimento das causas do fator de construção. O rendimento de um transformador de potência pode chegar a 99,8\%, quando a potência ultrapassa 500MVA. É, sem dúvida, a máquina elétrica com maior rendimento. 
O cálculo do núcleo do transformador é elaborado através de alguns dados de entrada como tensão induzida nos enrolamentos, potência, freqüência da rede em que ele será instalado, número de espiras nos enrolamentos e indução. Com esses dados, o projeto do núcleo transformador é iniciado. Além das dimensões do núcleo predefinidas no projeto inicial, é importante calcular a perda que será dissipada durante o funcionamento do equipamento.

O cálculo da perda no ferro é feito através de uma equação muito simples em que se multiplica a perda específica do material a determinadas indução e freqüência com a massa total do material utilizado na construção. Em seguida um fator é inserido para a correção deste cálculo.

As perdas específicas são fornecidas pelo fabricante das chapas do núcleo que coleta a amostra de determinado lote e realiza um ensaio através de determinada norma técnica. Normalmente, utiliza-se o quadro de Epstein para a obtenção desses dados que são a curva de perda por indução e a curva de magnetização da chapa.

Como o processo de fabricação do aço utilizado em transformadores de potência é muito complexo, os dados obtidos nos ensaios podem sofrer variações, dependendo do lote, do manuseio e do corte das chapas.

Por esse motivo, os fabricantes de transformadores utilizam fatores para calcular com maior precisão as perdas que são o fator de manuseio das chapas (FM) e o fator de fabricação local (FFL). Esses dois fatores juntos fornecem o fator de construção (FC). Por último, mas não menos importante, há o fator de empacotamento (ou empilhamento) do núcleo (FE) que corrige a seção efetiva de material ferromagnético no núcleo. Esse último é fornecido pelo fabricante das chapas, pois é definido através da espessura de laminação e da espessura de isolação das chapas.

O FC do núcleo é calculado através de dados empíricos. Cada fabricante tem um FC para cada tipo de material e de núcleo. Quanto maior o FC, maior quantidade de material é necessário para a fabricação do núcleo, aumentando, assim, a massa total do equipamento, sua dimensão e seu custo.

Adicionalmente, podem ocorrer perdas em regiões distintas do núcleo, como as perdas em furos nas lâminas, pressão nas chapas e perdas interlaminares, devido aos contatos entre as chapas do núcleo com baixa isolação; perdas nas estruturas 
metálicas de fixações e perdas nas junções coluna-jugo entre as chapas do núcleo [68].

O foco deste trabalho de pesquisa é estudar a influência dos diferentes tipos de junções e da dimensão do entreferro do núcleo no FC. Neste estudo, é utilizado o método numérico de elementos finitos (MEF) para obtenção do cálculo da perda localizada nas juntas, devido à saturação do campo e, com isso, reduzir o grau de empirismo do cálculo do fator de construção.

\subsection{Apresentação do problema}

Em núcleos de transformadores de potência, as juntas têm um papel muito importante na rigidez mecânica do equipamento. Na figura 1.2, é possível observar um núcleo de transformador em processo de montagem, sem o jugo superior. Estão assinaladas as regiões das juntas propriamente citadas.

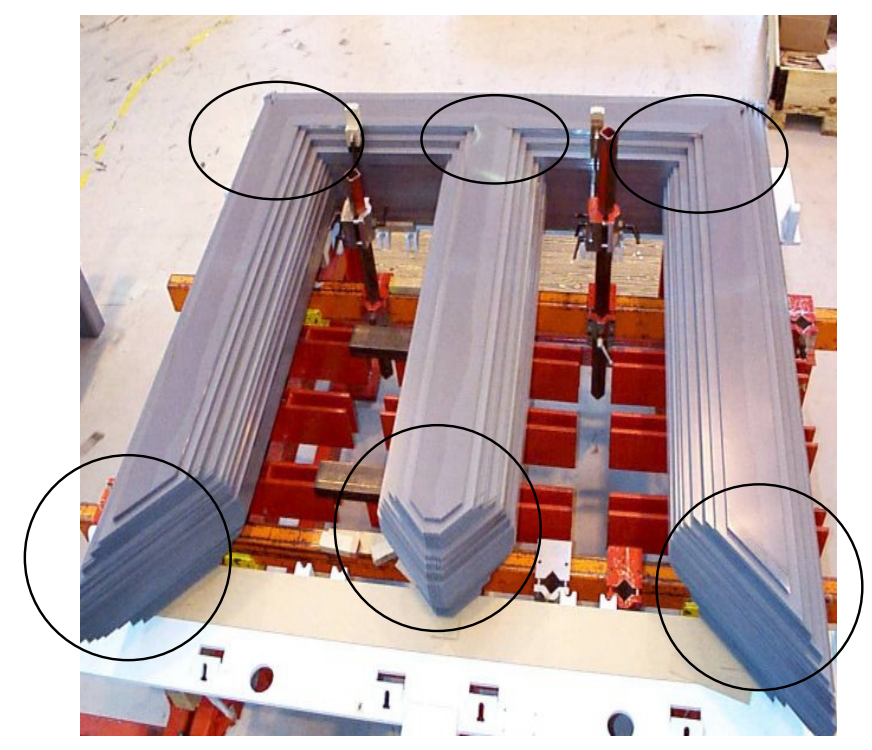

Figura 1.2 - Núcleo magnético de transformador com destaque para as regiões das juntas Foto cedida por: ABB-Brasil - Divisão Transformadores 
Cada núcleo tem um tipo de junta definida pelo projetista eletromecânico do transformador. São conhecidos na literatura dois tipos diferentes de juntas:

- junta step-lap;

- junta padrão ou non-step-lap.

A junta do tipo step-lap foi desenvolvida durante as décadas de 60 e 70 pela Westinghouse. Ao se aplicar esse tipo de junta no transformador, foi possível verificar um decréscimo de aproximadamente 10\% nas perdas magnéticas e de cinco a sete decibéis no nível de ruído para indução típica de operação de 1.77T, tomando-se como base um mesmo núcleo com juntas padrões.

O número de lâminas por camada influencia na dimensão do entreferro e no nível de ruído e é estabelecido a partir de análise econômica global de produção do núcleo. Quando são chapeadas 2 (duas) ou 3 (três) lâminas por camada os resultados são bastante satisfatórios [52].

Na figura 1.3, é apresentada a junta step-lap do núcleo em detalhe, com apenas duas lâminas por camada.

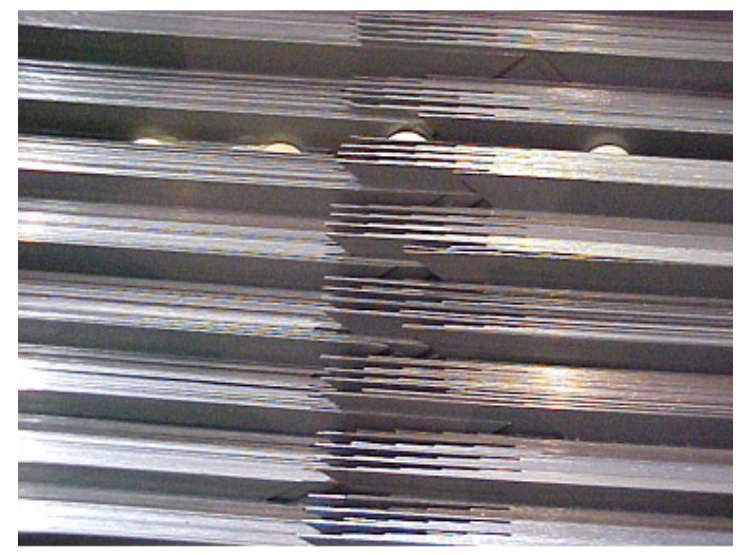

Figura 1.3 - Junta step-lap do núcleo de um transformador de potência Foto cedida por: ABB-Brasil - Divisão Transformadores

Após definido o FC e apresentadas as configurações de juntas, este trabalho apresentará um estudo, utilizando simulação numérica pelo MEF, comparando diferentes arranjos de juntas de núcleo ferromagnético para analisar qual o acréscimo, nas perdas totais, das perdas localizadas nas regiões das juntas, e para 
propor um novo fator, que será denominado fator de correção (FCR). Com esse fator de correção, o projetista do transformador poderá reduzir o grau de empirismo do fator de construção do núcleo adotado atualmente.

As juntas estudadas neste trabalho correspondem a dois tipos, denominadas V1 e V2. A junta V1, conhecida também como junta padrão, é a forma mais simples de junta de núcleo de transformador, até hoje utilizada em transformadores de baixa potência.

A junta V2 é conhecida como junta step-lap. Este trabalho procurará analisar diferenças entre as juntas step-lap e non-step-lap, além dos prós e contras das juntas step-lap.

Serão estudadas duas configurações de juntas, como as ilustradas na figura 1.4, com diferentes espaçamentos entre as chapas (entreferro). Esses diferentes espaçamentos estão na direção horizontal em que as chapas serão encostadas ou ficarão o mais próximo possível das outras.

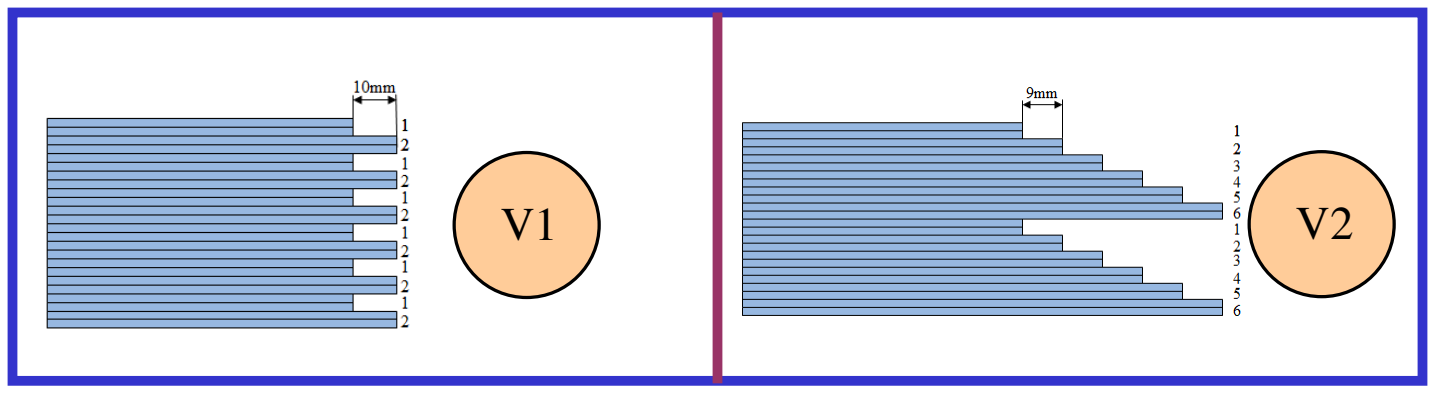

Figura 1.4 - Perfis das juntas non-step-lap - V1 e step-lap V2

Para este estudo será utilizado um aplicativo computacional comercial, Infolytica ${ }^{\circledR}$ [61], que permite realizar a simulação de dispositivos eletromagnéticos, através do MEF em duas dimensões.

A partir dos resultados da simulação pelo MEF, que fornece, entre outras coisas, a distribuição de induções magnéticas por todo o domínio de estudo, é possível calcular a distribuição das perdas magnéticas em vazio em todos os pontos do núcleo e, por fim, as perdas nesse núcleo. 
De posse dos resultados das simulações de dados de cálculos, dados reais de perdas em vazio de transformadores ensaiados em laboratório serão analisados, de forma a encontrar um FCR para um determinado tipo de núcleo trifásico sem coluna de retorno. Os erros referentes às medições de perdas em vazio e seus impactos nos resultados gerais não serão analisados no presente trabalho.

A intenção é encontrar um FCR para cada configuração de junta de núcleo, com variações de entreferro de $0,5 \mathrm{~mm}$ a $1,5 \mathrm{~mm}$.

Com o FCR, será possível efetuar o cálculo do novo FC global e FC local nas regiões das juntas, através de um equacionamento proposto que irá considerar a área do núcleo e a região das juntas. Com esses valores, será possível, ainda, propor uma correção para o cálculo total de perdas em um núcleo, diminuindo o grau de empirismo da técnica adotada até o momento.

A motivação para a continuação de um trabalho futuro é a aplicação desses conceitos magnéticos para se obter uma máxima eficiência sob o ponto de vista geral: magnético, térmico, mecânico-estrutural e econômico.

\subsection{Organização do documento}

O capítulo 1 introduzirá o leitor na importância do estudo em transformadores de potência, e explicitará a motivação para o estudo, suas justificativas e os objetivos principais desta pesquisa.

No capítulo 2 serão apresentados os principais artigos e trabalhos desenvolvidos desde a década de 70, sobre a utilização de métodos numéricos para cálculo de perdas em transformadores, até trabalhos mais atuais, sendo possível observar a evolução dos métodos e, assim, perceber o melhor caminho a ser seguido por esta pesquisa.

No capítulo 3 serão apresentados os principais conceitos sobre perdas no ferro do transformador (Histerese, Foucault e Suplementares), tipos de aço utilizados em 
transformadores, aspectos construtivos relevantes, além do conceito de capitalização de perdas no transformador e sua importância econômica para fabricantes e consumidores.

O capítulo 4 mostrará a metodologia e as metas do trabalho, a aplicação do MEF no cálculo de perdas devido às juntas, os resultados esperados e as contribuições acadêmicas.

O capítulo 5 abordará as aplicações da metodologia proposta e os resultados que serão confrontados com os oriundos da literatura apresentada no capítulo 2.

O capítulo 6 apresentará a proposta do fator de correção para cada tipo de junta.

O capítulo 7 apresentará os dados experimentais de transformadores reais, as conclusões do trabalho, as observações gerais e as dificuldades encontradas durante a pesquisa.

No apêndice A encontram-se as propriedades físicas dos materiais utilizados e os detalhes relativos ao programa computacional utilizado.

$O$ apêndice $B$ apresenta $O$ cálculo do fator de laminação para simplificação do modelo e, no anexo $\mathrm{A}$, é detalhado o cálculo de capitalização de perdas em vazio para um transformador. 


\section{ESTADO DA ARTE}

\section{$2.1 \quad$ Introdução}

Neste capítulo, iremos expor o conteúdo das principais publicações, seus resultados e conclusões. Os trabalhos abordam os seguintes temas: núcleo de transformador, materiais não-lineares, fator de construção de núcleos de transformadores e utilização de método numérico no cálculo magnético de transformadores (diferenças finitas ou elementos finitos).

\subsection{Revisão bibliográfica}

As primeiras publicações que abordaram a modelagem numérica e o cálculo de perdas em juntas de transformadores são creditadas a Moses e Thomas [38], em 1974. Nessa pesquisa, os autores mostram que as perdas podem ser consideravelmente reduzidas com a melhora da junta do núcleo do transformador, baseado no conhecimento do fluxo rotacional e circulante, tanto nos cantos como nos jugos.

O artigo também demonstra a existência do fluxo rotacional. Em algumas áreas do núcleo, o fluxo é puramente alternado, como nas colunas, mas há locais em que o fluxo é rotacional e, onde, portanto, ocorrem maiores perdas histeréticas nestas regiões. As perdas nas regiões em que ocorre o fluxo rotacional são maiores do que em outras áreas, mas a intensidade e as regiões em que isso ocorre dependem do 
tipo de junta de núcleo utilizado. A figura 2.1 mostra um exemplo de núcleo de transformador trifásico e as regiões em destaque onde ocorrerá concentração maior de campo, nos cantos e nas juntas.

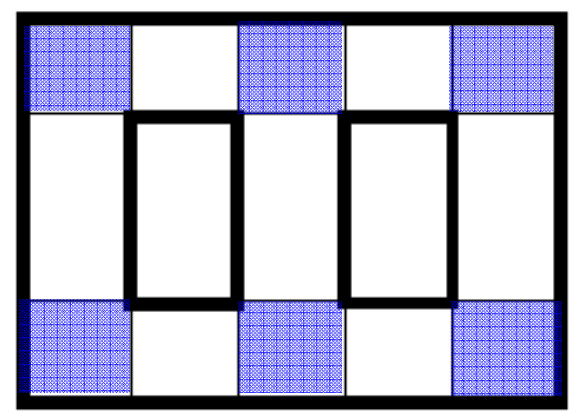

Figura 2.1 - Exemplo de configuração de núcleo, indicando em azul as regiões de cantos e juntas

Em casos de transformadores com núcleos grandes, as perdas nas juntas podiam exceder $2 \%$ de todas as perdas do núcleo, o que motivou o autor a buscar uma melhora na eficiência das juntas. Embora a perda no núcleo do transformador seja menor que $0,5 \%$ da potência total de saída do transformador, ganhos significativos foram obtidos com um melhor projeto das juntas do núcleo.

No mesmo ano, Charap e Judd [47] apresentaram um núcleo de transformador do tipo El e concluíram que a corrente de excitação e as perdas no núcleo são funções da distribuição do fluxo em cada lâmina. No entanto, consideram sempre um fluxo uniformemente distribuído, o que não ocorre na região das juntas do núcleo.

Uma das intenções dos autores era aperfeiçoar o transformador para alimentação de conversores, devendo, o mesmo, suportar alto nível de componentes de corrente contínua. A curva de magnetização foi obtida através do ensaio no quadro de Epstein em chapas de grão orientado (GO). A direção da densidade de fluxo é perpendicular à da laminação. A variação espacial da direção e densidade do fluxo foi considerada nas juntas e nos cantos do núcleo. Fontes de correntes nãosenoidais, devido ao conversor que produz diferentes formas de onda, não foram consideradas na análise desse artigo.

Foi verificado que a perda no núcleo e a corrente de excitação são mais significativas nas colunas do que nos cantos e juntas. A montagem de chapa única 
de aço-silício por camada de núcleo não reduz as perdas magnéticas em transformadores pequenos com núcleo do tipo $\mathrm{El}$, o que já não que se pode afirmar para transformadores de potência, concluem os autores. Laminações alternadas podem ser atrativas em grandes transformadores para reduzir as perdas no núcleo.

Nakata, Takahashi e Kawase [18] em 1982, utilizaram o método de elementos finitos, levando em consideração as correntes parasitas e a saturação magnética. Quatro efeitos foram avaliados: o comprimento do step-lap, o comprimento do entreferro, o número de chapas por camadas e a densidade de fluxo.

Os resultados obtidos nesse trabalho mostraram que, com um aumento no número de chapas de aço-silício por camada, a saturação no entreferro e a corrente de excitação são reduzidas e que as perdas no núcleo diminuem ligeiramente. Já quando se diminui o número de chapas por camada, verifica-se uma maior saturação e influência do entreferro.

No mesmo ano, Valkovic [52] apresentou um trabalho que mostrava que as propriedades magnéticas do núcleo do transformador são influenciadas por três fatores básicos: a qualidade do material empregado, o processamento das chapas de aço-silício durante a fabricação e o projeto do núcleo.

Os resultados obtidos por esses estudos mostram que as perdas no núcleo crescem com o aumento do comprimento do degrau (overlap). O autor comenta que esses dados não estão de acordo com os valores obtidos em suas referências bibliográficas e propõe maior investigação e discussões nesses casos. Com relação ao número de chapas de aço-silício por camada, o autor explica que, para reduzir o tempo de processo de fabricação do núcleo de um transformador de potência, utiliza de duas a três chapas por camada. Dessa maneira, as perdas aumentam, pois a montagem ideal é de apenas uma chapa por camada. Em seus estudos, é possível verificar que as perdas com uma ou duas chapas por camada são praticamente as mesmas, mas ao colocar três chapas por camada a perda aumenta em torno de $5 \%$.

As conclusões obtidas pelo autor são um pouco diferentes das demais publicações: o fator de construção do núcleo depende do seu tipo e de sua geometria. Os resultados dos experimentos mostram que a junta $\mathrm{V}-45^{\circ}$ não tem propriedade magnética melhor, como assumem outros autores em experimentos anteriores, e é 
possível observar que cada chapa adicional por camada aumenta de $2 \%$ a $3 \%$ as perdas no núcleo do transformador.

Quatro anos depois, Ikeda, Okabe e Ohmura [20] estudaram a aplicação de materiais com estrutura amorfa, não-cristalina, na construção de núcleos. Seus estudos envolveram o método de elementos finitos. Dois núcleos foram simulados, sendo que um deles possui juntas de $45^{\circ}$ e o outro juntas de $90^{\circ}$.

Foram determinadas e comparadas entre si perdas em chapas de aço-silício, cortadas com ângulo de 45, e perdas em material amorfo, com corte de $45^{\circ}$ e $90^{\circ}$. A conclusão foi que a forma de se obter as menores perdas consiste em cortar 0 material amorfo em 45․ Entretanto, não é simples efetuar esse tipo de corte. Outra conclusão interessante foi que o fator de construção para núcleos com materiais amorfos é menor que para o aço-silício.

Em 1990, Dedulle et al [5], utilizando o MEF, propuseram uma técnica para calcular o campo magnético no núcleo do transformador trifásico, levando em consideração a não-linearidade e a anisotropia do material. A permeabilidade magnética foi modelada por um tensor que depende do componente de campo, o método de Newton-Raphson foi utilizado na resolução e, também, uma malha auto-adaptativa foi utilizada para melhorar os resultados numéricos. Como se trata de uma simulação em duas dimensões, foram considerados dois eixos diferentes de magnetização: o eixo de fácil magnetização e o eixo de difícil magnetização.

Concluiu-se que a hipótese de material isotrópico (vetores $\mathrm{B}$ e H colineares) não é verificada nas juntas. Os resultados do modelo proposto mostram a diferença nas formas de indução para um material isotrópico e anisotrópico que ocorre em maior intensidade nas juntas do núcleo. Os autores ainda observam que em grandes núcleos é necessário levar em conta a anisotropia do material para que se possa minimizar as perdas em vazio.

Em 1994, Basak, Yu e Lloyd [46], apresentaram em seu trabalho uma ferramenta computacional de elementos finitos, considerando a anisotropia do material e sua não linearidade. O software gera uma malha com elementos triangulares em duas dimensões que são subdivididos em triângulos menores nas regiões mais críticas. Como resultado, o erro entre o valor medido e o valor calculado foi de apenas 5,6\%, 
atribuído ao erro computacional, ao fluxo de dispersão e à variação da construção do núcleo.

Em 1998, Girgis et al [23] estudaram, de forma experimental, algumas variáveis da construção de um núcleo de transformador. Os parâmetros estudados foram diferentes tipos de materiais e transformadores de núcleo monofásico e trifásico e os seguintes parâmetros de desempenho: perdas e corrente de excitação. Foi, também, apresentado o comportamento das perdas, em relação à pressão aplicada nos grampos que fixam o núcleo do transformador.

O artigo discorre que, no atual mercado global de transformadores, há cada vez mais pressão sobre o fabricante para reduzir as perdas no núcleo do transformador e para melhorar a precisão de cálculo de perdas no momento do projeto, a fim de aumentar o seu nível de confiança e de não pagar penalidades devidas a erros de cálculos. O fator de construção do núcleo do transformador é uma função de algumas variáveis, segundo sugestão dos autores, como: geometria do núcleo, tipo do material, orientação dos grãos, empacotamento e qualidade das chapas e isolações.

Foram construídos núcleos com step-lap e sem step-lap para verificar a implicação desses dois tipos de juntas e foram aplicadas induções de 1,0T até 1,8T. Os autores concluíram que o tipo de junta do núcleo, com uma ou duas chapas, afeta significativamente o fator de construção e que o fator de construção é muito mais sensível ao aumento do entreferro em junções step-lap do que em junções sem o step-lap. Na figura 2.2 é possível observar juntas de núcleo step-lap e sem step-lap. Nas juntas com step-lap existem cinco degraus com seis diferentes posicionamentos de chapas enquanto na junta sem step-lap há um degrau com dois diferentes posicionamentos de juntas. 


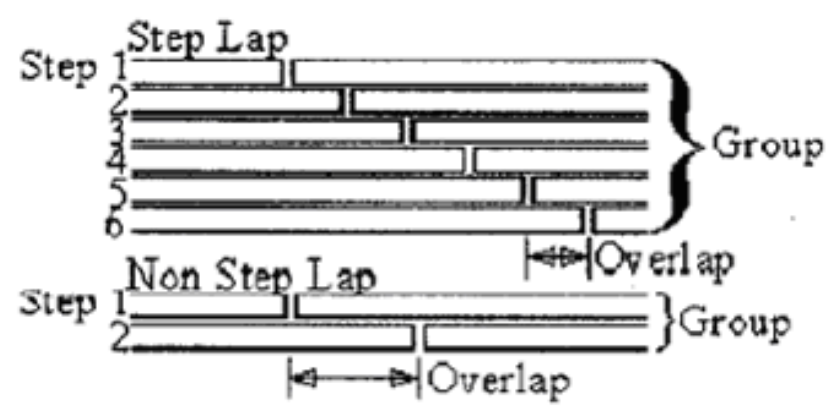

Figura 2.2 - Juntas com step-lap (superior) e sem step-lap (inferior) [23]

No mesmo ano, Mechler e Girgis [24] descreveram a solução semi-analítica e numérica do problema exposto anteriormente. Para efetuar tais cálculos, foi utilizado o método de diferenças finitas em duas dimensões para o cálculo de perdas, considerando o material anisotrópico e não-linear.

Foram avaliados os impactos causados por diferentes juntas do núcleo, número de degraus, tamanho do entreferro e espessura de laminação e qual a influência no desempenho geral do núcleo. O resultado dessa análise foi usado para desenvolver um novo desenho de núcleo para os transformadores de potência da ABB (Asea Brown Boveri).

Segundo os autores, a ferramenta desenvolvida para cálculo de perdas é muito confiável, pois trabalha com um modelo que contempla materiais anisotrópicos e não-lineares. Os resultados obtidos analiticamente foram baseados na lei de Ampère e as propriedades magnéticas das chapas foram retiradas dos manuais dos fabricantes. Como todas as modificações geométricas nas juntas podem ser modeladas e simuladas, esse método pode ser aplicado a uma grande variedade de projetos de transformadores. Já o ciclo de histerese e o tensor de relutividade foram simplificados para o modelo proposto. O cálculo de distribuição de fluxo pelo método descrito pode ser utilizado para calcular vibração e ruídos nos núcleos dos transformadores.

Tenyenhuis, Girgis e Mechler [25], em 2001, estudaram outros tipos de perdas no circuito magnético. Foi um trabalho dividido em três estudos específicos, sendo eles: perdas devido ao tipo de junta do núcleo; perdas relacionadas a falhas de empilhamento das chapas; e perdas devido ao corte das chapas na direção longitudinal, utilizado para adequá-las ao tamanho do núcleo. 
Concluiu-se que juntas com step-lap são mais eficientes na redistribuição de fluxo localizado com induções baixas. Já no caso de induções mais elevadas, o desempenho é similar às juntas sem step-lap. As conclusões quanto à geometria do núcleo são que há uma diminuição nas perdas de junções step-lap em relação às junções sem step-lap e a perda localizada é um pouco maior quando se trata de uma junção step-lap. Todos os estudos desse artigo foram analisados apenas através de simulação computacional, com método de diferenças finitas; ou seja, não houve validação experimental.

Em 2002, Mac et al [8], propuseram um algoritmo para utilizar curvas de magnetização equivalente, corrente de excitação e perdas no núcleo do transformador, através de análise pelo método de elementos finitos. Além disso, a condição de contorno de Neumann foi utilizada e ali o fluxo foi considerado perpendicular, ou seja, normal às chapas. Foi estudado um transformador trifásico, considerando juntas com step-lap. Esse trabalho foi totalmente numérico, não tendo nenhuma validação experimental. Concluiu-se que a maior influência da curva de magnetização e da corrente de excitação era devida mais à quantidade de camadas de chapas de aço-silício do que ao entreferro ou ao tamanho dos degraus (overlap). A parcela de perdas que tem influência mais significativa nas perdas do núcleo corresponde àquelas devido a correntes parasitas, pois as histeréticas praticamente não variam. Concluiu-se, também, que a corrente de excitação depende mais do fator de laminação do que da espessura da chapa de aço-silício.

No mesmo ano, So, Anseneau e Hanique [40] estudaram como as perdas em vazio se comportam quando são alimentadas com forma de onda não-senoidal e concluíram que existe a necessidade de um método mais geral de correção de medição para esses casos. Propuseram uma análise empírica baseada em dados de ensaios como conclusão desse estudo.

Em 2006, Abbaszadeh [9] utilizou o método de elementos finitos para obtenção da distribuição de fluxo e das perdas totais no núcleo de um transformador monofásico. A ferramenta é baseada na solução da equação de Poisson para a Magnetostática, na qual são inseridos os valores da curva de magnetização em quatro segmentos de reta e interpolação por um polinômio de terceira ordem. 
Após o cálculo, o autor mostrou a relação dos dados medidos e dos dados calculados numericamente com uma malha com 1056 elementos e outra com 4183 elementos e como o refinamento da malha diminui o erro neste caso.

\section{$2.3 \quad$ Resumo}

Neste capítulo, foi mostrado um panorama dos estudos já efetuados acerca das perdas em juntas de transformadores e as diversas abordagens de cálculo, com ênfase na simulação do problema por métodos numéricos. Até o momento, não foi publicado nenhum artigo sobre como o tipo de junta do núcleo interfere diretamente no fator de construção do núcleo de transformadores de potência e, por esse motivo, este trabalho apresentará uma proposta de como calcular o fator de construção localizado na região das juntas. É necessário determinar numericamente qual o valor do fator de construção do núcleo de transformadores de potência. Até o momento, não foram identificados, tampouco, trabalhos mostrando cálculos de fator de construção para diferentes tipos de juntas e entreferro.

Os fundamentos de núcleo de transformadores, os materiais utilizados, os aspectos construtivos e as perdas em núcleos de transformadores de potência serão apresentados no capítulo seguinte. Nesse ponto, será possível entender e observar quais são as dificuldades dos fabricantes das chapas de aço-silício, por que o entreferro é inevitável e por que minimizá-lo nas junções do núcleo e o que ele pode causar nas perdas totais do núcleo e no fator de construção. 


\section{$3 \quad$ PERDAS NO NÚCLEO DO TRANSFORMADOR}

\subsection{Introdução}

As perdas no ferro são caracterizadas pela dissipação de potência no núcleo de transformadores. O intuito deste capítulo é contextualizar o material aço-silício - o mais importante deste estudo - explicitar quais são as perdas encontradas quando se aplica um campo magnético e como ele é montado em um transformador.

Serão apresentados os tipos de perdas encontradas no aço-silício e a relação dessas perdas com o Fator de Construção do núcleo. A capitalização de perdas em vazio e os aspectos construtivos do núcleo serão discutidos neste capítulo.

\subsection{Materiais para núcleo de transformadores}

Materiais ferromagnéticos $\left(\mu>>\mu_{0}\right)$ são utilizados na construção de núcleos de transformadores. Propriedades especiais, como reduzidas perdas magnéticas, reduzidas forças coercivas $\left(H_{c}\right)$ e elevada saturação são requisitos fundamentais para esses materiais. Os materiais comercialmente empregados nos núcleos têm como base o ferro e suas ligas. O ferro puro (Fe) tem um ponto de saturação de $2,12 \mathrm{~T}$, um dos valores mais elevados entre todos os elementos encontrados e pode ser tratado para que haja uma redução da força coerciva e de suas perdas magnéticas. Através de processos especiais, pode-se obter propriedades necessárias para um bom desempenho em máquinas elétricas, especificamente em 
transformadores de potência, como descrito acima. O ferro, por ser encontrado com abundância na natureza, possui um custo de refinamento baixo e é o material mais empregado para máquinas elétricas de pequeno e grande porte.

As perdas magnéticas podem ser separadas principalmente em dois grandes tipos, as perdas histeréticas e as perdas por correntes parasitas ou Foucault. A perda por histerese é a potência necessária para magnetizar o material do núcleo e é afetada pela orientação de grãos, impurezas e tensões internas do material.

Um fluxo magnético variável induzirá correntes parasitas no material do núcleo. As perdas associadas a essas correntes são diretamente proporcionais à condutividade $\sigma$ do material do núcleo e ao quadrado da espessura, indução magnética e freqüência.

\subsubsection{Aço-silício}

A condutividade do aço elétrico pode diminuir com a adição de silício em sua liga. Um aço com $3 \%$ de silício tem sua condutividade reduzida em até $70 \%$, se comparado com o ferro puro. Todavia, a adição de silício eleva o endurecimento e a fragilidade mecânica do material do núcleo e isso deve ser levado em consideração, pois os transformadores de potência são, geralmente, transportados por centenas ou milhares de quilômetros até sua instalação em um determinado ponto. Esses transportes causam impactos severos ao equipamento e, por esse motivo, existe a necessidade do material do núcleo não ser muito frágil.

Além disso, o silício reduz o envelhecimento caracterizado pela elevação gradual das perdas no núcleo durante a operação. O envelhecimento era uma característica marcante da "lâmina negra", muito utilizada antes de 1930. Atualmente, o teor de silício está entre $4 \%$ e $5 \%$. 


\subsubsection{Laminação}

A espessura das lâminas do núcleo do transformador deve ser reduzida ao máximo para que sejam diminuídas as perdas, já que são inversamente proporcionais à espessura. Todavia, numa determinada camada de isolação, o fator de empilhamento (space-factor) decresce com a redução da espessura das lâminas.

A tendência dos fabricantes é utilizar chapas com baixas espessuras e com a melhora das tecnologias de produção de aço-silício, as chapas vão sendo mais planas, ou seja, sem ondulações, em conjunto com a redução da camada de verniz da isolação.

Atualmente, são empregadas chapas com espessuras a partir de $0,18 \mathrm{~mm}$ até $0,50 \mathrm{~mm}$, laminadas a frio ou a quente, com ou sem tratamento por irradiação a laser. O tratamento por irradiação a laser diminui o tamanho dos cristais com significante redução de perdas em aproximadamente $20 \%$.

Em geral, o aço é obtido em lingotes que, então, são laminados e recozido à $800^{\circ} \mathrm{C}$. Durante o processo da laminação, verifica-se que:

- os grãos se estiram na sua direção;

- as propriedades mecânicas, magnéticas e elétricas tornam-se heterogêneas;

- devido ao estiramento dos grãos, a área do ciclo de histerese aumenta e elevam-se as perdas por histerese;

- a condutividade é reduzida pelo endurecimento associado à laminação, diminuindo as perdas por correntes induzidas. Essa manifestação pode também ocorrer durante o corte, a montagem e/ou a prensagem do núcleo do transformador.

A laminação pode ser a frio ou a quente. A laminação a frio melhora as propriedades magnéticas para a indução, na direção de laminação e piora em outras direções, 
particularmente na direção transversal de laminação. Assim, o aço laminado a frio apresenta elevada anisotropia, em relação ao aço laminado a quente.

A tabela abaixo apresenta valores comparativos de perdas específicas para aços laminados segundo os dois processos.

Tabela 3.1 - Perdas específicas máximas de aço para núcleos laminados a frio e laminados a quente

\begin{tabular}{|c|c|c|c|c|c|}
\hline \multirow{2}{*}{ Laminação } & \multirow{2}{*}{ Silí́cio } & \multirow{2}{*}{ Espessura } & \multicolumn{3}{|c|}{ Perda Específica Máxima } \\
\cline { 4 - 6 } & {$[\%]$} & {$[\mathbf{m m}]$} & $\mathbf{1 , 0 T} ; \mathbf{5 0 H z}$ & $\mathbf{1 , 5} ; \mathbf{5 0 H z}$ & $\mathbf{1 , 7 T ;} \mathbf{5 0 H z}$ \\
\hline Quente & $2,8-4,0$ & 0,5 & 2,0 & {$[\mathbf{W} / \mathbf{k g}]$} & - \\
\hline Frio & $2,5-3,5$ & 0,5 & 1,3 & 2,5 & 3,8 \\
\hline
\end{tabular}

\subsubsection{Tratamento térmico}

Após a laminação dos lingotes, as lâminas são tratadas termicamente através de recozimento à temperatura de, aproximadamente, $800^{\circ} \mathrm{C}$. Os benefícios do recozimento são:

- aumento das dimensões dos grãos com conseqüente redução das perdas por histerese;

- melhora do desempenho das lâminas de aço quando essas são submetidas a operações de corte, manuseio, prensagem e esforços mecânicos.

O processo de recozimento é realizado em atmosfera de hidrogênio, eliminando a oxidação do aço. 


\subsubsection{Orientação dos grãos}

A introdução da orientação de grãos foi uma inovação fundamental nos processos de fabricação de aços para núcleos.

O aço para núcleo é formado por cristais cúbicos. A orientação magnética preferencial é ao longo dos lados desses cristais. Com uma direção do fluxo ao longo da lâmina, passa a ser vantajoso orientar os cristais também ao longo da lâmina. Esse processo é denominado de orientação de grãos.

Atualmente, para as chapas de maior espessura em produção, um desvio médio de até $3^{\circ}$, a partir da direção preferencial, pode ser encontrado. Desde 1900, as perdas específicas de materiais para núcleos foram reduzidas em até mais de quatro vezes.

A figura 3.1 mostra uma lâmina de aço para núcleos. $O$ aço é composto de cristais cúbicos e as suas orientações apresentam um ângulo, $\alpha$, de desvio a partir da direção de laminação ou preferencial. $O$ aço possui uma cobertura externa de um fino filme de vidro que é aplicado durante o processo de resfriamento. Além desse filme de vidro, a lâmina de aço possui um verniz de fosfato (carlite) aplicado como proteção externa.

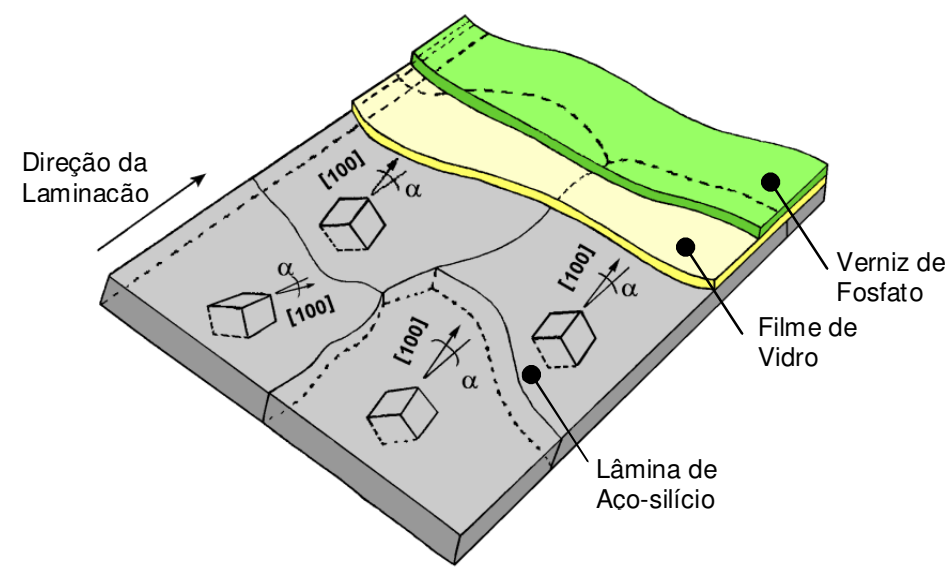

Figura 3.1 - Construção de lâmina de aço para núcleos magnéticos com $\alpha$ no plano da laminação [64] 


\subsubsection{Anisotropia cristalina}

As lâminas de aço para núcleos, constituídas da liga Fe-Si (ferro-silício), laminadas a frio e com grãos orientados, apresentam um eixo preferencial de magnetização, segundo o eixo de orientação de seus cristais. Quando o fluxo magnético flui segundo a direção desse eixo, as perdas magnéticas são baixas.

Anisotropia cristalina é a propriedade de alguns materiais magnéticos segundo a qual a permeabilidade magnética de um cristal cúbico é uma função da orientação do campo magnético aplicado.

A figura 3.2 mostra um cristal cúbico e a variação de perdas associadas.

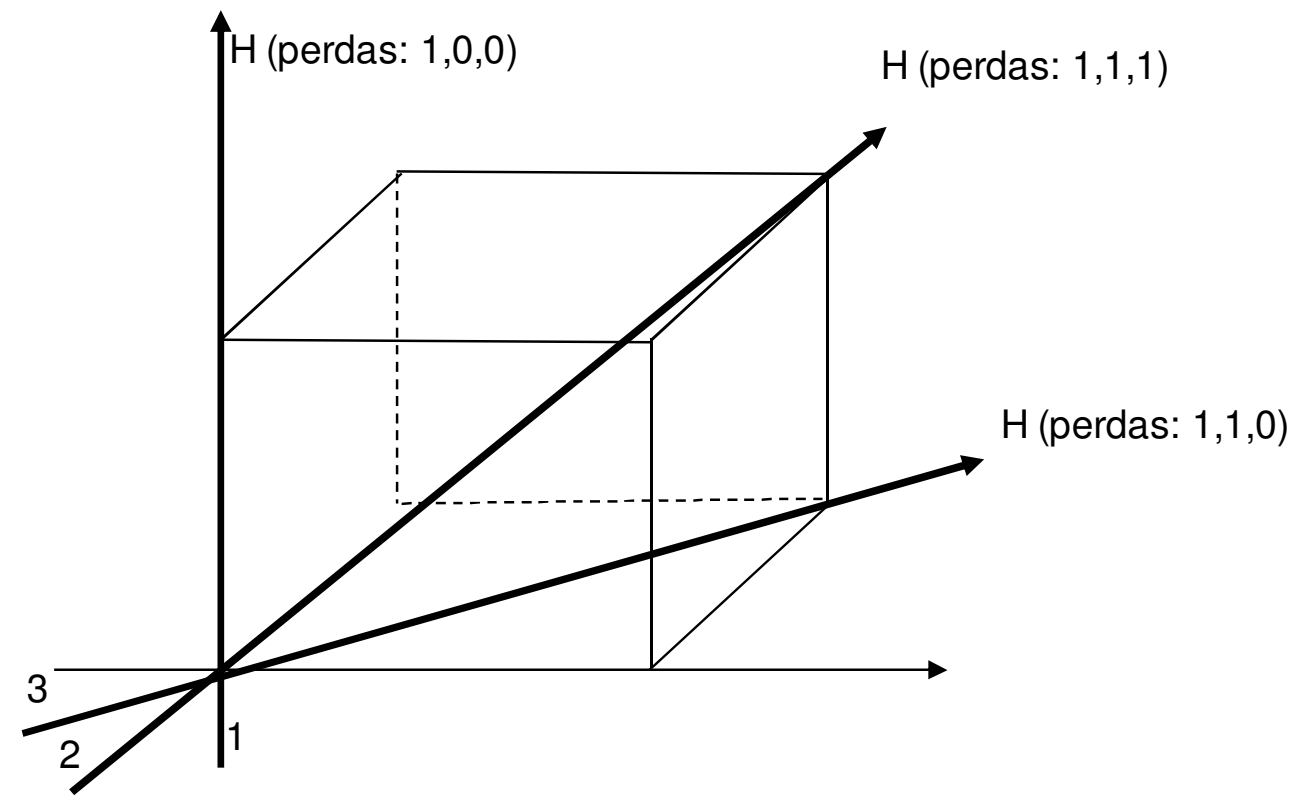

Figura 3.2 - Cristal cúbico exibindo anisotropia cristalina $(\vec{B}=\mu \cdot \vec{H})$

Algumas direções cristalinas conduzem melhor o fluxo magnético. Portanto, é interessante determinar o eixo preferencial de magnetização para as aplicações práticas. As lâminas de aço laminadas a frio, por exemplo, apresentam maior anisotropia cristalina que as lâminas de aço laminadas a quente. 


\subsubsection{Perdas em núcleos ferromagnéticos}

Além das perdas no núcleo, existem outras perdas que influenciam no rendimento do transformador, como as perdas devido ao ruído, nos enrolamentos e sistemas auxiliares. As perdas magnéticas diminuem o rendimento de máquinas elétricas como o transformador.

Este trabalho aborda as perdas magnéticas no ferro sob o enfoque da Engenharia Elétrica. É sabido que as perdas em aço elétrico sob o enfoque da Engenharia Metalúrgica são cinco:

1. perda devido à energia de troca;

2. perda devido à energia da anisotropia magneto cristalina;

3. perda devido à energia magnetostática do campo externo;

4. perda devido à energia magnetostática do campo desmagnetizante;

5. perda devido à energia magnetostrictiva.

$\mathrm{Na}$ Engenharia Elétrica, são consideradas apenas três tipos de perda em aço elétrico:

1. perda histerética;

2. perda por corrente induzida ou Foucault;

3. perda anômala (inter domínios) ou suplementar.

A fim de reduzir as correntes induzidas no núcleo, o aço para essa finalidade é laminado em espessuras da ordem de centésimos de milímetro.

As perdas magnéticas em lâminas de aço-silício podem ser medidas de várias formas, sendo algumas delas padronizadas por normas. Dentre os aparelhos utilizados na caracterização, tem-se o quadro de Epstein, o Single Sheet Tester (SST) e os métodos que utilizam transformadores de núcleo toroidal. 
No quadro de Epstein, as lâminas são inseridas para formar um circuito magnético fechado de quatro braços, no formato de um quadrado, sendo exigido um mínimo de doze lâminas (três por braço). O teste padronizado com o quadro de Epstein é o mais empregado atualmente.

A indução média no núcleo é obtida através do número de espiras no enrolamento secundário, $N_{s}$, a seção transversal do núcleo, $S$, e a tensão no secundário, $v_{s}(t)$, dada pela expressão:

$$
B(t)=\frac{1}{N_{s} \cdot S} \int v_{s}(t) d t
$$

O campo magnético no material é calculado através do número de espiras no primário, $N_{p}$, caminho magnético médio, $l_{m}$, e corrente no primário, $i_{p}(t)$, isto é:

$$
H(t)=\frac{N_{p}}{l_{m}} \cdot i_{p}(t)
$$

Com os valores de indução em Tesla $(T)$ e Campo Magnético em ampèreespira/metro $(A e s p / m)$, é possível calcular o valor das densidades de energia magnéticas totais do dispositivo, através da eq.(3.3), em que $\gamma_{v}$ é a densidade específica do material em $\mathrm{kg} / \mathrm{m}^{3}$, da seguinte forma:

$$
W_{t}=\int_{0}^{B} H \cdot d B\left[\mathrm{~J} / \mathrm{m}^{3}\right] \quad \text { ou } \quad W_{t}=\frac{1}{\gamma_{v}} \int_{0}^{B} H \cdot d B[\mathrm{~J} / \mathrm{kg}]
$$

Para fins industriais, utiliza-se, freqüentemente, a unidade de perda em W/kg, bastando, então, multiplicar esse valor pela freqüência de teste, dado pela expressão:

$$
P_{t}=W_{t} \cdot f \quad[\mathrm{~W} / \mathrm{kg}]
$$


As perdas no núcleo ferromagnético $P_{F e}$ podem ser separadas em perdas por histerese, $P_{H}$, e perdas por correntes induzidas ou Foucault, $P_{F}$, isto é:

$$
P_{F e}=P_{H}+P_{F}
$$

As perdas que aparecem sob a condição de operação em vazio, $P_{0}$, resultam das perdas no ferro, $P_{F e}$, das perdas ôhmicas associadas à circulação da corrente de magnetização nos enrolamentos do transformador, $P_{C}$, e das perdas dielétricas adicionais, $P_{A}$, como aquelas nas isolações desta forma a perda em vazio é dada por:

$$
P_{0}=P_{F e}+P_{C}+P_{A}
$$

Em geral, as perdas ôhmicas e dielétricas adicionais são desprezíveis quando se trata de um estudo exclusivo do transformador em vazio, resultando:

$$
P_{0} \cong P_{F e}
$$

As perdas no material ferromagnético, $P_{F e}$, são função das perdas específicas do material, massa e de um fator de construção (building factor), associado às dimensões e ao projeto do núcleo.

\subsection{Perdas por histerese}

A energia dissipada durante a movimentação dos domínios magnéticos, devido à magnetização cíclica, é chamada de perda histerética. A perda por histerese em transformadores é de, aproximadamente, um terço das perdas no ferro.

Alguns fatores que aumentam as perdas por histerese são os tratamentos a frio, adição de carbono na fabricação, imperfeições e impurezas dos materiais. Sob o aspecto metalúrgico, os fatores são: volume, tamanho do grão, distribuição de impurezas, orientação dos cristais, níveis de stress do material, entre outras 
características microestruturais. Steinmetz propôs um modelo até hoje utilizado, e seus parâmetros são obtidos por meio de ensaios.

Em determinados materiais, a perda histerética é muito elevada, como no ferro doce. No aço, esse tipo de perda é menor, ligas especiais de aço-silício de grão orientado, utilizado em transformadores de potência, apresentam perda por histerese reduzida. A perda histerética é uma função de $k_{H}$, coeficiente de perdas histeréticas, intimamente relacionado com a área do ciclo de histerese, $G_{F e}$, massa do núcleo, $\gamma_{F e}$, densidade do ferro, $f$, freqüência e $B_{\max }$, indução máxima e é dada pela expressão:

$$
P_{H}=k_{H} \cdot \frac{G_{F e}}{\gamma_{F e}} \cdot f \cdot B_{\text {max }}^{\alpha}[\mathrm{W}]
$$

sendo,

$$
V o l=\frac{G_{F e}}{\gamma_{F e}}
$$

Steinmetz propôs que a área do ciclo de histerese fosse proporcional a $B_{\max }^{y}$, em que, $y \cong 1,6$ para aços doces e $y \cong 1,7-2,0$ para o Fe-Si.

Tratamentos térmicos são utilizados para reduzir o valor do coeficiente de perdas histeréricas que, inclusive, é sensivelmente influenciado pela direção da magnetização dos materiais ferromagnéticos, relativamente à sua estrutura cristalina. 


\subsection{Perdas por correntes parasitas ou Foucault}

Perda por correntes parasitas é a potência dissipada por efeito Joule, devido à circulação de correntes induzidas na massa metálica do material. Como o ferro doce e o aço são bons condutores, o núcleo está sujeito a ter correntes induzidas, quando submetido a um campo magnético variável no tempo. Tais correntes são chamadas de correntes parasitas ou correntes de Foucault. A minimização das correntes de Foucault é conseguida substituindo o núcleo compacto por um conjunto de lâminas ou chapas metálicas. As lâminas são revestidas com um verniz isolador, de modo que não haja passagem de corrente de uma para outra. Assim, qualquer corrente parasita produzida fica restrita a uma única lâmina de metal. Devido ao fato de a área seccional de cada chapa ser muito pequena e por possuir silício, as resistências individuais são relativamente elevadas. Isso mantém as correntes de Foucault baixas e a perda em potência muito menor.

A figura 3.3 apresenta a seção transversal de uma lâmina de aço-silício que compõe o núcleo magnético e com indução magnética, $B$, apenas na direção de $z$.

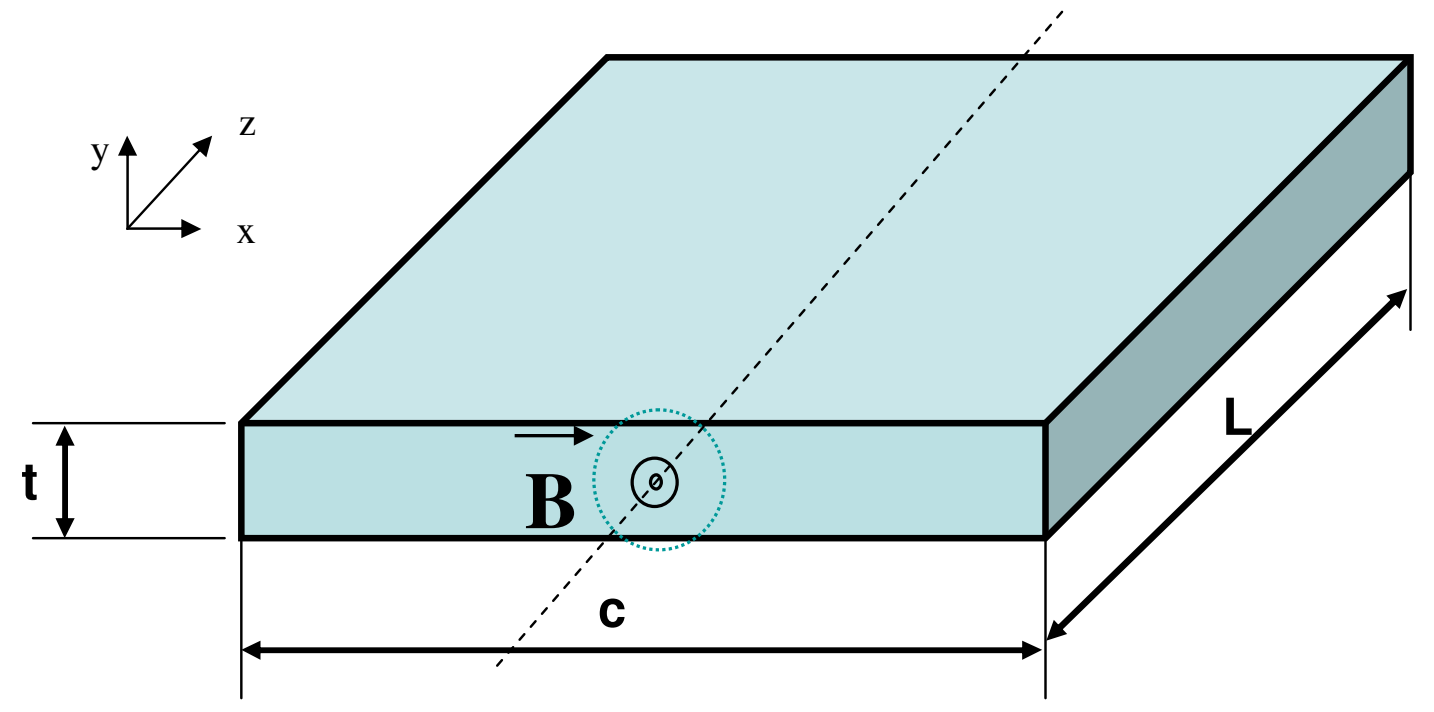

Figura 3.3 - Seção transversal da lâmina do núcleo 
Para a lâmina indicada na figura 3.3, são estabelecidas as seguintes condições de contorno:

- $c>l$;

- $B=\frac{\phi}{c \cdot t}$, está distribuído uniformemente em toda a seção;

- $B_{\max }=B_{m}$ e varia senoidamente no tempo.

Assim, é possível demonstrar que as perdas por correntes induzidas, ou Foucault, são dadas por:

$$
P_{F}=k_{F} \cdot \frac{G_{F e}}{\gamma_{F e}} \cdot f^{2} \cdot B_{m}^{2} \cdot t^{2} \quad[\mathrm{~W}] \quad(3.10),
$$

na qual a constante de proporcionalidade, $k_{F}$, é uma função da condutividade, $\sigma$, do material do núcleo.

Em termos bastante gerais, a constante, $k_{F}$ é determinada, experimentalmente, e leva em conta os seguintes fatores:

- A indução magnética, $\vec{B}$, não tem distribuição uniforme na seção do núcleo, devido ao efeito pelicular a ela associado.

- A isolação entre lâminas não é perfeita, resultando em caminhos de corrente diferentes dos retangulares considerados na figura 3.3. 


\subsection{Perdas anômalas no ferro}

As perdas chamadas de anômalas são perdas de difícil caracterização e ainda hoje são um grande objeto de pesquisa da Engenharia Elétrica e Metalúrgica. Estão associadas às correntes induzidas nas fronteiras dos domínios magnéticos e são, atualmente, incorporadas às perdas no ferro convencionais.

Como ainda hoje não existe formulação analítica para perdas anômalas, e os cálculos empíricos não são suficientemente robustos para cálculo do acréscimo de perda, são estimados fatores de construção para o núcleo, também conhecidos como building factors. Esses fatores são calculados, muitas vezes, por métodos estatísticos.

\subsection{Perdas totais no núcleo ferromagnético}

As perdas totais em núcleos ferromagnéticos de transformadores resultam no somatório das perdas Foucault, $P_{F}$, e perdas por histereses, $P_{H}$. É muito comum encontrar na literatura apenas a soma dessas duas perdas. Neste trabalho, também será considerada a perda anômala ou suplementar no núcleo do transformador, $P_{\text {anomalas }}$. Portanto a perda total é a soma dessas três perdas como é dada pela expressão abaixo:

$$
P_{F e}=P_{H}+P_{F}+P_{\text {anomalas }}
$$

Para o cálculo de perdas, é necessário o conhecimento de alguns valores como a massa de ferro, perda específica e os fatores de cálculo que serão apresentados a seguir: 
- $G_{F e}$ é a massa total do material ferromagnético em [kg];

- $\left[\frac{W}{k g}\right]$ representa a perda específica que é a característica de uma dada chapa estabelecida a determinada freqüência e indução;

- $k_{c}$ representa o fator de construção (building factor) que é uma função do tipo de núcleo e do fabricante, da indução, tipo de chapa, qualidade de montagem, entre outras e é um fator admensional.

- $k_{H}, k_{F}$ e $k_{\text {Anomalas }}$ são os coeficientes das perdas por histerese, perdas Foucault e perdas anômalas respectivamente.

Ao considerar os três tipos de perdas introduzidas, a perda total é dada expressão abaixo:

$$
P_{F e}=k_{H} \cdot \frac{G_{F e}}{\gamma_{F e}} \cdot f \cdot B_{\max }^{\alpha}+k_{F} \cdot \frac{G_{F e}}{\gamma_{F e}} \cdot f^{2} \cdot B_{m}^{2} \cdot t^{2}+k_{\text {Anomalas }} \cdot \frac{G_{F e}}{\gamma_{F e}}
$$

ou ainda,

$$
P_{F e}=G_{F e} \cdot\left[\frac{1}{\gamma_{F e}} \cdot\left(k_{H} \cdot f \cdot B_{\max }^{\alpha}+k_{F} \cdot f^{2} \cdot B_{m}^{2} \cdot t^{2}+k_{\text {Anomalas }}\right)\right]
$$

sendo que,

$$
\left[\frac{1}{\gamma_{F e}} \cdot\left(k_{H} \cdot f \cdot B_{\max }^{\alpha}+k_{F} \cdot f^{2} \cdot B_{m}^{2} \cdot t^{2}+k_{\text {Anomalas }}\right)\right]=\left[\frac{W}{k g}\right] \cdot k_{c}
$$

Portanto, por (3.13), tem-se:

$$
P_{F e}=G_{F e} \cdot\left[\frac{W}{k g}\right] \cdot k_{c}
$$


O fator de construção utilizado nas equações apresentadas é o fator de construção com um alto grau de empirismo que é calculado de forma empírica. Durante os próximos capítulos, será introduzido o fator de construção com grau de empirismo menor para a correção deste fator.

Adicionalmente, podem ocorrer perdas devido aos entreferros do núcleo (que serão contempladas neste trabalho); perdas em furos nas lâminas destinados a elementos de fixação, devido à repartição não uniforme do fluxo magnético; perdas interlaminares, devido aos contatos entre as chapas do núcleo com má isolação; e perdas nas estruturas metálicas de fixações. 


\subsection{Aspectos construtivos}

O núcleo de um transformador é concebido de maneira a atingir as características de desempenho (elétricas, térmicas, mecânicas e ambientais) dele requeridas.

Neste contexto, é importante o projeto da seção transversal, dos canais de resfriamento, da estrutura de fixação e das junções coluna-jugo que serão apresentados a seguir.

\subsubsection{Seção transversal do núcleo}

A seção transversal do núcleo é projetada de maneira a maximizar o aproveitamento da área de um círculo de diâmetro $D_{n}$ pela alocação econômica de lâminas de material ferromagnético de seção retangular e espessura reduzida. Está associada ao fluxo magnético para uma dada indução magnética.

Em geral, a seção transversal das colunas apresenta aspecto circular com degraus associados às dimensões de cada um de seus pacotes. Por outro lado, a seção do jugo pode apresentar aspecto circular ou retangular, associado a vantagens construtivas de outros componentes internos do transformador. 


\subsubsection{Canais de resfriamento}

Em função da elevação de temperatura admissível óleo-ambiente, da indução magnética e do diâmetro do núcleo, um ou mais canais internos de resfriamento podem ser necessários. Em geral, eles apresentam espessura de $5 \mathrm{~mm}$ e são construídos com espaçadores isolantes a base de fibra de vidro, Nomex ${ }^{\circledR}$ ou cerâmicas.

\subsubsection{Junção coluna-jugo de núcleo}

A anisotropia cristalina do material ferromagnético laminado a frio estabelece os fundamentos do projeto da junção coluna-jugo. Adicionalmente, a necessidade de transferir elevados esforços mecânicos, devido a montagem, curto-circuito e transporte, pode influenciar o projeto da junta quanto à sua capacidade de reação por atrito mecânico entre as lâminas.

A anisotropia impõe a inclinação das juntas em relação ao eixo de laminação. Em geral, as juntas são construídas pela justaposição de lâminas recortadas a $90^{\circ}$ ou pela justaposição em recortes a $45^{\circ}$, tipo $\mathrm{V}$.

Para aplicações de baixo índice de desempenho, a composição de lâminas retangulares pode ser executada. A figura 3.4 mostra um exemplo de núcleo em que há composição de lâminas retangulares e é possível observar o caminho do fluxo, de forma simplificada, por direção transversal à laminação, através das setas. 
Camadas: $1,3,5, \ldots$

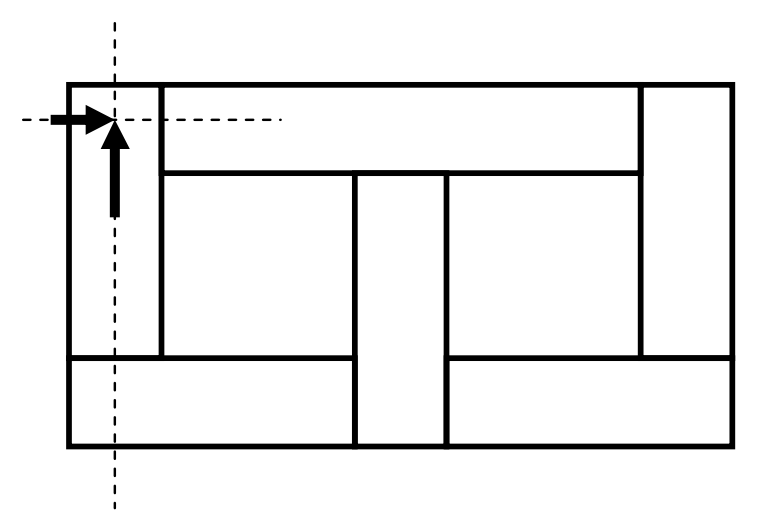

Camadas: $2,4,6, \ldots$

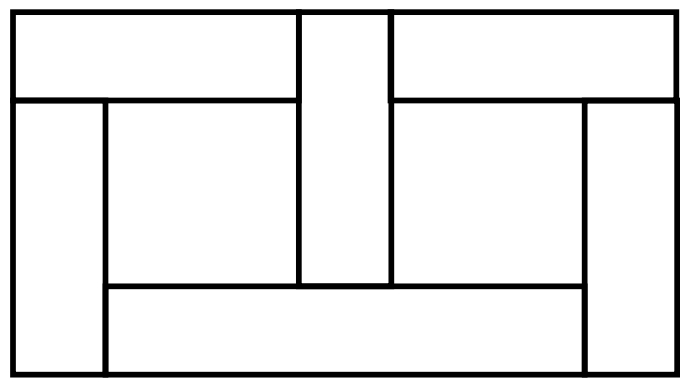

Figura 3.4 - Composição de núcleo com chapas em corte de 90 na junta: as flechas indicam o caminho do fluxo

Por outro lado, a figura 3.5 mostra a composição de lâminas recortadas à 45ํㅜㄴ (standard joint) e com recorte tipo $\mathrm{V}$ ( $V$ notch) na coluna central.

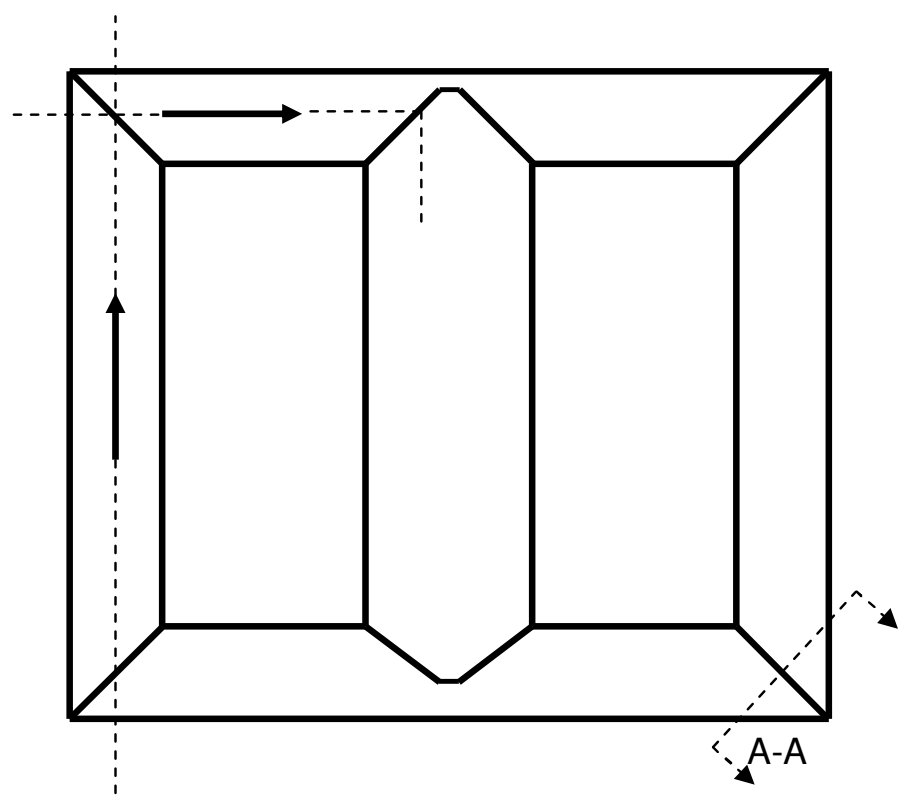

Figura 3.5 - Composição de núcleo com chapas em corte de 45ํㅡas juntas: as fechas indicam o caminho do fluxo 
Adicionalmente, nas juntas, devido ao valor elevado da relutância do entreferro e à distribuição não-uniforme do fluxo na passagem entre lâminas adjacentes e frontais, há a concentração de perdas magnéticas e, conseqüentemente, a possibilidade de ocorrência de temperaturas elevadas.

O entreferro influencia também o valor da corrente magnetizante, e sendo $\mu_{0}<<\mu_{F e-S i}$, tem-se que:

$$
\mathfrak{R}_{0}=\frac{1}{\mu_{0}} \cdot \frac{l_{0}}{S} \gg>\Re_{F e-S i}=\frac{1}{\mu} \cdot \frac{l_{m}-l_{0}}{S}
$$

sendo $\mathfrak{R}_{0}$ a relutância do entreferro, $\mathfrak{R}_{F e-S i}$ a relutância do núcleo de aço-silício, $l_{m}$ o comprimento do circuito magnético e $l_{0}$ o comprimento total dos entreferros do circuito magnético. Dessa forma, reduzindo o entreferro, ocorre redução do valor da corrente magnetizante.

A figura 3.6 mostra o corte A-A, em destaque na figura 3.5 para a composição alternada sucessiva de junta, standard joint, e para a composição periódica de junta, step-lap.
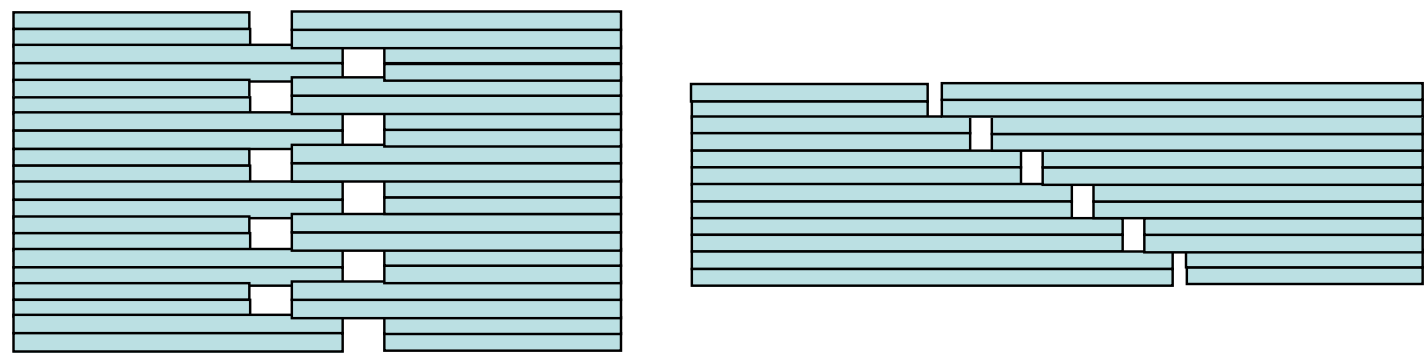

Figura 3.6 - Detalhe do corte representando a junta de núcleo padrão à direita e step-lap à esquerda

O número de lâminas por camada influencia a dimensão do entreferro e o nível de ruído e é estabelecido a partir de análise econômica global de produção do núcleo. Resultados satisfatórios têm sido obtidos pelo chapeamento com 2 (duas) ou 3 (três) lâminas por camada. 


\subsection{Capitalização de perdas}

O custo total de um transformador consiste em dois grandes fatores: o primeiro deles é o custo inicial que considera o preço de compra acrescido do custo de ensaios e de instalações do equipamento; o segundo custo é o chamado custo operacional. Este é o custo pago durante toda a vida útil do equipamento.

O custo inicial gera o custo de capital. O custo operacional consiste em seguro, manutenção, imposto e energia necessária para cobrir as perdas do transformador.

Os fabricantes oferecem transformadores de acordo com as especificações do cliente, como potência, tensão, coordenação de isolamento e requerimentos térmicos e mecânicos. Um transformador pode ser projetado para ter o menor custo inicial possível, mas, por outro lado, suas perdas serão maiores e, portanto, o custo operacional também será elevado.

Aumentando a seção dos condutores e do núcleo, além de diminuir o carregamento do transformador, esse projeto teria menores perdas e, com isso, menor custo de operação. Entretanto, necessitaria de mais material e, naturalmente, seu custo inicial (preço de venda) seria maior.

A figura 3.7 mostra o princípio de como o preço de fabricação e a massa do transformador são variáveis diretamente proporcionais e a perda é uma variável inversamente proporcional ao custo de fabricação e à massa. Assim, é preciso aperfeiçoar massa e perdas, através da soma de perdas e massas, mas o importante é saber o quanto se deve aumentar a massa para se obter uma perda aceitável, conforme a figura 3.8.

Na figura 3.8, é mostrada uma curva em vermelho que caracteriza o custo total do transformador, tanto em perdas quanto no custo de fabricação. Nesta etapa é possível encontrar um custo ótimo para o equipamento, ou seja, um valor aceitável de perdas e um valor aceitável de projeto que terá o menor custo durante a vida útil total do equipamento. 


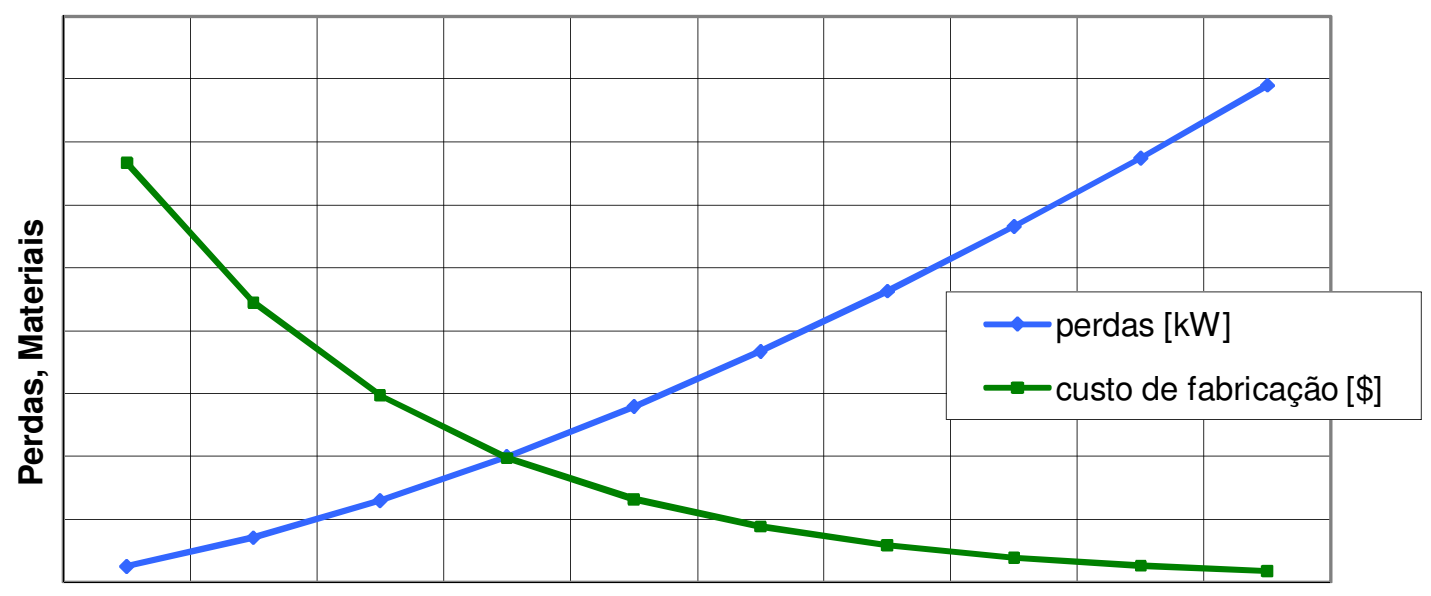

Massa do Transformador

Figura 3.7 - Gráfico de perdas no núcleo versus custo de fabricação [64]

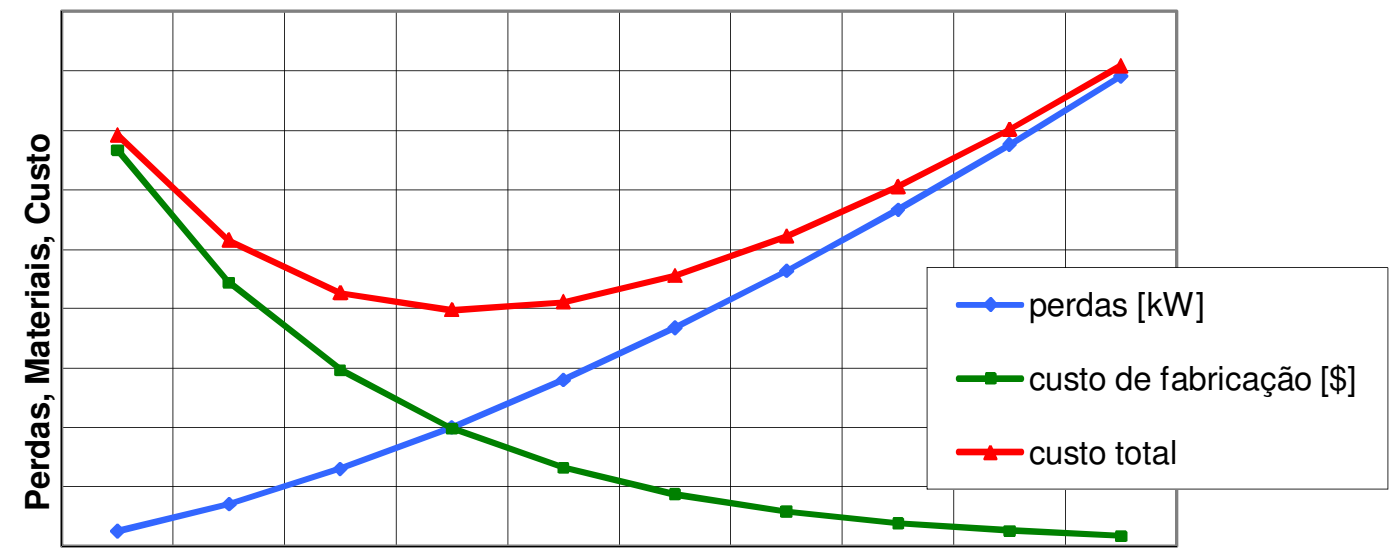

\section{Massa do Transformador}

Figura 3.8 - Gráfico de perdas no núcleo versus custo de fabricação; determinação do ponto de otimização [64]

As concessionárias de energia elétrica e as indústrias solicitam aos fabricantes de transformadores um nível máximo admissível de perdas para o equipamento. Caso seja ultrapassado esse limite, o transformador é reprovado ou o fabricante paga uma multa ao cliente.

Isso é um motivador para o estudo de perdas em núcleos de transformadores, pois melhorando o conhecimento acerca das perdas, tem-se a chance de determiná-las com maior precisão e, com isso, os fabricantes terão a possibilidade de reduzir o 
grau de empirismo em seus cálculos e os consumidores de confiar nos valores de perdas garantidas pelo fabricante.

O valor do dinheiro em perdas é chamado de valor de perdas capitalizado e isso expressa o valor máximo que o usuário pretende investir para reduzir as perdas nos transformadores por uma unidade de quilowatt.

Nos transformadores, as perdas são descritas em dois grandes grupos: perdas em vazio e em carga.

As perdas em vazio são devidas à corrente de magnetização do núcleo do transformador. Essa perda está sendo dissipada em forma de calor em $100 \%$ do tempo em que o transformador está energizado, com ou sem carga. Por esse motivo, concessionárias de transmissão e distribuição de energia têm interesse em estudar formas de minimizar perdas em vazio, já que elas acompanham o transformador durante toda a sua vida útil, sem que possa ser faturado do cliente final. O anexo A apresenta maiores detalhes sobre cálculo de capitalização de perdas em vazio.

\subsection{Sumário}

Este capítulo apresentou os conceitos de perdas magnéticas em núcleos de transformadores, seus aspectos construtivos, a importância da redução de perda em vazio para efeito de capitalização e o aço-silício em si. Este trabalho trará, no próximo capítulo, as metodologias utilizadas para o modelo de cálculo computacional que serão simulados e analisados através de ferramenta computacional. 


\section{METODOLOGIAS E METAS}

\subsection{Introdução}

A metodologia adotada para este estudo é o cálculo de perdas no núcleo de açosilício, utilizando um software comercial - Infolytica ${ }^{\circledR}[61]$-, baseado no método de elementos finitos em duas dimensões.

As análises serão efetuadas através da formulação magnetostática em duas dimensões, mesmo sendo um problema magnetodinâmico em três dimensões. Estas simplificações foram adotadas para efeito de cálculo de perdas, visto que a curva de perda inserida no programa contempla as perdas em regime magnetodinâmico, sendo necessária apenas a determinação do nível de induções no núcleo. O cálculo das perdas é feito automaticamente pelo programa, a partir da indução calculada de cada elemento. Os dados de entrada relevantes são: a curva de perda versus a indução do material do núcleo e a curva normal de magnetização do material. Através dessas curvas, o programa calcula, inicialmente, o valor de indução em cada elemento e encontra a perda magnética em cada um do domínio discretizado. Sabemos que as perdas totais (histeréticas, Foucault e anômalas) estão representadas na curva de perdas do fabricante, mas o programa só calcula perdas corretamente se a curva de perda estiver na mesma freqüência da simulação. $O$ programa também é limitado para induções acima de 1,8T de pico, pois as curvas fornecidas pelo fabricante não contemplam valores além daquela indução, não é garantida nessa região de saturação. O material utilizado para a simulação da chapa será um material não-linear e anisotrópico.

Inicialmente, serão testados alguns tipos de modelos do núcleo para encontrar qual é mais apropriado para o cálculo de perdas. Essas simulações serão calculadas com chapas de aço-silício de grão orientado sem junta, ou seja, sem entreferro. Depois de encontrado o modelo mais adequado, serão realizadas análises com diferentes 
tipos de juntas comerciais, variando o tamanho do entreferro e a indução nas chapas.

O erro do cálculo será efetuado ao analisar a curva de perda a uma determinada indução e compará-la com o valor de perda encontrado pela simulação com chapas sem entreferro.

Serão utilizados métodos apontados no capítulo 2, sendo um deles a simulação computacional em duas dimensões. Será representada apenas uma região simplificada das juntas para análise das perdas localizadas no núcleo e com duas chapas por camada.

Comparando o presente trabalho com os precedentes, é possível destacar alguns pontos que nortearão as simulações numéricas.

O núcleo do transformador consiste de um número elevado de chapas de baixa espessura $(0,2 \mathrm{~mm}$ a $0,3 \mathrm{~mm})$, com alta permeabilidade e separadas entre si pela isolação superficial de $10 \mu \mathrm{m}$. Por esse motivo, o fluxo é fortemente concatenado nas chapas de aço-silício, a menos que se obtenha alta saturação magnética, o que permitiria a escolha de um modelo bidimensional para calcular o fluxo de distribuição no plano da laminação.

As propriedades magnéticas do aço-silício utilizadas no cálculo serão obtidas através de dados do fabricante e inseridas no programa de elementos finitos.

Como um núcleo de transformador é um circuito magnético com vários entreferros, que estão aqui sendo tratados como junções do núcleo, e estes entreferros repetemse ao longo do circuito magnético, a condição de contorno considerada será a periódica, de fluxo normal às chapas.

O objetivo deste estudo é encontrar o fator multiplicativo que será utilizado para cálculo de correção de perdas em transformadores de potência nas regiões das juntas do núcleo, pois nessa região do núcleo, o espraiamento de fluxo é maior e o material satura nas extremidades, devido aos entreferros. Esse fator será determinado através de uma relação entre o valor de perdas em uma situação sem juntas e outras com juntas.

Fatores como rebarbas, pressão entre as chapas e tipo de isolamento não foram contemplados neste estudo. 
Neste capítulo, serão apresentados os modelos adotados e verifica-se se os resultados estão de acordo com os resultados de referência.

Depois de encontrado o modelo mais conveniente, serão selecionados valores adequados de correntes de magnetização para cada tipo de junta e entreferro, através de simulações preliminares, para que seja mantido sempre o mesmo valor de indução nominal das chapas nas regiões extra-juntas.

\subsection{Modelagem 2D}

O modelo geométrico do problema foi gerado através de um software comercial CAD Pro-Engineer ${ }^{\circledR}$. A modelagem foi feita em três dimensões, mas utilizou-se apenas um corte transversal.

O programa utilizado não dispõe de elementos do tipo shell ou lineic, ou seja, foi necessário inserir uma região volumétrica de ar entre as chapas com a dimensão real do isolamento entre as mesmas. Para tornar possível a observação do comportamento das chapas de aço-silício, foram desenhadas trinta e seis chapas da mesma espessura e empilhadas para que, se necessário, algumas sejam desprezadas.

O fator de empilhamento do núcleo é 0,96, tipicamente utilizado em grandes transformadores de potência, ou seja, $4 \%$ da seção transversal do núcleo não é de material magnético. 


\subsection{Materiais utilizados}

Para as simulações magnéticas, foram utilizados três materiais distintos. O cobre foi introduzido no enrolamento de modo a indicar região com corrente imposta.

Dentro do núcleo, o material utilizado foi o aço-silício (vide apêndice A para maiores detalhes das propriedades magnéticas) que é não-linear, anisotrópico e que possui chapas de espessura muito reduzida, dificultando a modelagem e aumentando o tempo de processamento da simulação e a malha.

Por último, foi utilizado o ar no restante do domínio.

\subsection{Condições de contorno utilizadas}

As seguintes condições de contorno estão disponíveis no programa utilizado:

- Condição de fluxo tangencial: essa é a condição de contorno padrão da ferramenta, também conhecida como condição de contorno de Dirichlet homogênea, na qual o vetor potencial magnético é igual a zero no contorno. $O$ programa não permite a inserção de uma condição de contorno de Dirichlet não-homogênea.

- Condição de fluxo normal: conhecida como condição de contorno de Neumann, essa condição se impõe numa determinada face do problema fluxo magnético normal.

- Condição periódica: even periodic é a condição de contorno utilizada quando o dispositivo tem geometria periódica. Dessa forma, é possível eliminar do 
modelo geométrico os trechos repetidos, representando apenas um deles e impondo uma condição de contorno adequada às interfaces entre as partes repetidas, no caso correspondente ao mesmo valor de potencial. Esse tipo de contorno é também denominado condição cíclica.

\subsection{Excitação}

Devido ao fato do programa não permitir a inserção de condição de contorno de Dirichlet não-homogênea, a excitação do problema a ser estudado deve ser obtida através da bobina de uma única espira, de modo a induzir um fluxo magnético adequado no circuito magnético do núcleo a ser estudado.

O cálculo da corrente de excitação para os casos estudados foi inicialmente estimado com o auxílio da Lei de Ampère aplicada à geometria considerada, como segue:

$$
\oint H \cdot d l=N I_{\text {excitacao }}
$$

Se considerarmos que o número de espiras, $N$ igual a 1, e $H$ uniforme ao longo do $L_{\text {medio }}$ (caminho magnético médio do circuito magnético), a equação (4.1) fica:

$$
H \cdot L_{\text {medio }}=N I_{\text {excitacao }}
$$

No entanto, não será possível calcular a corrente de excitação, pois o $H$ é variável ao longo de todo o circuito. Nesse caso, decidiu-se encontrar a corrente de excitação através da imposição de uma corrente arbitrária na bobina e, por tentativa e erro, corrigir esse valor até se encontrar valores de indução no núcleo os mais próximos possíveis daqueles que são esperados nas chapas longe das junções, quais sejam 1,0/1,2/1,4/1,73 e 1,77T (pico). De posse dessas correntes (chapas sem junções), verificou-se que os mesmos variam com o tipo de junta e tamanho do entreferro. Nesses casos, a corrente de excitação foi ajustada para que a indução de pico nas chapas seja sempre a mesma para qualquer comparação. 


\subsection{Detalhamento das simulações}

\subsubsection{Chapas e espiras em contato com limite de contorno e condição de contorno periódica}

Nesta análise, foi considerada condição de contorno periódica e a espira foi prolongada até o contato total com a superfície lateral do modelo. A condição de contorno periódica foi inserida em toda a superfície lateral do modelo e não apenas na superfície das chapas de aço-silício. A figura 4.1 ilustra o modelo adotado para este estudo.

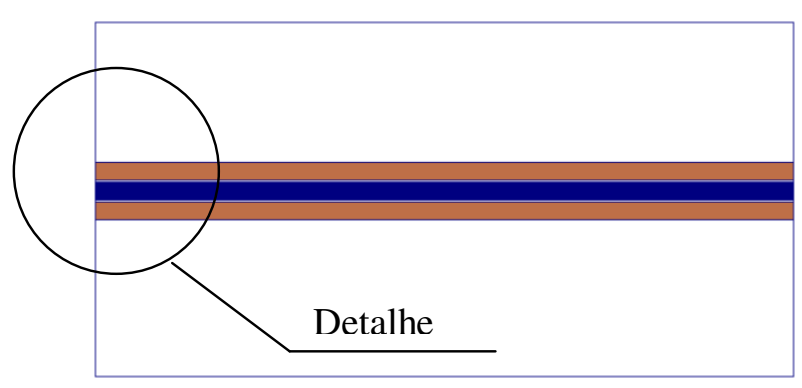

(a)

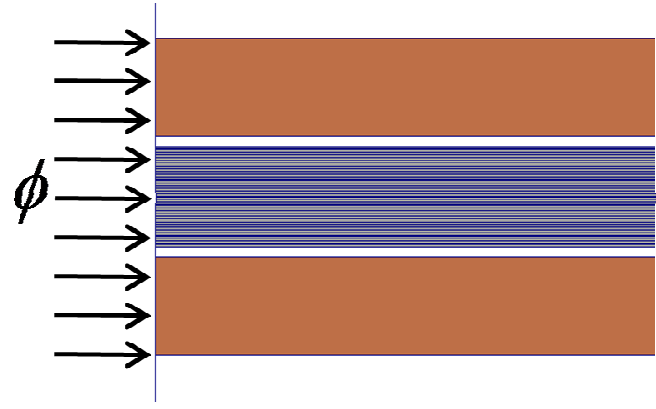

(b)

Figura 4.1 - (a) Modelo geométrico para simulação do trecho de núcleo (azul) e bobina de excitação (marrom). (b) Detalhe aumentado da interface com a condição periódica e a direção do fluxo magnético

A figura 4.2 apresenta a malha de elementos finitos do modelo da Fig. 4.1, onde é possível observar a grande quantidade de elementos nas regiões das chapas de aço-silício. 


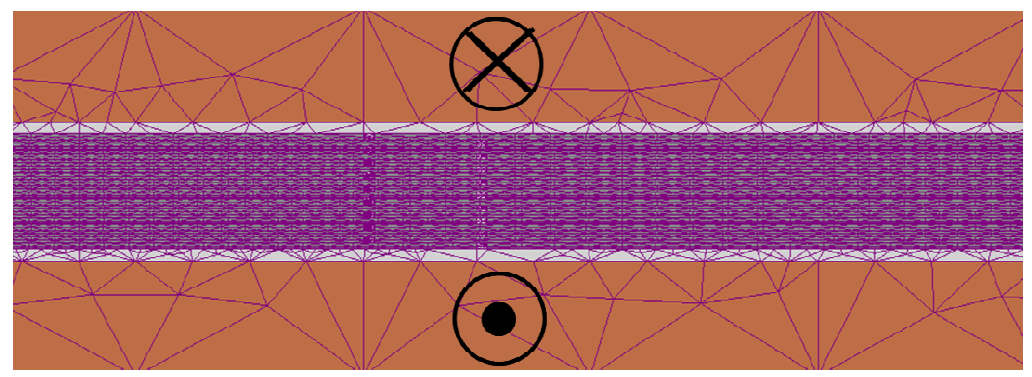

Figura 4.2 - Malha de elementos finitos do modelo da Fig. 4.1 


\subsubsection{Homogeneização do núcleo}

Outra alternativa para o modelo seria a adoção de uma representação do pacote laminado na forma de um núcleo homogeneizado [59], [60] e [61]. Esta abordagem tem a vantagem da redução de tempo de processamento, graças a uma redução do número de elementos da discretização. Esse modelo pressupõe uma formulação específica do tipo anisotropia "geométrica", diferente da anisotropia cristalina convencional.

O modelo sugere que o material laminado seja substituído por um bloco equivalente não-laminado, homogêneo e anisotrópico (figura 4.3) com propriedades $[\mu]$ e $[\sigma]$ [59], [60] e [61], como segue:

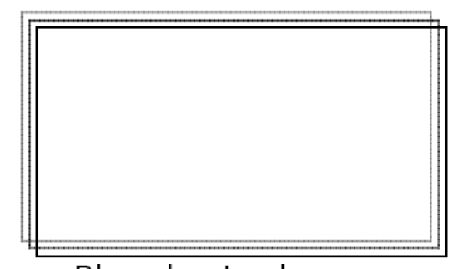

Bloco laminado

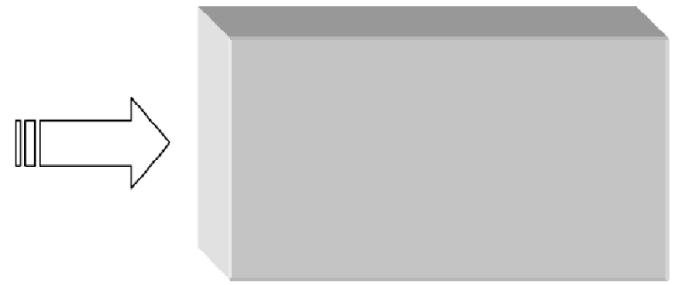

Bloco equivalente

Figura 4.3 - Bloco de material laminado e bloco equivalente homogeneizado

$$
\begin{aligned}
& {[\mu]=\left[\begin{array}{cc}
\mu_{t} & 0 \\
0 & \mu_{n}
\end{array}\right]} \\
& \mu_{t}=\varepsilon \mu_{0}+(1-\varepsilon) \mu_{f} \\
& \frac{1}{\mu_{n}}=\frac{\varepsilon}{\mu_{0}}+\frac{(1-\varepsilon)}{\mu_{f}} \\
& {[\sigma]=\left[\begin{array}{cc}
\sigma_{t} & 0 \\
0 & \sigma_{n}
\end{array}\right]} \\
& \sigma_{t}=(1-\varepsilon) \sigma_{f}
\end{aligned}
$$




$$
\sigma_{n}=0
$$

sendo $\mathcal{E}$ o fator de empilhamento, $\mu$ a permeabilidade absoluta, $\sigma$ a condutividade do material e os índices $f$, $t$ e $n$ indicando, respectivamente, ferro, transversal e normal.

Uma vantagem importante desse método é que não é necessária a modelagem do entreferro entre a isolação das chapas, mas apenas na junta do núcleo. A figura 4.4 ilustra o modelo com núcleo homogeneizado, sendo possível observar a sua simplicidade em relação ao anterior, reduzindo a malha e tempo de processamento.

A utilização desse modelo exige, no entanto, os seguintes cuidados:

- assumir o material linear, ou seja, $\mu_{f}$ constante não saturado;

- utilizar valores baixos de corrente de excitação para não ultrapassar o valor de saturação da curva de magnetização do aço-silício;

- a espessura da isolação entre as chapas deve ser desprezível frente ao entreferro devido às juntas.

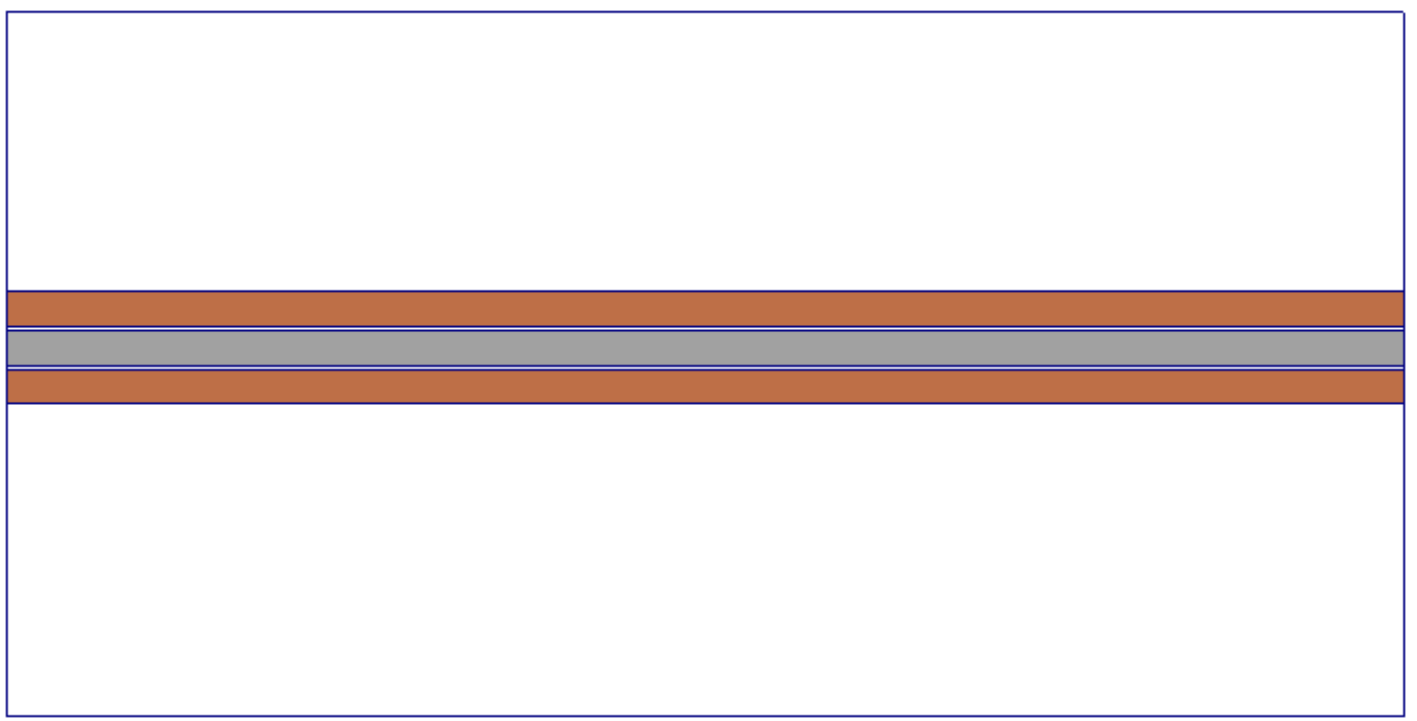

Figura 4.4 - Modelo para a simulação do núcleo homogeneizado 


\subsubsection{Imposição de fluxo através de condição de Dirichlet não-homogênea}

Conforme Mechler e Girgis [24], existe a possibilidade de induzir um fluxo no interior do núcleo, com a imposição do vetor potencial magnético como condição de contorno. Primeiramente, deve-se realizar uma simulação bidimensional do transformador no plano das chapas, conforme a figura 4.5 e encontrar o valor do fluxo magnético em uma determinada linha com comprimento $p$. A partir desse ponto, sabe-se que o valor total do fluxo nas chapas é determinado pelo vetor potencial magnético no topo e na base da área calculada, assumindo que o fluxo na direção y é igual a zero.

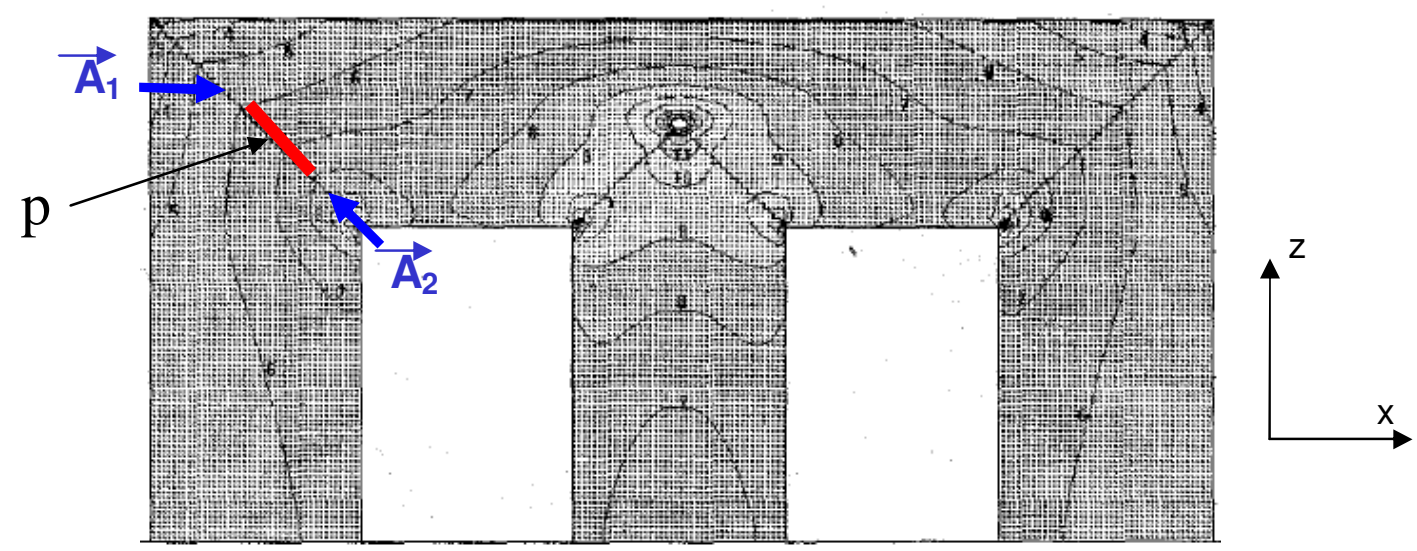

Figura 4.5 - Vista do núcleo do transformador Adaptado de [24]

É possível definir o fluxo magnético dentro de um núcleo através da imposição de valores do vetor potencial magnético, conforme está detalhado a seguir.

A figura 4.6 apresenta a configuração utilizada para o problema. A simulação deve, agora, ser realizada no plano $\mathrm{xy}$, no sentido perpendicular ao plano das chapas (plano que inclui as regiões hachuradas em cinza). 


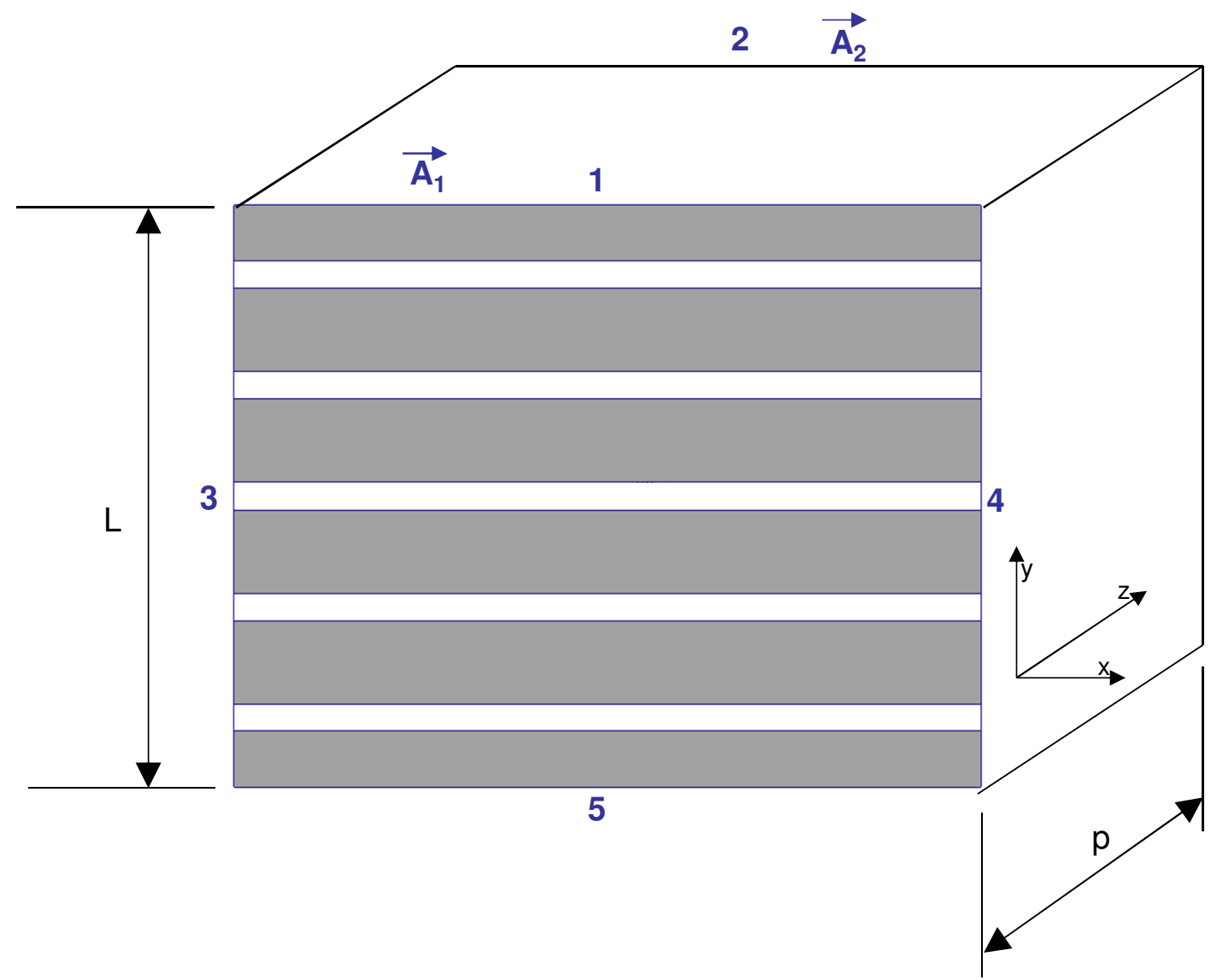

Figura 4.6 - Configuração para análise com condição de contorno de Dirichlet não-homogênea

O plano contendo as linhas 1 e 2, mostrado na figura 4.6, corresponde à superfície paralela ao plano da laminação (representada na figura 4.5) e à direção do vetor densidade de fluxo. É utilizada a condição de contorno de Dirichlet não-homogênea nas superfícies perpendiculares, linhas 1 e 5 na figura 4.6, e nas laterais (linhas 3 e 4 da figura 4.6) é imposta condição de contorno de Neumann.

A condição de Dirichlet não-homogênea a ser imposta nas fronteiras 1 e 5 se calcula a partir do fluxo magnético $\phi$, obtido a partir de $A_{1}$ e $A_{2}$, resultados da primeira simulação (figura 4.5), como segue:

$$
\oint \vec{A} \cdot d l=\phi
$$

que, aplicado ao segmento de comprimento $p$ da figura 4.5, resulta em

$$
\left(\vec{A}_{1}-\vec{A}_{2}\right) \cdot p=\phi
$$

e a seção $S$ é dada pela expressão, 


$$
S=l \cdot p
$$

a seção de passagem do fluxo. A indução magnética média nessa seção é dada por:

$$
\vec{B}=\frac{\phi}{S}
$$

Nessa modelagem, não é necessário incluir a corrente de excitação, pois o fluxo será estabelecido pela diferença do vetor potencial magnético. 


\subsection{Chapas em contato com limite de contorno e com condição de contorno periódica}

Os resultados da simulação com o modelo proposto mostraram resultados coerentes com a realidade: todas as chapas estão com a mesma indução magnética ao longo de todo o domínio. Não foi observado o efeito de borda ou nenhum ponto em que o material tenha saturado. $O$ cálculo do erro, em relação às perdas oriundas das curvas do fabricante para a indução de $1,0 \mathrm{~T}$ foi de $1,67 \%$, que pode ser considerado bem satisfatório para nossos propósitos, validando, portanto, o modelo proposto.

A figura 5.1 mostra a carta de cores da distribuição de induções nas chapas, no entreferro e no cobre.
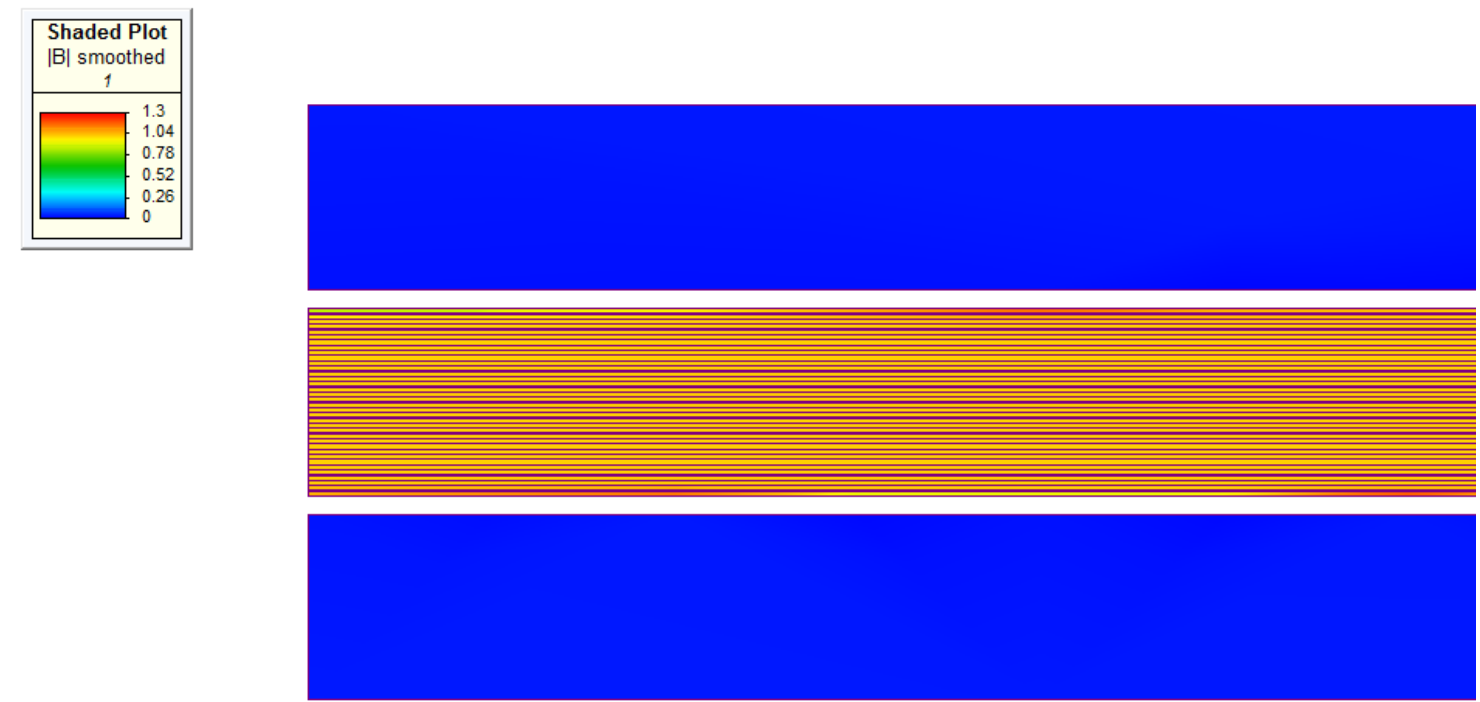

Figura 5.1 - Carta de cores da distribuição de induções no domínio de estudo, obtida da simulação por elementos finitos: representação de chapas e sua isolação. No detalhe, escala do valor das induções em T 
O modelo que conduziu ao resultado da figura 5.1 é mais complexo do ponto de vista de pré-processamento, devido à necessidade da criação da malha no interior das chapas, no entreferro e nas isolações entre as chapas. Entretanto, é o modelo que mais se aproxima da realidade. O tempo de processamento é longo, uma vez que ocupa muita memória computacional, devido à quantidade de nós resultante na malha de elementos finitos.

\subsection{Homogeneização do núcleo}

Os cálculos das propriedades físicas para a aplicação deste modelo $\left(\mu_{t}, \mu_{n}, \sigma\right.$ e etc) estão detalhados no apêndice B e, para tanto, utilizou-se o modelo de material anisotrópico convencional, uma vez que o programa utilizado não dispõe de modelo com anisotropia cristalina. Dessa forma, só foi possível testar essa abordagem considerando o material linear. Os valores de indução obtidos com essa abordagem apresentam um desvio de, aproximadamente, $10 \%$ em relação àqueles do item anterior e são exibidos na figura 5.2.
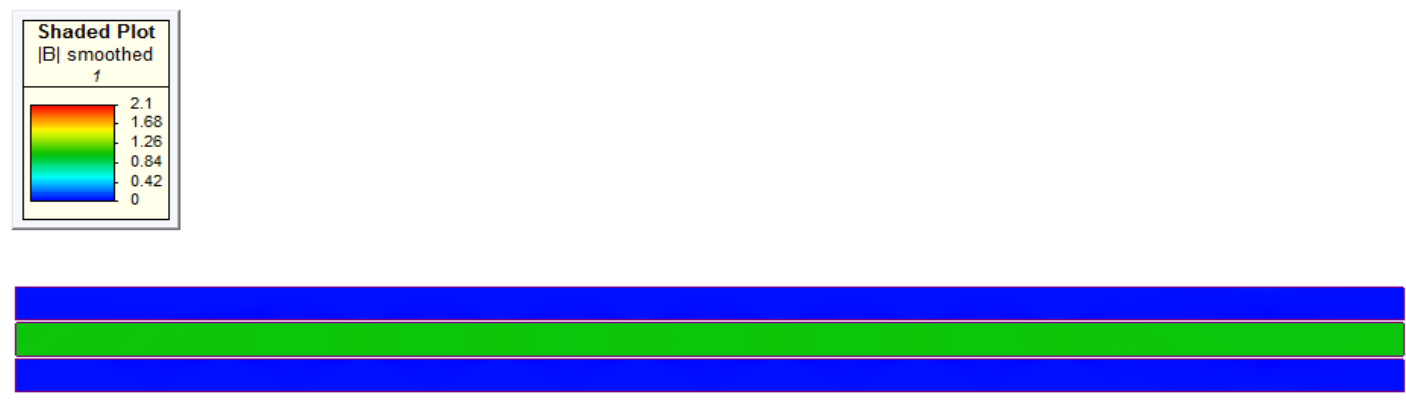

Figura 5.2 - Carta de cores da distribuição de induções no domínio de estudo, obtida da simulação por elementos finitos: representação do núcleo por material homogeneizado. No detalhe, escala do valor das induções em $T$ 
O erro obtido nessa simulação a 1,0T, em relação às perdas da curva do fabricante, foi de $9,37 \%$. Entre todas as propostas apresentadas neste trabalho, esse é o modelo mais simplificado e de mais rápida resolução computacional, visto que a malha é muito mais simples. Infelizmente, ele não será confiável no momento em que a indução aumentar e que o aço entrar na região de saturação, pois o programa utilizado admite apenas a atribuição de propriedades físicas anisotrópicas lineares quando se utiliza tensores, inviabilizando a utilização dessa abordagem.

\subsection{Imposição de fluxo através do vetor potencial magnético não-homogêneo}

Novamente devido a limitações do programa utilizado, não foi possível utilizar condições de contorno de Dirichlet não homogênea neste trabalho, pois o programa não conta com esse recurso.

Outras limitações também foram observadas durante a preparação dos modelos, além das já citadas, como, por exemplo, elementos especiais, tipo shell e lineic, que possibilitam a geração de modelos muito mais compactos e, como conseqüência, maior rapidez nas simulações e possibilidade de gerar um maior número de resultados. Há, ainda, outras limitações, como ausência de malha de quadriláteros nessa versão do programa utilizado. 


\section{APLICAÇÕES E RESULTADOS PRELIMINARES}

Nesta etapa da pesquisa, após estabelecer o modelo para simulação magnética das juntas em núcleo de transformadores, foram escolhidos dois tipos diferentes de juntas, comumente utilizadas em transformadores de potência, a fim de se realizar os casos teste.

A primeira junta utilizada, chamada de V1, por ser a primeira versão das juntas de núcleo, também é conhecida comercialmente como junta padrão ou standard joint e está ilustrada na figura 6.1(a).

A junta padrão V1 utilizada tem um degrau de $10 \mathrm{~mm}$, fator de empilhamento de 0,96 e duas chapas de lâmina de aço-silício por camada.

$\mathrm{Na}$ junta com step-lap, como a ilustrada na figura 6.1(b), há um degrau de 9mm, fator de empilhamento de 0,96 e duas chapas de lâmina de aço-silício por camada. Tanto do ponto de vista magnético como do mecânico, esta junta foi desenvolvida para melhorar o desempenho do núcleo do transformador, tanto no que diz respeito às perdas em vazio, quanto à estrutura mecânica, devido à maior região de contato da junta do núcleo e menor ruído.

É possível verificar que para cortes de juntas step-lap são necessários seis dimensões de cortes diferentes, ao contrário das juntas padrões que utilizam apenas dois tamanhos de chapas.

$\mathrm{Na}$ figura 6.1 estão ilustradas as duas configurações de juntas estudadas: junta padrão V1 (a) e a junta step-lap V2 (b). 


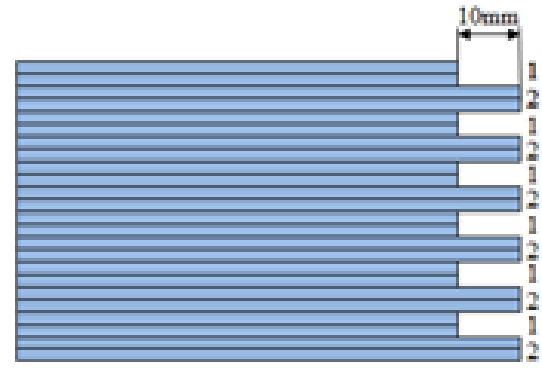

(a)

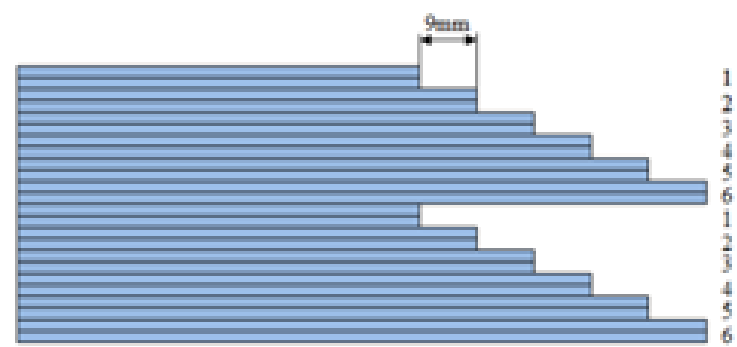

(b)

Figura 6.1 - Exemplo de juntas de transformadores estudadas: (a) Junta Padrão sem step-lap. (b) Junta com step-lap - V2 [67]

\subsection{Modelagens realizadas}

Após a modelagem das duas formas de juntas, foram inseridos três tamanhos de entreferro entre as chapas: $0,50 \mathrm{~mm}, 1,00 \mathrm{~mm}$ e $1,50 \mathrm{~mm}$.

Havendo dois tipos de juntas e cada uma com três diferentes tipos de entreferro, além da modelagem das chapas sem nenhuma junta, apenas utilizada para configuração, temos, 7 (sete) modelos para simulação.

As simulações efetuadas foram com induções de pico de $B_{\text {pico }}=1,0 / 1,2 / 1,4 / 1,73$ e 1,77T. Optou-se por não ultrapassar a indução de pico de 1,77T, pois o programa apresenta-se muito instável a partir desse ponto, uma vez que na região das junções

o material já está bastante saturado. É possível salientar que esta instabilidade é devida aos dados fornecidos pelo fabricante das chapas de aço-silício que não ultrapassam 1.9T.

Cinco intensidades diferentes de indução com sete tipos distintos de modelagem geraram 35 (trinta e cinco) simulações. A partir de cada uma, é calculada a perda total nas chapas de aço-silício a $60 \mathrm{~Hz}$, e esse valor é dividido pela massa total das chapas consideradas na modelagem. 


\subsection{Resultados}

Inicialmente realizou-se a simulação de um caso extraído de Mechler e Girgis [24], a fim de se comparar os resultados com aqueles representados nessa referência.

A figura 6.2 apresenta a distribuição de induções em módulo numa porção de núcleo com juntas através de uma carta de cores. Nessa figura acha-se indicada também uma linha para o traçado de um gráfico do módulo da indução, a fim de se comparar com o fornecido em [24]. A figura 6.3 apresenta esse traçado. Comparada à figura 6.4, extraída de [24], pode-se verificar a concordância dos mesmos, tanto para os valores de pico como para os valores mínimos.

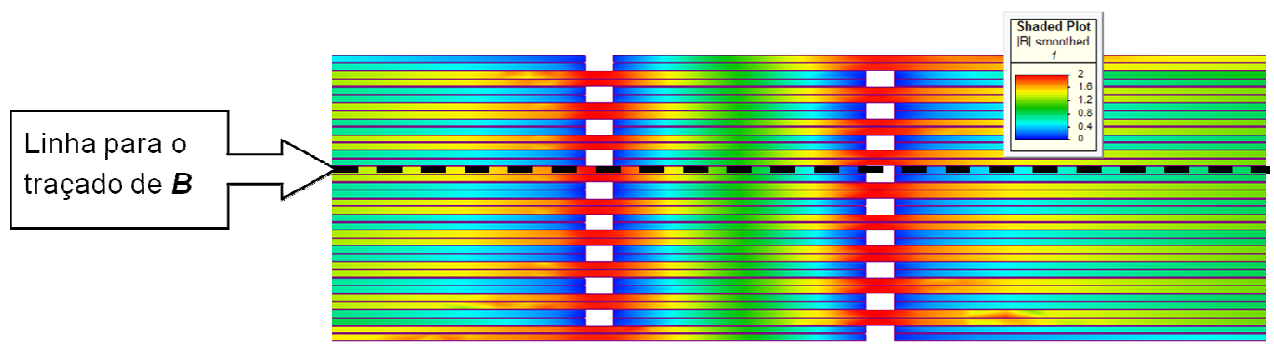

Figura 6.2 - Núcleo com juntas indicando linha para o traçado da indução. A carta de cores fornece o módulo da distribuição de induções

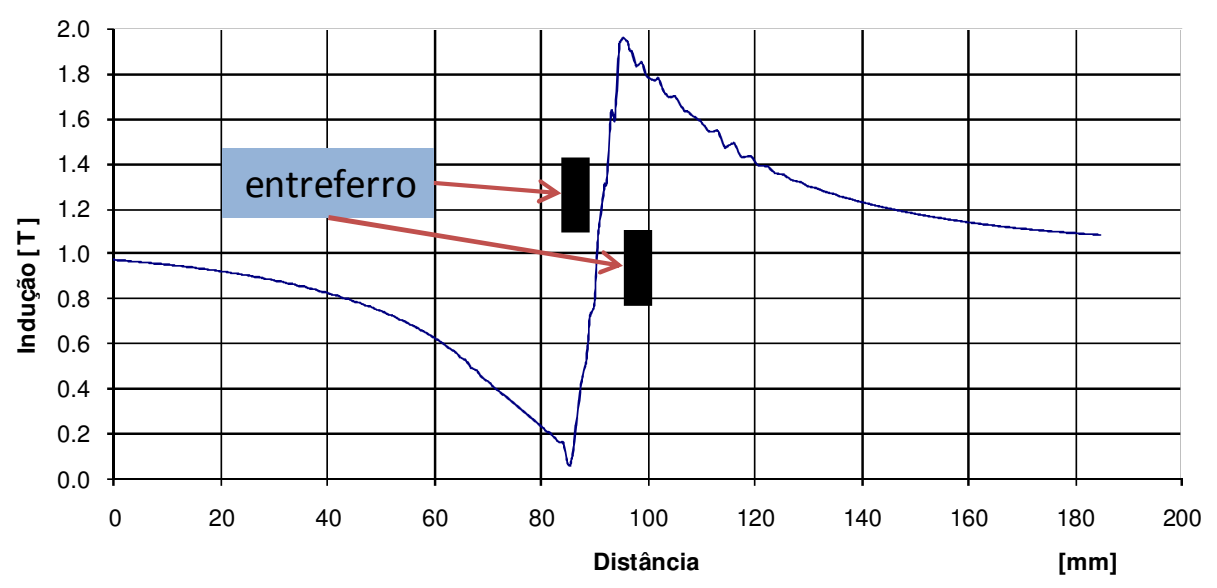

Figura 6.3 -Indução magnética axial no interior de uma chapa de aço-silício para indução de média $1,0 T$ calculada pela simulação 


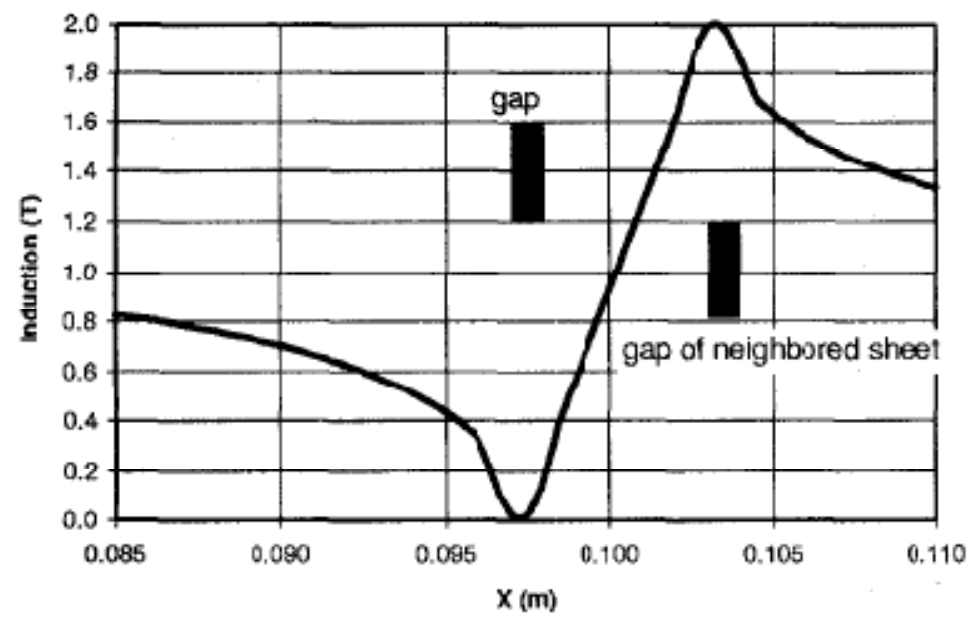

Figura 6.4 -Indução magnética axial no interior de uma chapa de aço-silício para indução média de $1,0 \mathrm{~T}$ de [24]

Pode-se verificar dessa forma que os valores obtidos com as simulações apresentam boa concordância com os encontrados em [24], validando dessa forma o modelo proposto.

\subsection{Cálculo do erro}

Nesta etapa, será calculado o erro entre os valores de perdas obtidos pelas simulações e os valores experimentais.

O cálculo do erro foi realizado partindo-se da curva de perda magnética versus indução. A tabela 6.1 é dada pelo fabricante do aço-silício. A partir desses valores interpolou-se uma função polinomial de sexta ordem com a ajuda do aplicativo MS Exce $^{\circledR}$. Essa função foi a que resultou num melhor ajuste utilizando-se o Método dos Mínimos Quadrados. O resultado desse ajuste pode ser visualizado na Fig. 6.5, que mostra o traçado da perda em função da indução para a interpolação polinomial (em azul) e dos valores experimentais (em vermelho). 
Tabela 6.1 - Indução de pico versus perda magnética fornecida pelo fabricante a $60 \mathrm{~Hz}$ [69]

\begin{tabular}{|c|c|}
\hline B [mT] & Perda (W/kg) \\
\hline 200 & 0.025 \\
\hline 300 & 0.047 \\
\hline 400 & 0.081 \\
\hline 600 & 0.175 \\
\hline 800 & 0.302 \\
\hline 1000 & 0.462 \\
\hline 1200 & 0.659 \\
\hline 1300 & 0.775 \\
\hline 1400 & 0.908 \\
\hline 1500 & 1.066 \\
\hline 1600 & 1.274 \\
\hline 1700 & 1.589 \\
\hline 1800 & 2.100 \\
\hline 1850 & 2.381 \\
\hline 1900 & 2.631 \\
\hline
\end{tabular}

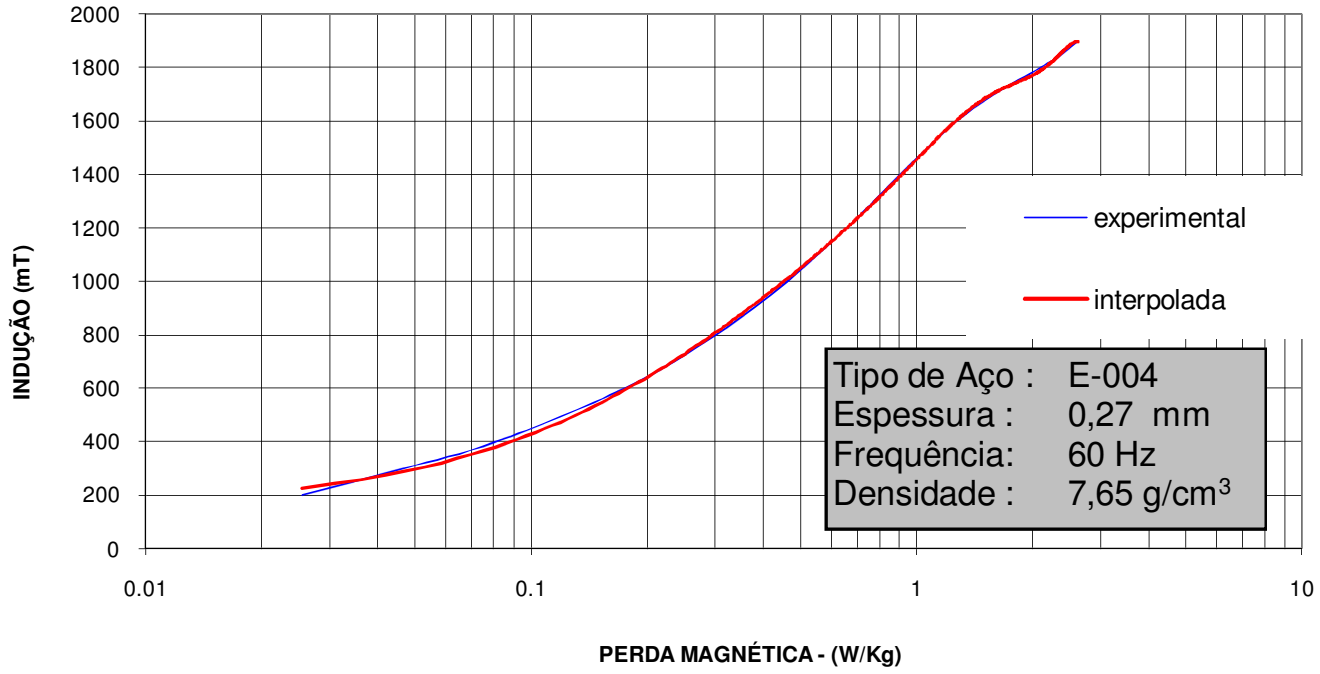

Figura 6.5 - Perda em função da indução a $60 \mathrm{~Hz}$ (valores interpolados e experimentais). 
A função polinomial obtida foi a seguinte:

$$
f_{\text {perdas }}(x)=1.9 \cdot 10^{-19} \cdot x^{6}+0.17 \cdot 10^{-15} \cdot x^{5}-4.62 \cdot 10^{-12} \cdot x^{4}+5.02 \cdot 10^{9} \cdot x^{3}-1.8610^{6} \cdot x^{2}+3.7610^{4} \cdot x
$$

com um valor de resíduo do método dos mínimos quadrados de 0,99939.

A tabela 6.2 apresenta os valores de perdas calculadas através do MEF e da eq.(6.1), doravante chamados de valores de perdas semi-analíticos, para valores de indução fixados entre 1,0T e 1,77T.

O erro é calculado através da eq. 6.2, como segue:

$$
\text { Erro }=\frac{\left|P_{\text {semi-analitico }}-P_{M E F}\right|}{P_{\text {semi-analitico }}} \cdot 100 \%
$$

Tabela 6.2 - Perdas (Valores numéricos e semi-analíticos)

\begin{tabular}{|c|c|c|c|}
\hline $\mathrm{B}[\mathrm{mT}]$ & MEF $[\mathrm{W} / \mathrm{kg}]$ & Semi-Analítico $[\mathrm{W} / \mathrm{kg}]$ & Erro \\
\hline 1,00 & 0,463 & 0,471 & $1,67 \%$ \\
\hline 1,17 & 0,643 & 0,620 & $3,62 \%$ \\
\hline 1,41 & 0,966 & 0,886 & $8,96 \%$ \\
\hline 1,70 & 1,643 & 1,530 & $7,41 \%$ \\
\hline 1,74 & 1,828 & 1,686 & $8,41 \%$ \\
\hline 1,77 & 1,967 & 1,803 & $9,11 \%$ \\
\hline
\end{tabular}

Tratando-se de uma simulação numérica pelo MEF, os valores de erro calculados acima são considerados satisfatórios. Observa-se que os valores calculados pelo MEF geralmente são maiores que os valores de perdas semi-analíticos, porque o cálculo de MEF utiliza um polinômio de terceira ordem para interpolar a tabela 6.1. Dessa forma, os valores de erro encontrados são razoáveis. É importante salientar que na faixa de interesse, entre 1,7T e 1,77T, o valor do erro é de aproximadamente $9 \%$. 


\subsection{Induções utilizadas para cálculo}

Para transformadores de potência, é necessário que não ocorra saturação no núcleo para não haver perdas excessivas e deformações na corrente do secundário, podendo conduzir problemas para a carga.

No entanto, ao calcular a indução de um núcleo em transformador de potência, é necessário garantir que a indução de pico não ultrapasse 1,9T. Como qualquer transformador normalizado necessita trabalhar com sobre-excitação de até $10 \%$ sobre a nominal, o cálculo da indução de pico deve levar em consideração esse fator. Logo, para transformadores de potência, serão utilizadas induções de, no máximo, 1,77T de pico em regime nominal.

Foi verificado que, ao entrar na região em que a permeabilidade magnética é não linear, os entreferros das chapas influenciam fortemente na corrente de magnetização, porque aumentam a relutância do circuito magnético, devido ao fluxo disperso, o que não ocorre no caso linear.

\subsection{Resultados das simulações}

Depois de encontrado o valor de FCR para tipo de junta e indução, foram gerados alguns gráficos que mostram qual a influência do tipo de junta para cada indução.

O valor médio refere-se ao cálculo da média do FCR para os três tamanhos de entreferro calculado: 0,50mm, 1,00mm e 1,50mm.

$\mathrm{Na}$ figura 6.6, é possível verificar pelo valor médio do fator de correção que as juntas do tipo V2 são mais apropriadas em quase todas as induções. 


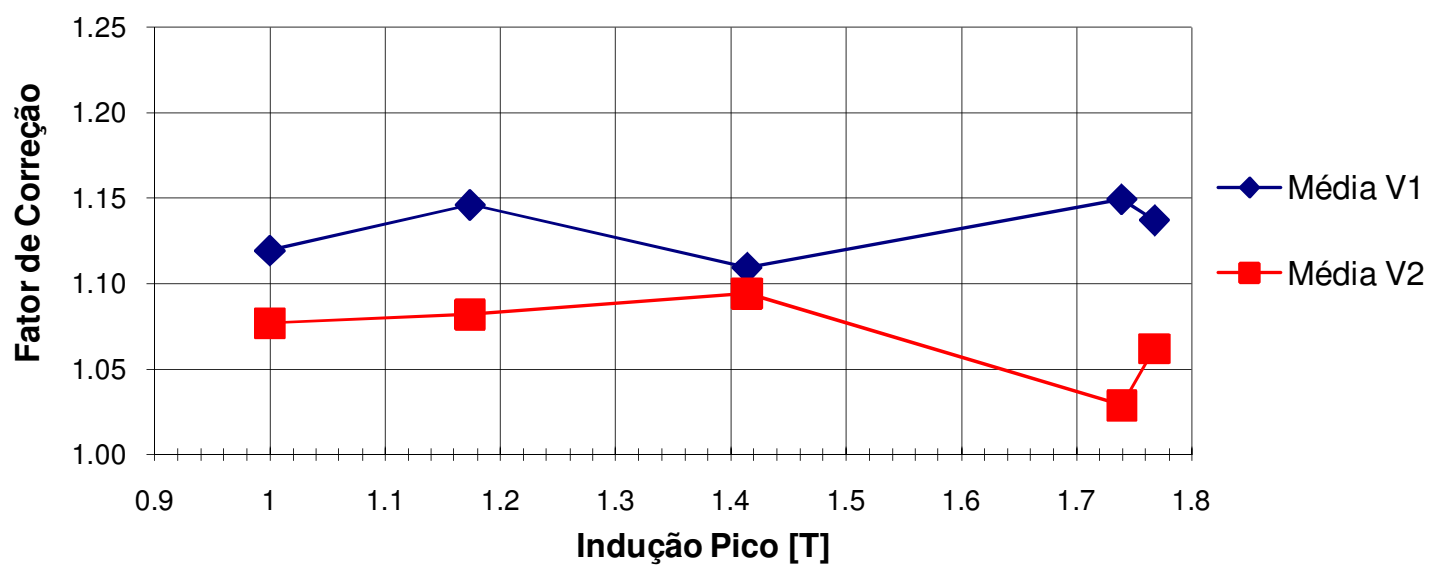

Figura 6.6 - Comparação entre os fatores de correção para dois tipos de juntas

Outra observação importante é que, para induções nominais de pico de aproximadamente 1,75T, as juntas do tipo V2, com step-lap, são aproximadamente $10 \%$ mais eficientes do que as juntas do tipo V1, sem step-lap.

$\mathrm{A}$ junção do tipo $\mathrm{V} 1$ tem desempenho inferior à junta $\mathrm{V} 2$, mas o desempenho da primeira piora para induções maiores que 1,5 T. Esse fato se deve à saturação concentrada, que é possível se observar na figura 6.7.

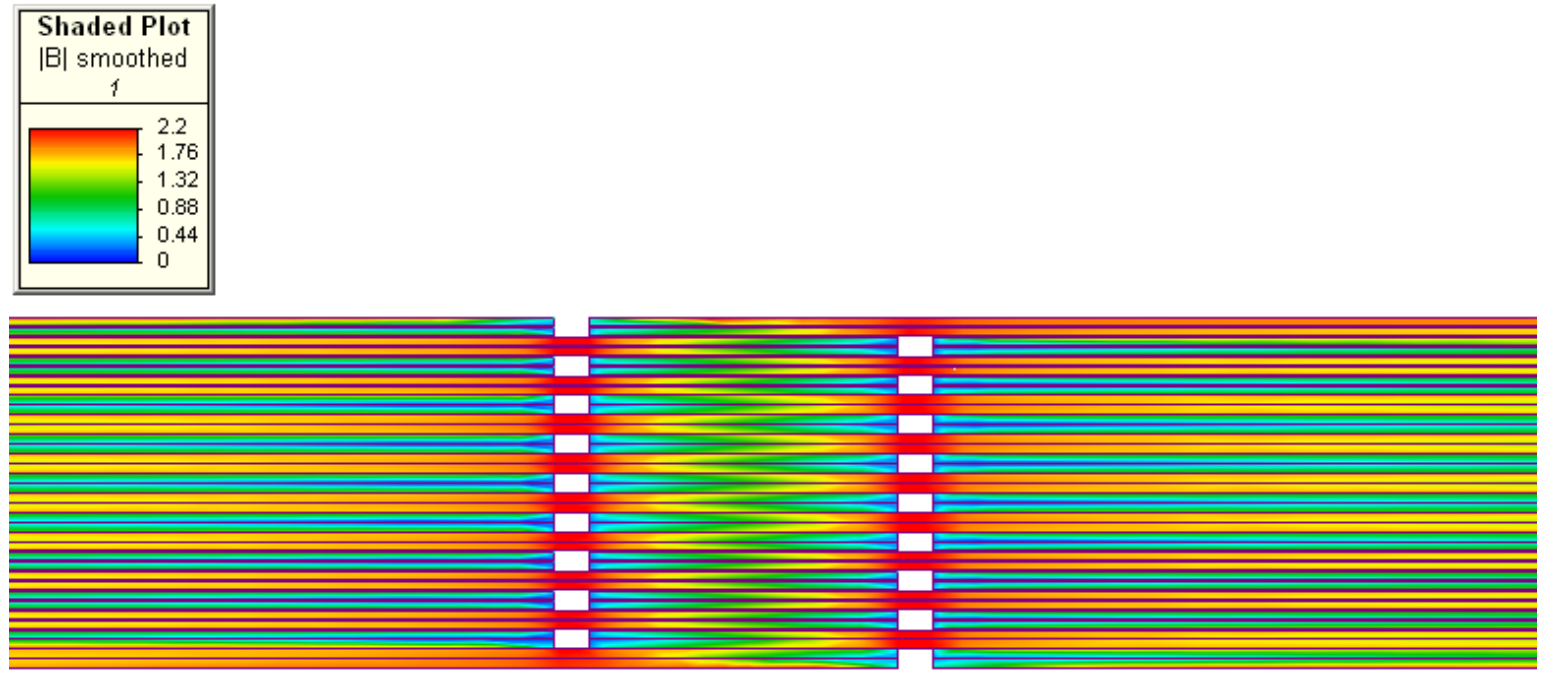

Figura 6.7 - Indução em juntas sem step-lap - V1 - com 1,00mm de entreferro e 1,77T de indução nominal 
Na figura 6.8 apresenta-se a densidade de fluxo nas juntas step-lap do tipo V2. Pode-se observar, também, que existe uma melhor distribuição de fluxo magnético nas chapas, com a diminuição da máxima indução no núcleo.
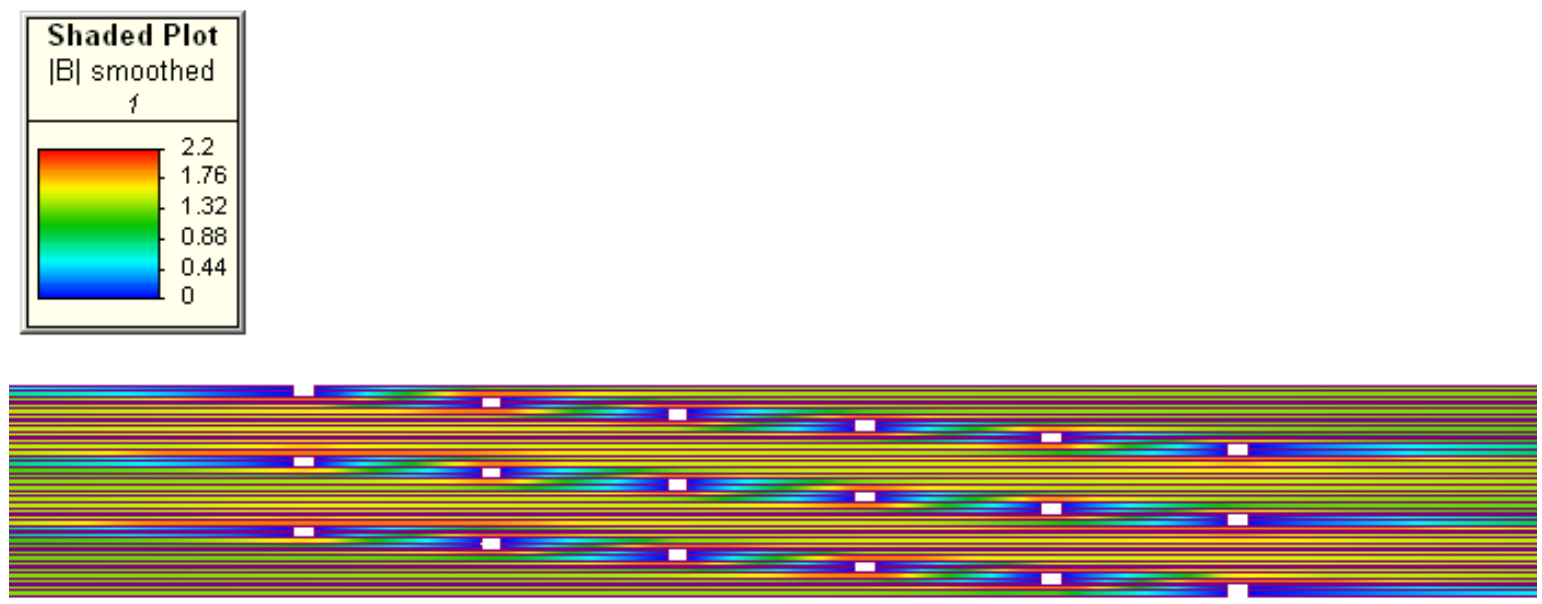

Figura 6.8 - Indução em juntas step-lap - V2 com 1,00mm de entreferro e 1,77T de indução nominal

Nas figuras. 6.7 e 6.8 é possível verificar que a saturação é muito maior na junta do tipo V1 do que nas juntas do tipo V2 com step-lap. Com essa região concentrada de saturação, as perdas magnéticas nas chapas aumentam. Logo, o fator de construção para a junta V1 é maior, reduzindo o desempenho.

Por esse motivo, atualmente esse tipo de junta é muito pouco empregada em núcleos de transformadores de grande porte que necessitam de melhor eficiência.

A figura 6.9 apresenta o comportamento do fator de correção para a junta do tipo V1 quando o entreferro varia. Conforme é esperado, quanto maior o tamanho do entreferro, maior é o valor do fator de construção do núcleo e, portanto, maior o fator de correção para a junta. O valor referente à V1 com entreferro de 1,50mm e 1,73T é um valor fora do esperado, devido ao erro de cálculo numérico. 


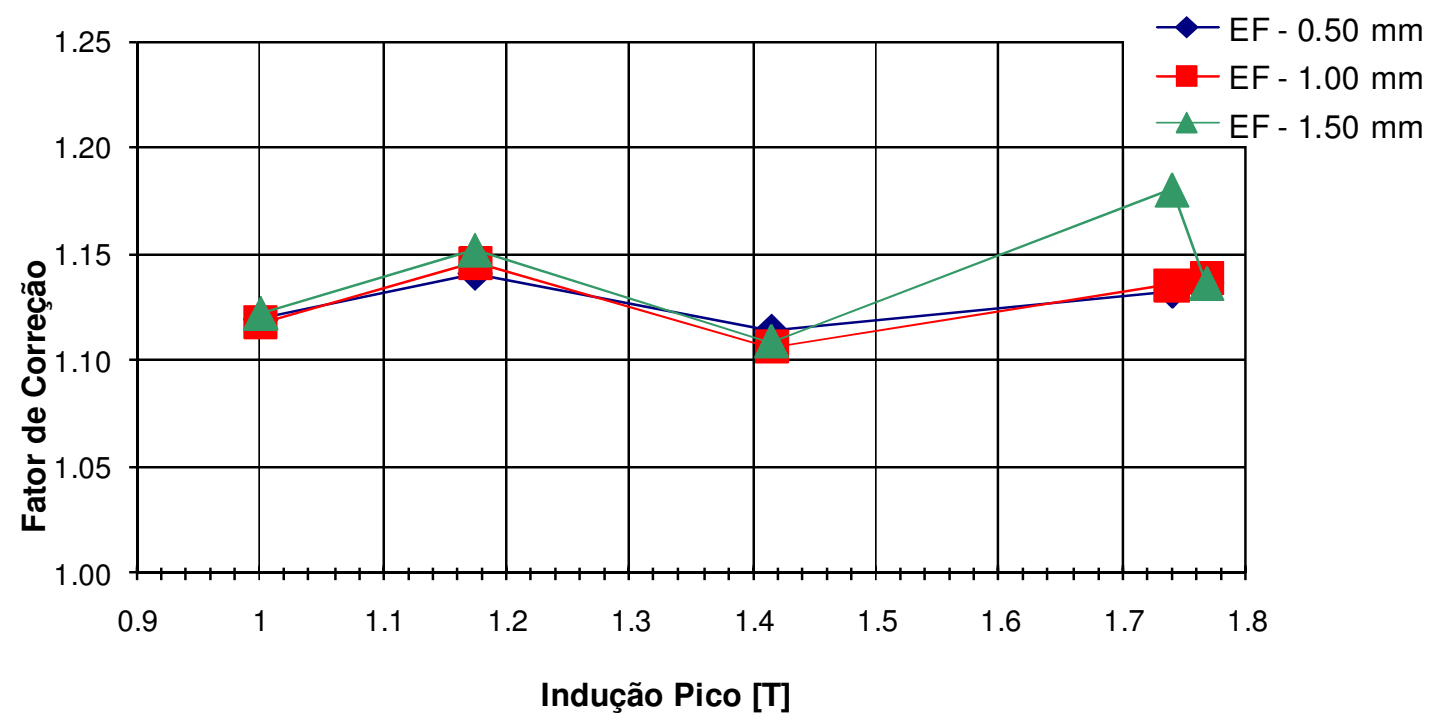

Figura 6.9 - Fator de correção para junta V1, sem step-lap, e vários valores de entreferro

Na figura 6.10 observa-se, novamente conforme esperado, que, ao aumentar o tamanho do entreferro, o fator de correção da junta aumenta e para induções menores que 1,7T, o FCR é muito maior para entreferro de 1,50mm. Observa-se que para juntas sem step-lap a influência do entreferro é menor do que para junta com step-lap da mesma forma que observado por [23]. Pelas figuras 6.9 e 6.10 vê-se que quanto maior o entreferro, maior será a influencia no Fator de Correção, e conseqüentemente no Fator de Construção do núcleo, devido à alta relutância que o entreferro insere no circuito magnético. 


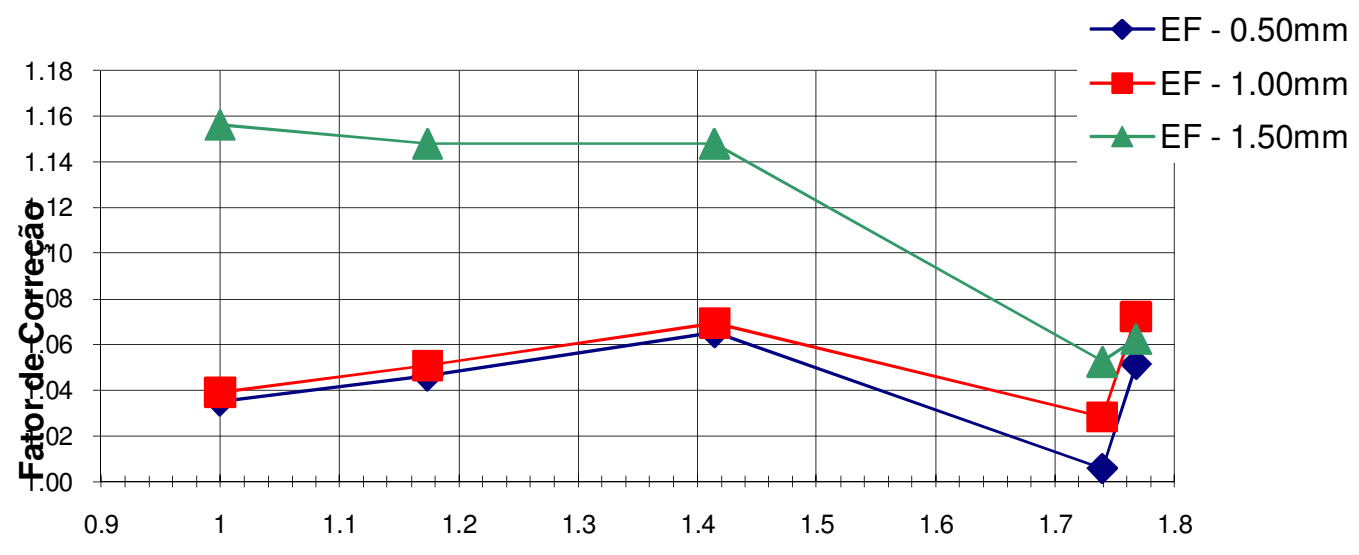

Indução Pico [T]

Figura 6.10 - Fator de correção para junta step-lap V2 e vários valores de entreferro

\subsection{Regiões de contato das juntas}

Foram estudados dois tipos de juntas, conforme a figura 6.1. A junta $\mathrm{V} 1$, sem steplap, e a junta V2, com step-lap.

Em alguns casos, o que irá definir a escolha de um tipo de junta no projeto eletromecânico é a rigidez mecânica das juntas magnéticas e o tempo de construção do núcleo do transformador, e não a sua qualidade magnética referente às perdas.

Para tanto, uma forma de observar esses dados é avaliando o tempo de construção das chapas. Outra é a avaliação da superfície de contato das juntas. Em grandes núcleos de transformadores de potência, os jugos superiores são montados mais facilmente com junta step-lap do tipo V2, que também é a junta com maior velocidade de montagem comparado com a junta $\mathrm{V} 1$.

A tabela 6.3 mostra a região de contato nas juntas do núcleo. Podemos observar que as juntas V1 são menos rígidas se comparadas com a junta V2. No entanto, não 
se pode afirmar que a junta V2 seja a mais apropriada, pois sua fabricação é mais complexa devido aos cortes das chapas.

Tabela 6.3 - Área de superfície de contato entre chapas de aço-silício

\begin{tabular}{|c|c|c|}
\hline Tipo de Junta & $\begin{array}{c}\text { Dimensão de } \\
\text { Contato }[\mathrm{mm}]\end{array}$ & $\begin{array}{c}\text { Razão para base } \\
\text { V2 }\end{array}$ \\
\hline V1 - padrão & $\mathbf{6 0}$ & $\mathbf{0 , 6 6}$ \\
\hline V2 - step-lap & $\mathbf{9 0}$ & $\mathbf{1}$ \\
\hline
\end{tabular}




\section{VALORES DE PERDAS MEDIDAS}

Os dados utilizados neste capítulo para a validação dos resultados numéricos são de um banco de dados fornecido por uma empresa de transformadores de potência. Nesse banco de dados, o tipo de núcleo com maior número de amostras é o de transformador trifásico com três colunas e, por esse motivo, foi o escolhido para estudo. Esse tipo de geometria de núcleo cobre, aproximadamente, $70 \%$ dos núcleos de transformadores de potência fabricados atualmente no mundo.

Nesse espaço amostral têm-se, aproximadamente, quarenta transformadores com potência entre 20 e 375MVA, com massa de núcleo média de 22 toneladas. Outros dados obtidos do banco de dados são as perdas em vazio medidas em laboratórios de ensaios de transformadores e a indução nominal de cada transformador a ser estudado.

Inicialmente, foi calculada a perda no núcleo do transformador, a partir de sua massa e indução nominal. Esse valor foi comparado com o valor medido em laboratório. Como já era esperado, o valor medido foi superior ao calculado analiticamente. Neste banco de dados o valor medido foi, em média, 5,6\% superior ao calculado de forma analítica.

\subsection{Definição do fator de correção}

A proposta inicial deste trabalho era a de analisar as eventuais divergências entre os valores calculados pelo método proposto e os valores de fator de construção estatísticos, além de encontrar uma forma de corrigir os fatores de construção para cada tipo de junta magnética. 
A contribuição deste trabalho é a identificação dos fatores de construção do núcleo dos transformadores de potência, utilizando o método de elementos finitos para um cálculo preciso dos valores de perdas, quando comparado com os valores medidos.

Atualmente, os fatores de construção são calculados de forma estatística, pois cada tipo de chapa e de fabricante de transformadores tem seu próprio fator. Este é composto de outros dois fatores distintos: o fator de manuseio das chapas (FM), $k_{m}$, e o fator de fabricação local (FFL), $k_{l}$. Os dois fatores combinados compõem o fator de construção do núcleo de transformador de potência, dado por:

$$
k_{c}=k_{m}+k_{l}
$$

Devido à dificuldade de uma formulação analítica sobre os fatores de manuseio e fabricação, esse fator é único e sempre é considerado como fator de construção ou building factor, na terminologia anglófona.

Outra contribuição deste trabalho é a análise do fator de construção diferenciado e localizado na região das juntas magnéticas, também chamado de fator de correção, devido às perdas nessas regiões.

\subsection{Definição dos demais fatores}

A potência média dos transformadores do banco de dados utilizado neste trabalho é de 75MVA. A figura 7.1 representa um corte do núcleo de um transformador trifásico na região central do núcleo (pacote central), em que as siglas $\mathrm{AJ}, \mathrm{AN}, D_{n}$ e FF, respectivamente, indicam: a altura da janela, a altura total do núcleo, o diâmetro nominal do núcleo e a distância entre eixos das colunas do núcleo. 

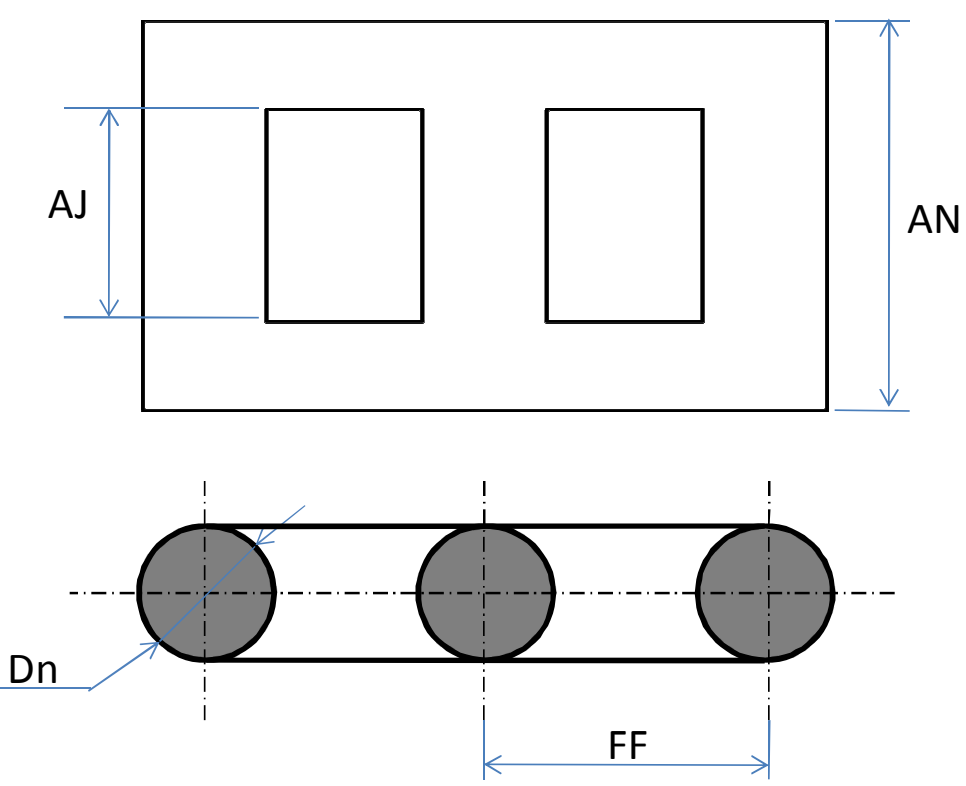

Figura 7.1 - Vista frontal e superior de um núcleo de transformador trifásico com três colunas e sem retorno

Como exemplo, foi simulado um núcleo trifásico em um transformador com dimensões típicas em que os dados foram obtidos no banco de dados.

O intuito desta simulação é mostrar em qual região do núcleo se tem maior intensidade de campo magnético e, conseqüentemente, maiores perdas, como é apresentado na figura 7.2.
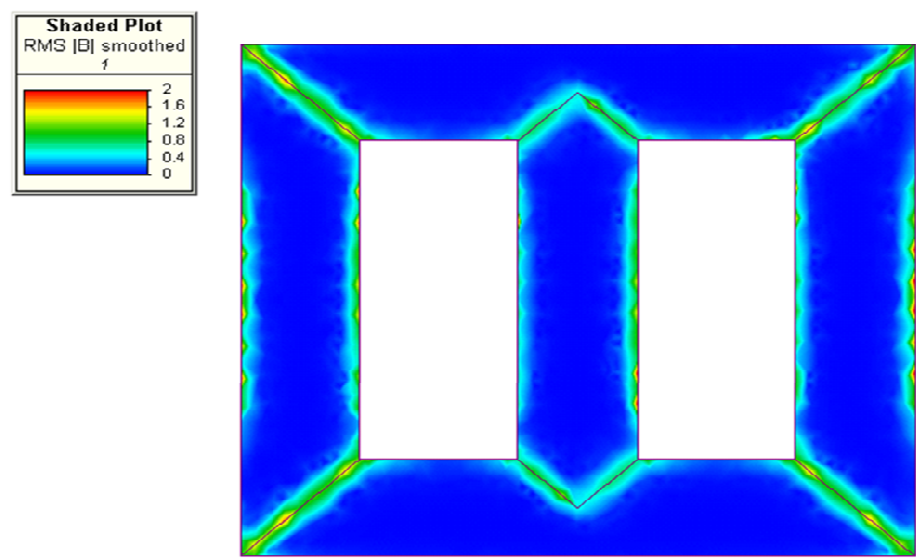

Figura 7.2 - Indução em núcleo de transformador trifásico, com detalhe para a região das juntas magnéticas no pacote central 
$\mathrm{Na}$ figura 7.2, pode-se observar a concentração de induções e perdas nas regiões de juntas no pacote central e, então, simplificar o modelo do núcleo dividido, conforme é apresentado na figura 7.3. Nesta figura, as regiões em azul são conhecidas como áreas das juntas do núcleo, nas quais será aplicado o FCR. As demais áreas serão calculadas de acordo com o FC.

O fator de juntas, $F_{\text {junta }}$, será definido pela razão entre a área total das juntas, $A_{\text {juntas }}$, e a área total do núcleo, $A_{\text {total }}$, ou seja:

$$
\frac{A_{\text {juntas }}}{A_{\text {total }}}=F_{\text {junta }}
$$

A área total das juntas é a soma dos retângulos azuis na figura 7.3 e a área total do núcleo é a soma de toda a área colorida, incluindo a área das juntas no pacote central. É importante salientar que o $F_{\text {junta }}$ não é constante para todos os pacotes do núcleo, neste caso, é possível fazer uma análise para cada um dos pacotes.

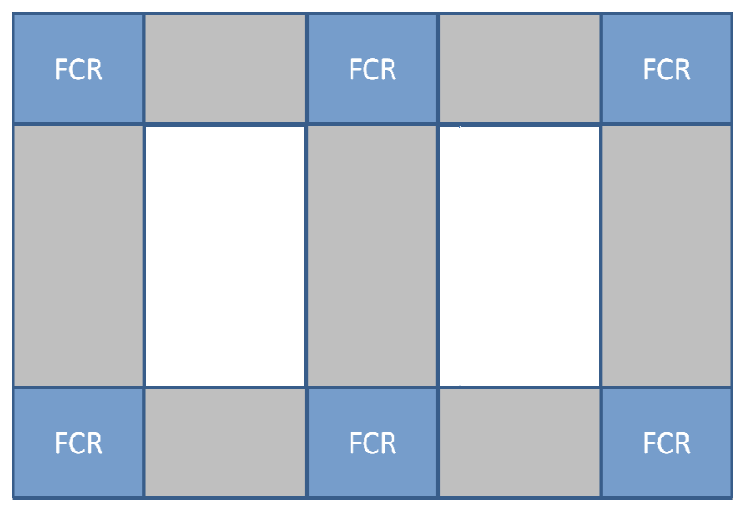

Figura 7.3 - Divisão de um núcleo trifásico em diferentes regiões para cálculo de perdas. As regiões em azul correspondem àquelas das juntas no pacote central

Através da eq.(3.15), tem-se que a perda no ferro calculada é a multiplicação da massa do núcleo magnético por sua perda específica, a uma determinada indução magnética, e por seu fator de construção, que é um dado empírico, como segue:

$$
P_{F e}=G_{F e} \cdot\left[\frac{W}{k g}\right] \cdot k_{c}
$$

O cálculo analítico das perdas será, então, obtido por: 


$$
P_{\text {analitica }}=G_{F e} \cdot\left[\frac{W}{k g}\right]
$$

Nesta etapa, serão definidos dois fatores de construção distintos:

- fator de construção propriamente dito que tem alto grau de empirismo, $K_{c 1}$;

- fator de construção corrigido, $K_{c 2}$, dado pela equação:

$$
P_{F e}=P_{\text {analitica }} \cdot K_{c 1}=P_{c j} \cdot k_{c 2}
$$

O fator $k_{c 2}$ é calculado através do FCR, $K_{\text {corręãa }}, \mathrm{FCR}$, obtido pelo MEF.

A perda no núcleo, $P_{c j}$, é a perda considerando o adicional de perdas nas juntas, com os dados obtidos através do MEF.

A perda no núcleo, considerando a parcela relativa às juntas, $P_{c j}$, é então calculada pela expressão:

$$
P_{c j}=G_{F e} \cdot\left[\frac{W}{k g}\right] \cdot\left[\left(F_{\text {junta }} \cdot K_{\text {correģão }}\right)+\left(1-F_{\text {junta }}\right) \cdot 1\right]
$$

Tendo como dados de entrada material do núcleo, indução nominal, entreferro, tipo de junta a ser utilizada, geometria do núcleo e massa do núcleo, é possível obter a perda específica, o fator de juntas e o fator de correção referente às juntas.

Dessa maneira, as perdas no núcleo ferromagnético podem ser obtidas, incorporando os fatores previamente definidos, conforme eq.(7.5).

Pode-se definir, então, uma "redução do FC", dada em porcentagem, $R_{F C}$, e calculada como:

$$
R_{F C}=\left[\frac{\left(K_{c 1}-1\right)}{\left(K_{c 2}-1\right)}-1\right] \cdot 100 \%
$$

Ou, ainda, como:

$$
R_{F C}=\left[\frac{\left(\left(G_{F e} \cdot\left[\frac{W}{k g}\right] \cdot\left[\left(F_{\text {junta }} \cdot K_{\text {corrę̧äo }}\right)+\left(1-F_{\text {junta }}\right)\right]\right)-1\right)}{\left(\left(G_{F e} \cdot\left[\frac{W}{k g}\right]\right)-1\right)}-1\right] \cdot 100 \%
$$




\subsection{Aplicativo de cálculo}

Com o fator de correção definido, é possível reduzir o grau de empirismo no momento do cálculo do transformador, melhorando a utilização de material e a redução do custo do equipamento.

Após o cálculo analítico, usa-se esse fator de correção para corrigir o valor analítico. Quanto maior a precisão do cálculo do fator de construção, menor será o desvio entre o valor calculado e o valor medido das perdas; e quanto menor esse desvio, melhor será a utilização do material do núcleo.

As juntas do núcleo ficam em uma região do circuito magnético em que ocorre maior concentração de campo magnético devido a: anisotropia do material ferromagnético; perdas localizadas devido a saturação indesejada; e rebarbas que ocorrem no momento do corte das chapas. O fator de juntas, ou seja, a porcentagem do núcleo que corresponde a estas áreas varia de 15\% a 30\%. Todos esses fatores reunidos aumentam a perda nessa região, motivando o desenvolvimento das ferramentas propostas.

Os valores médios de fator de correção das chapas, encontrados através de interpolação nos gráficos das figuras 6.9 e 6.10 e das induções médias nos transformadores, são apresentados no gráfico da figura 7.4.

Naquela figura se vê, nitidamente, que as perdas variam de forma acentuada com o aumento do entreferro. Pode-se verificar, também, que as chapas sem step-lap são menos eficientes do que as chapas com step-lap.

O aplicativo computacional desenvolvido tem um banco de dados com as informações dos fatores de correção para cada tipo de junta e entreferro. Seus dados de entrada são dimensões geométricas do núcleo (AN, AJ, $D_{n}$ e FF), fator de construção do núcleo obtido pelo fabricante de forma estatística, massa do núcleo e indução nominal. Com esses dados, o aplicativo calcula o fator de construção corrigido e o disponibiliza ao usuário para todos os tipos de juntas, bem como a 
perda corrigida e o fator de redução do FC. A figura 7.5 apresenta um screenshot do aplicativo.

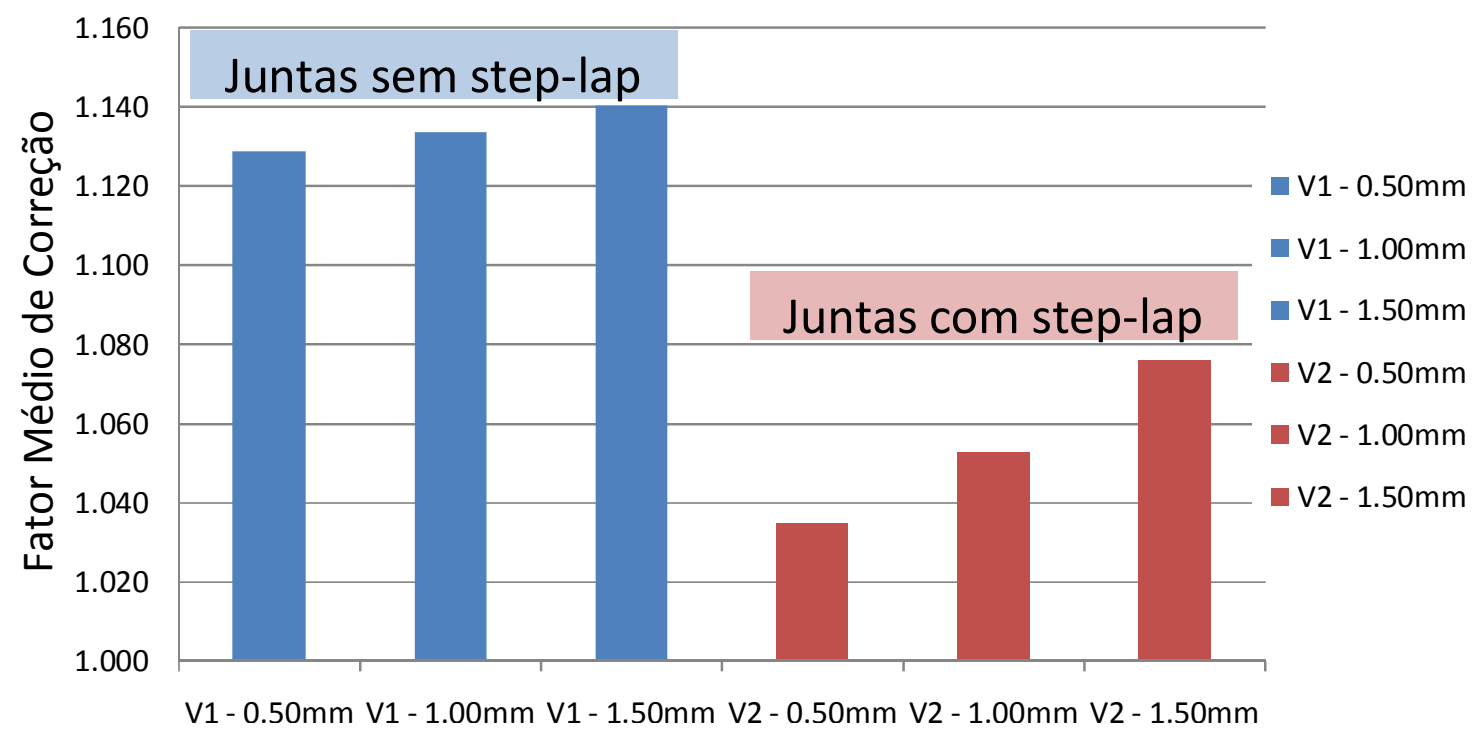

Figura 7.4 - Fator médio de correção, estimado através do valor de indução média obtido do banco de dados

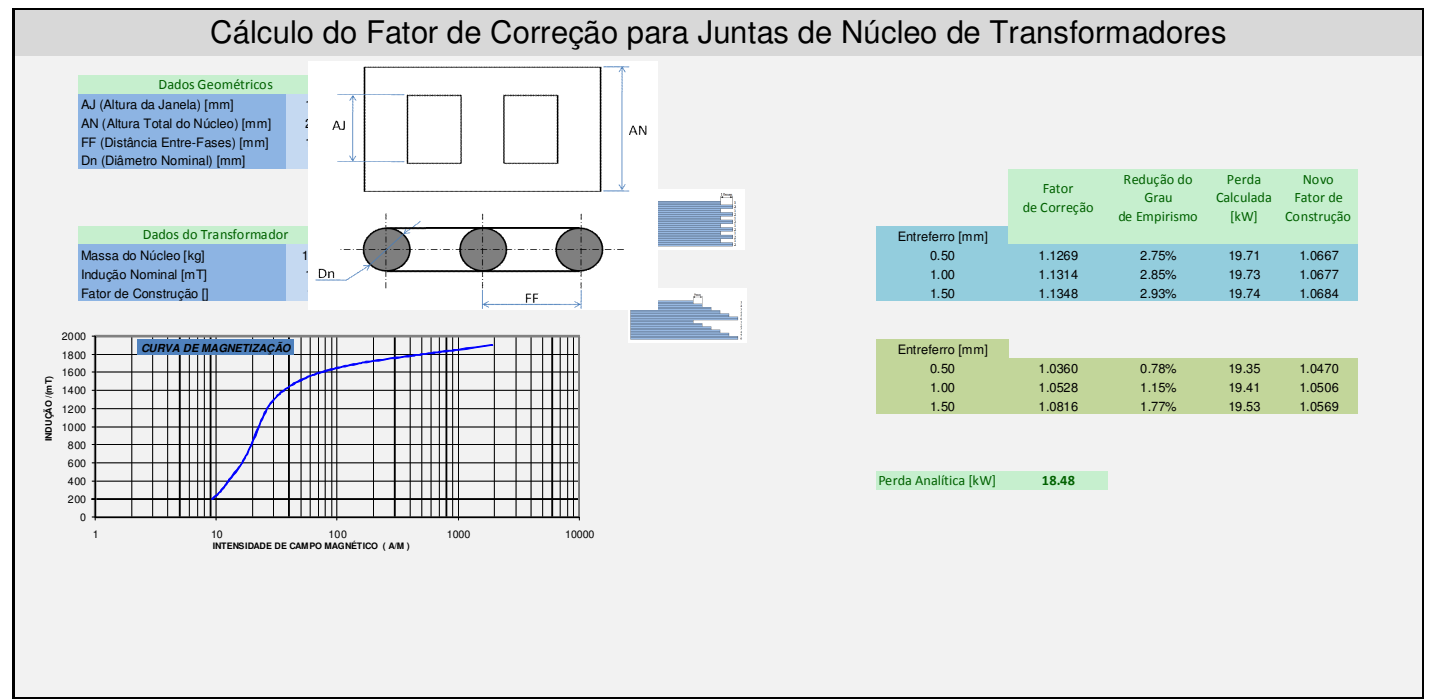

Figura 7.5 - Screenshot do aplicativo desenvolvido para cálculo de FCR e FC corrigido

O aplicativo desenvolvido apresenta todas as opções de juntas, e entreferros de 0,50mm a 1,50mm, não sendo mais necessário efetuar nenhuma simulação por elementos finitos. 


\subsection{Resultados}

O modelo estabelecido no capítulo 4 será agora aplicado para análise de perdas em juntas de núcleos de transformadores de potência. Inicialmente, através do banco de dados, foram encontrados os valores de perdas calculadas e perdas medidas. Como se trata de banco de dados de uma empresa privada, com dados confidenciais, apenas alguns valores foram autorizados para divulgação e puderam ser inseridos no aplicativo.

Três situações foram consideradas no aplicativo:

- Situação 1 - Valores Médios do Banco de Dados.

- Situação 2 - Valores Máximos do Banco de Dados.

- Situação 3 - Valores Mínimos do Banco de Dados.

As três situações exigem a introdução de grandezas, geométricos e de operação.

A figura 7.6 mostra o screenshot do aplicativo para a situação 1, a figura 7.7, para a situação 2 e a figura 7.8, para a situação 3 .

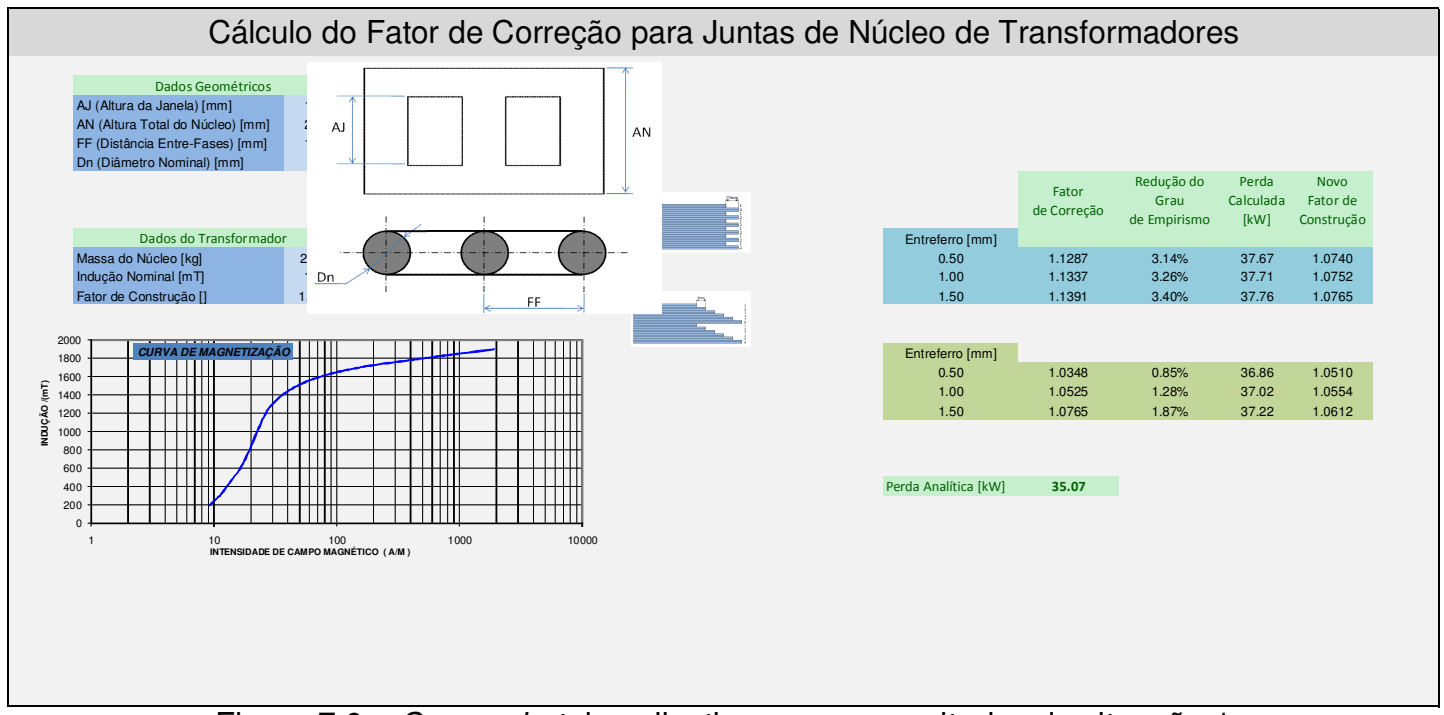

Figura 7.6 - Screenshot do aplicativo com os resultados da situação 1 


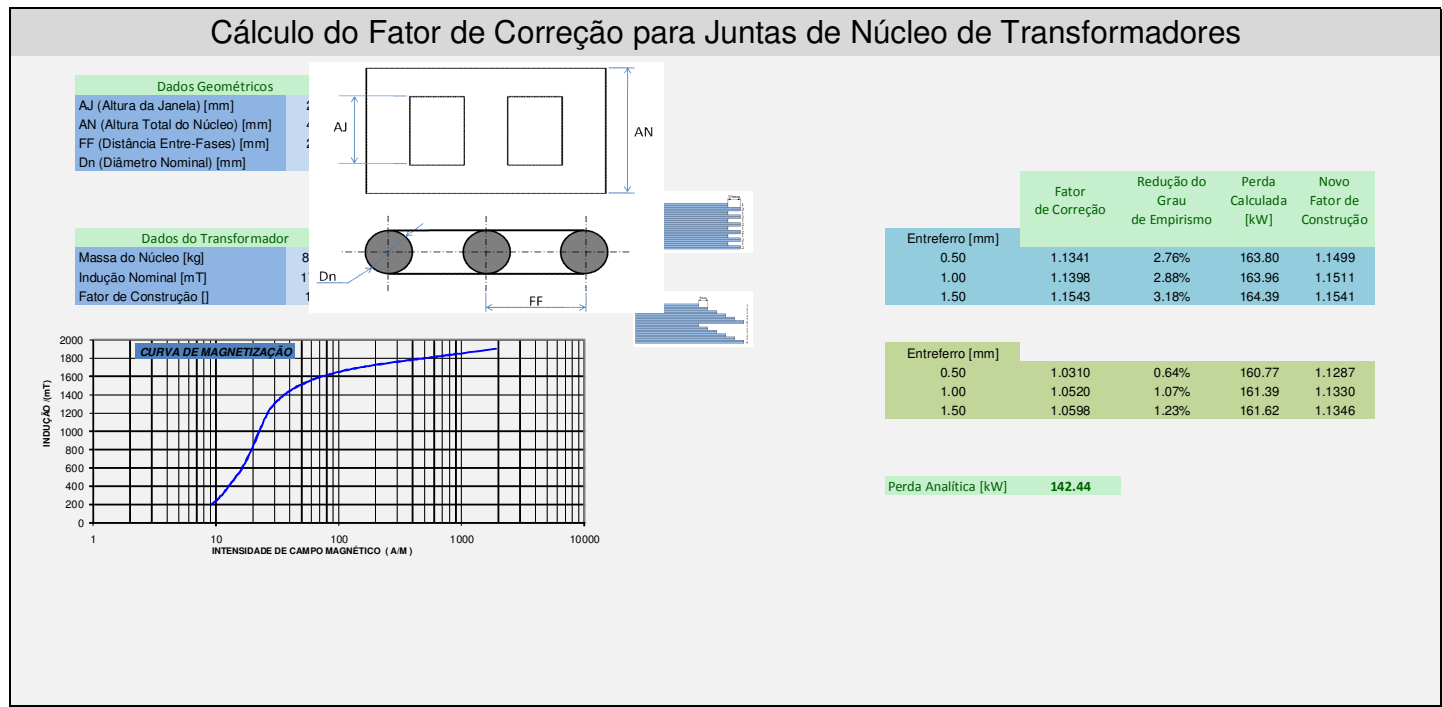

Figura 7.7 - Screenshot do aplicativo com os resultados da situação 2

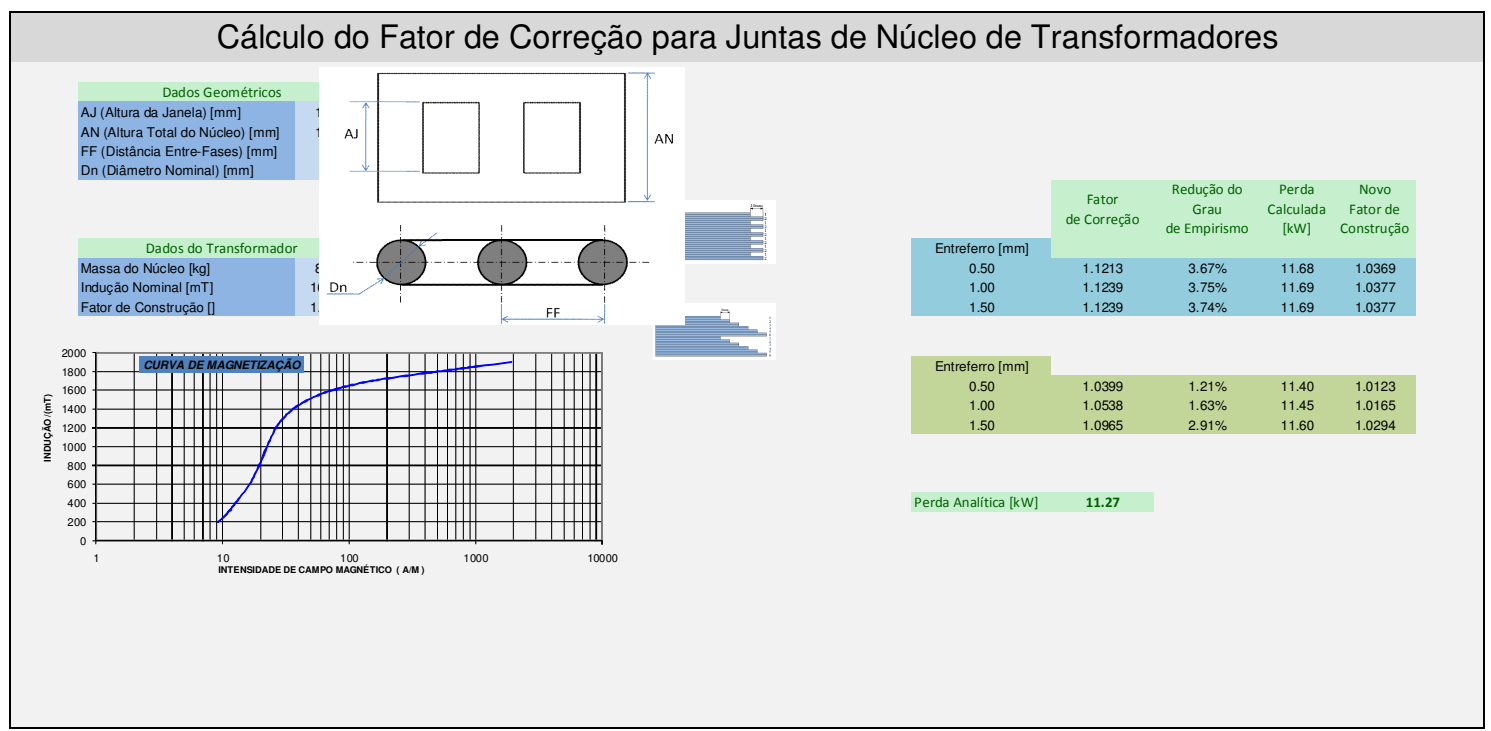

Figura 7.8 - Screenshot do aplicativo com os resultados da situação 3

A figura 7.9 apresenta um gráfico com o valor da redução do FC para todos os tipos de juntas e entreferro estudados neste trabalho. 


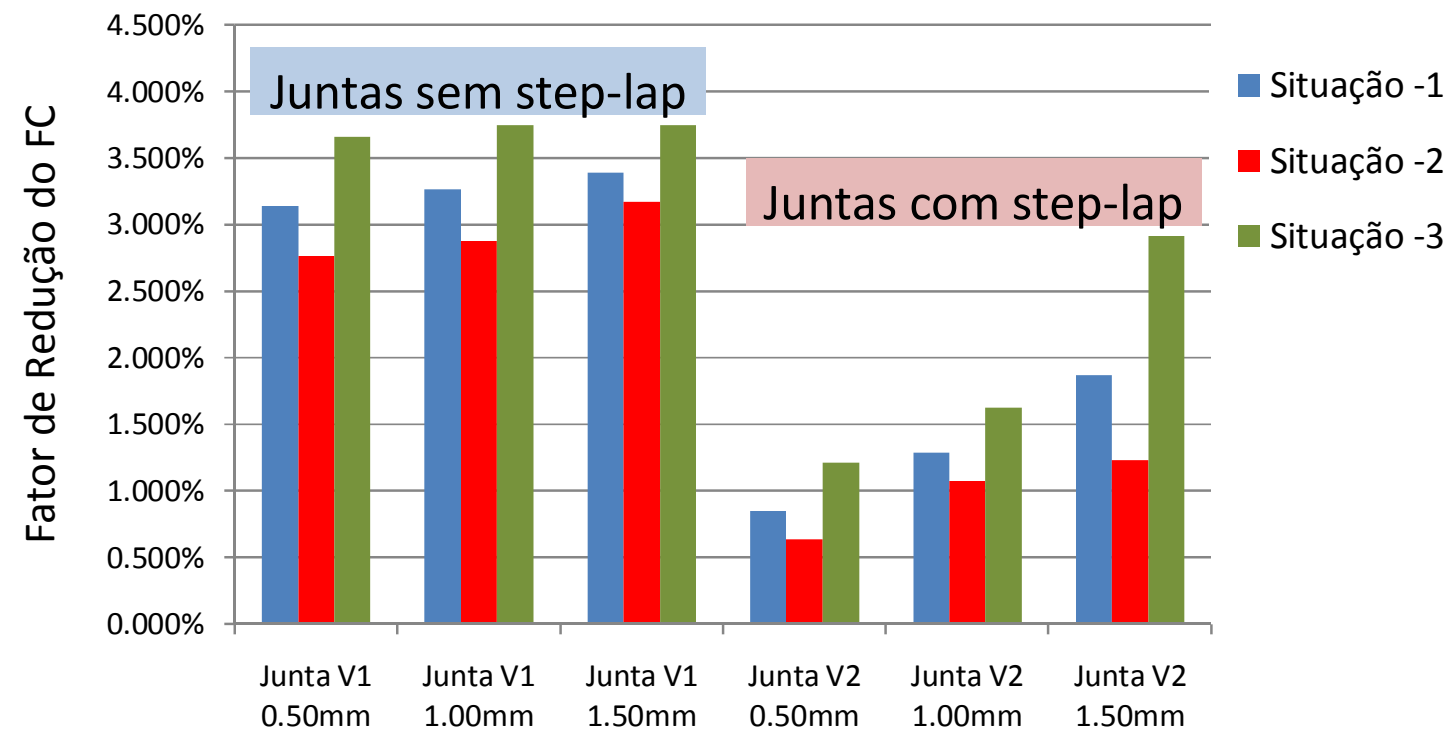

Figura 7.9 - Fator de redução do grau de empirismo do FC para diversas configurações de juntas

Pode-se observar pela figura 7.9 que é possível reduzir o FC em até 3,5\% em juntas sem step-lap e até 2,8\% em juntas com step-lap. De forma geral, pode-se reduzir $2 \%$ para todos os tipos de juntas empregadas nas indústrias, comprovando, portanto, a eficácia da ferramenta.

Ao reduzir o fator de empirismo do fator de construção global de um núcleo de transformador de potência, é possível obter um ganho financeiro considerável para a indústria.

Após o cálculo das perdas em núcleos de transformadores, o fabricante deve inserir mais um fator de segurança, conhecido como fator de garantia. Esse fator é então aplicado às perdas totais em núcleos de transformadores para garantir ao comprador que as perdas máximas solicitadas serão respeitadas.

Ao reduzir o erro de cálculo através de novos modelos, como o proposto, e mantendo o mesmo fator de garantia, é possível reduzir a massa e, conseqüentemente, o custo do núcleo e do transformador.

Segundo relatório da Acesita [69], a capacidade de produção de aço-silício de Grão orientado, GO, é de 1,5 milhões de toneladas ao ano, no mundo, e, no Brasil, de 40 mil. No início da década de 90, o mercado brasileiro consumiu, aproximadamente, 13 mil toneladas e, em 2005, esse valor atingiu 40 mil toneladas. A projeção é que esse mercado consuma, aproximadamente, 58 mil toneladas em 2010. Noventa por cento do mercado consumidor de aços de grão orientado são as indústrias de 
transformadores de energia, totalizando uma estimativa de aproximadamente 52 mil toneladas. Como $5 \%$ dessa massa é sucateada nas indústrias durante o corte das chapas, o restante pode ser utilizado de forma adequada para construção de núcleos de transformadores. Então, se for reduzido em $2 \% \circ$ grau de empirismo, pode-se reduzir o consumo do material na ordem de $0,1 \%$.

Atualmente, a tecnologia de transformadores de potência está convergindo para um ponto ótimo e amadurecendo. Novos materiais empregados, sistema de monitoramento durante a vida útil e ferramentas modernas de simulação são novas tecnologias que servem para reduzir o custo operacional e aumentar sua confiabilidade. Neste contexto, $0,1 \%$ de redução em material é um valor significativo. 


\subsection{Tópicos para futuros trabalhos}

Este trabalho não contemplou o estudo da influência do campo magnético para a elevação de temperatura em regiões localizadas em núcleo de transformadores de potência, o que configura uma extensão natural.

Outros fatores como rebarbas, falhas no revestimento das lâminas e qualidade das lâminas, gerando perdas interlaminares não foram contempladas tampouco.

É fortemente indicada uma futura integração do projeto de núcleo a enrolamentos de transformadores em situações da rede elétrica; ou seja, um entendimento de como se comportam as perdas dos transformadores para transitórios de baixas, médias e altas freqüências, bem como para transformadores com alimentação não-senoidal e retroalimentação. Outra sugestão para futuros trabalhos é acoplar o MEF, tanto para campo magnético quanto para campos elétricos, com os transitórios de redes elétricas, a fim de prever como será o comportamento do equipamento quando ocorrerem variações de tensões, curto-circuito e sincronismo fora de fase, podendose, posteriormente, propor recomendações para a especificação do projeto elétrico e eletromecânico de transformadores de potência.

Devido ao fato do parque de transformadores de potência no Brasil estar envelhecendo, cada vez mais trabalhos voltados para a área de estudos de reparos e revitalização de transformadores serão necessários. Tendo em vista que o custo do núcleo de transformadores pode chegar a 35\% do custo final do equipamento, trabalhos como estudo de viabilidade econômica, capitalização de perdas e aspectos de impactos ambientais para construção de núcleos serão necessários. 


\section{REFERÊNCIAS}

[1] URATA, S. et al. The Calculation Considered Two-Dimensional Vector Magnetic Proprieties Depending on Frequency of Transformers. In: IEEE Transactions on Magnetics, $n \div 4,2006$. v.42, p.687-690.

[2] SODA, N.; ENOKIZONO, M. Improvement of T-Joint Part Constructions in ThreePhase Transformer Cores by Using Direct Loss Analysis with E\&S Model. In: IEEE Transactions on Magnetics, no4, 2000. v.36, p.1285-1288.

[3] OLIVEIRA, A. M. et al. Generalization of Coupled Circuit-Field Calculation for Polyphase Structures. In: IEEE Transactions on Magnetics, no5, 2001. v.37, p.3444-3447.

[4] OKABE, M.; OKADA, M.; TSUCHIYA, H. Effects of Magnetic Characteristics of Materials on the Iron Loss in the Three Phase Transformer Core. In: IEEE Transactions on Magnetics, no5, 1983. v.mag-19, p.2192-2194.

[5] DEDULLE, J. M. et al. Magnetic Fields in Nonlinear Anisotropic Grain-Oriented Iron-Sheet. In: IEEE Transactions on Magnetics, no2, 1990. v.26, p.524-527.

[6] NOURDINE, A.; MEUNIER, G.; KEBOUC-LEBOUC, A. Numerical Computation of a Vectorial Hysteresis $H(B)$ Magnetization Law. In: IEEE Transactions on Magnetic, №3, 2003. v.39, p. 1393-1396.

[7] ROUVE, L-L. et al. Magnetic Flux and Loss Computation in Electrical Laminations. In: IEEE Transactions on Magnetic, no5, 1996. v.32, p.4219-4221.

[8] MAC, A. et al. A Study of Characteristic Analysis of Tree-Phase Transformer With Step-Lap Wound-Core. In: IEEE Transactions on Magnetics, nํ2, 2002. v.38, p.829-832.

[9] ABBASZADEH, K., S. Modeling of B-H loop for Core Loss Calculations in Power Transformer Using Finite Element Method. In: IEEE PD4-4, 1-4244-0320-0/06, 2006.

[10] BASAK, A.; LLOYD, G.; YU, C. H. A Computation Study of Localised Loss in a Distribution Transformer. In: Wolfson Centre for Magnetics Technology, Universaty of Wales College of Cardiff, U.K. p.56-59. 
[11] ALONSO, G.; ANTONIO, J. A New Method for Calculating of Leakage Reactances and Iron Losses in Transformers. In: University of the Basque Country, E. U. Igeniería Técnica Industrial, Dpto de Ingeniería Eléctrica. p.178-181.

[12] BARTON, M. L. Loss Calculation in Laminated Steel Utilizing Anisotropic Magnetic Permeability. In: IEEE Transaction on Power Apparatus and Systems, n-3, 1980. v. PAS-99, p. 1280-1287.

[13] NOGAWA, S. et al. Study of Modeling Method of Lamination of Reactor Core. In: IEEE Transactions on Magnetics, n4, 2006. v.42, p. 1455-1458.

[14] MALOBERTI, O. An Energy-Based Formulation for Dynamic Hysteresis and Extra-Losses. In: IEEE Transactions on Magnetics, n-4, 2006. v.42, p.895-898.

[15] CHIAMPI, M.; NEGRO, A. L.; TARTAGLIA, M. Alternating Electromagnetic Field Computation in Laminated Cores. In: IEEE Transactions on Magnetics, nㄴ, 1983. v. MAG-19, p. 1530-1536.

[16] MOREAU, O. 3-D High Frequency Computation of Transformer R, L Parameters. In: IEEE Transactions on Magnetics, n5, 2005. v. 41, p. 1364-1367.

[17] LAVERS, J. D.; BOLBORICI, V. Loss Comparation in the Design of High Frequency Inductors and Transformers. In: IEEE Transactions on Magnetics, nㄷ, 1999. v.35, p.3541-3543.

[18] NAKATA, T.; TAKAHASHI, N.; KAWASE, Y. Magnetic Performance of Step-Lap Joint in Distribution Transformer Cores. In: IEEE Transaction on Magnetics, n으, 1982. v.MAG-18, p.1055-1057.

[19] LUK, L.; DAWSON, G. E.; EASTHAM, A. R. Finite Element and Finite Difference Analysis of Losses in Laminated Material. In: IEEE Transactions on Magnetics, nํ6, 1988. v.24, p.2679-2681.

[20] IKEDA, H., OKABE, M., OHMURA, T. Iron Loss of Staked Cores Using Amorphous Alloys. In: IEEE Transactions on Magnetics, n5, 1986. v.MAG-22, p.529531.

[21] GYSELINCK, Johan J. C.; VANDEVELDE, L.; MELKEBEEK, Jan A. A. 2D FE Modelling of a Transformer with Direct Inclusion of the Iron Losses and Core Joint Effects. 
[22] GYSELINCK, J.; MELKEBEEK, J. Two-dimensional finite element modelling of overlap joints in transformer cores. In: COMPEL The International Journal for Computation and Mathematics in Electrical and Electronic Engineering. $\mathrm{n}=1$, 2001. v.20, p.253-268.

[23] GIRGIS, R. S. et al. Experimental Investigations On Effects Of Core Production Attributes On Transformer Core Loss Performance. In: IEEE Transactions on Power Delivery, no2, 1998. v.13, p.526-531.

[24] MECHLER, G. F.; GIRGIS, R. S. Calculation of Spatial Loss Distribution in Stacked Power and Distribution Transformer Core. In: IEEE Transactions on Power Delivery, no2, 1998. v.13, p. 532-537.

[25] TENYENHUIS, Ed G.; GIRGIS, R. S.; MECHLER, G. F. Other Factors Contributing to the Core Loss Performance of Power and Distribution Transformers. In: IEEE Transactions on Power Delivery, n4, 2001. v.16, p.648-653.

[26] HENRIKSEN, T. Transformer leakage flux modeling. In: SINTEF Energy Research, Sem Saelandsvei 11, N-7465 Trondheim, Norway, 2001.

[27] PFÜTZNER, H. Three-dimensional Flux Distributions in Transformer Cores as a Function of Package Design. In: IEEE Transactions on Magnetics, nㄷ, 1994. v.30, p.2713-2727.

[28] YU, C. H.; BASAK, A. Optimum Design of Transformer Cores by Analysing Flux and Iron Loss with the Aid of a Novel Software. In: IEEE Transaction on Magnetics, no2, 1993. v.29, p.1446-1449.

[29] NAPIERALSKA, E.; GRZYBOWSKI, R. Modelling of losses due to eddy currents and histeresis in converter transformer cores during failure. In: IEEE Transaction on Magnetics, nํㅜ, 1995. v.31, p.1718-1721.

[30] STENSLAND, T. Modeling of Magnetizing and Core-Loss Currents in SinglePhase Transformers with Voltage Harmonics for Use in Power Flow. In: IEEE Transaction on Power Delivery, nำ2, 1997. v.12, p.768-774.

[31] WIESERMAN, W. R.; KUSIC, G. L. Characterization of Soft Magnetic Material Power Delivery. In: IEEE Transactions on Power Delivery, n4, 1995. v.10, p.18431850. 
[32] PAVLIK, D.; JOHNSON, D. C.; GIRGIS, R. S. Calculation and Reduction of Stray and Eddy Losses in Core-Form Transformers Using a Highly Accurate Finite Element Modelling Technique. In: IEEE Transactions on Power Delivery, ํㅜ1, 1993. v.8, p.239-245.

[33] SIPPOLA, M.; SEPPONEN, R. E. Accurance Prediction of High-Frequency Power-Transformer Losses and Temperature Rise. In: IEEE Transactions on Power Electronics, n5, 2002. v.17, p.835-847.

[34] PICANÇO, A. F. et al. Avaliação Econômica de Transformadores de Distribuição de Alta Eficiência. 2006.

[35] LISITA, L. R. et al. Additional Loss in the Core of Three Phase Transformers Feeding Non Linear Loads. In: IEEE, 2004. v.2, p.48-56.

[36] RAY, S. Predication of hysteresis losses produced by distorted flux in low-loss silicon-iron transformer core laminations. In: IEE Proceedings-c, №3, 1993. v.140, p.229-236.

[37] MOSES, A. J.; THOMAS, B.; THOMPSON, J. E. Power Loss and Flux Density Distributions in the T-Joint of Three Phase Transformer Core. In: IEEE Transactions on Magnetics, 1972. v.8, p.785-790.

[38] MOSES, A. J.; THOMAS, B. Problems in the Design of Power Transformers. In: IEEE Transaction on Magnetics, no2, 1974. v. MAG-10, p. 148-150.

[39] GEORGILAKIS, P. S.; HATZIARGYRIOU, N. D.; PAPARIGAS, D. G. Steps Towards Intelligent Core Loss Modeling. In: 10th Mediterranean Electrotechnical Conference, MEleCon. 2000. v.III, p.1011-1014.

[40] SO, E.; ANSENEAU, R.; HANIQUE, E. No-Load Loss Measurements of Power Transformers Under Distorted Supply Voltage Waveform Conditions. In: Electrical Insulation Conference and Electrical Manufacturing \& Coil Winding Conference, 0-7803-7242-5/02 / p.236.

[41] YU, C. H.; BASAK, A. Optimum Design of Transformer Cores by Analysing Flux and Iron Loss with Aid of Novel Software. In: IEEE Transactions on Magnetics, no2, 1993. v.22, p. 1446-1449. 
[42] GOETHE, P. K.; GOETHE, W. D. How Core Losses Affect Operating Costs for Transformers Delivering Non-Sinusoidal Loads. In: IEEE Transactions on Magnetics, 1974. v.10. p.231-234.

[43] TAGUCHI, S.; YAMAMOTO, T.; SAKAKURA, A. New Grain-Oriented Silicon Steel with High Permeability ORIENTCORE HI-B. In: IEEE Transactions on Magnetics, $\mathrm{n} \cong 2$, 1974. v.10, p. 123-127.

[44] FINDLAY, R.; BELMANS, R.; MAYO, D. Influence of the Stacking Method on the Iron Losses in Power Transformer Cores. In: IEEE Transaction on Magnetics, $\mathrm{n} \div 5$, 1990. v.26, p. 1990-1992.

[45] MOSES, A. J. Comparison of Transformer Loss Prediction from Computed and Measured Flux Density Distribution. In: IEEE Transactions on Magnetics, $\mathrm{n} \div 4$, 1998. v.34, p. 1186-1188.

[46] BASAK, A.; YU, C. H.; LLOYD, G. Efficient Transformer Design by Computing Core Loss Using a Novel Approach. In: IEEE Transaction on Magnetics, nํ5, 1994. v.30, p. 3725-3728.

[47] CHARAP, S. H.; JUDD, F. F. A Core Loss Model for Laminated Transformers. . In: IEEE Transaction on Magnetics, 1974. v.10, p.678-681.

[48] GEORGILAKIS, P. S et al. A Neutral Network Framework for Predicting Transformer Core Losses. In: IEEE 0-7803-5478-88/99,1999. p.301-308.

[49] DOULAMIS, A. D.; DOULAMIS, N. A Neutral Network-Genetic Algorithm Scheme for Optimal Grouping of Individual Core in Three-Phase Distributed Transformers. In: IEEE 0-7803-7503-3/02, 2002. v.2, p1061-1064.

[50] GEORGILAKIS, P.; HATZIARGYRIOU, N.; PAPARIGAS, D. Al Helps Reduce Transformer Iron Losses. In: IEEE ISSN 0895-0156/99, 1999. v.12, p.41-46.

[51] SIERADZKI, S.; RYGAL, R.; SOINSKI, M. Apparent Core Losses and Core Losses in Five-Limb Amorphous Transformer of 160 kVA. In: IEEE Transaction on Magnetics, no4, 1998. v.34, p. 1189-1191.

[52] VALKOVIC, Z. Influence of the Transformer Core Design on Power Losses. In: IEEE Transaction on Magnetic, n², 1982. v. MAG-18, p. 801-804. 
[53] MECHLER, G. F.; GIRGIS, R. S. Magnetic Flux Distribution in Transformer Core Joints. In: IEEE Transaction on Power Delivery, no1, 2000. v.15, p. 198-203.

[54] MOSES, A. J.; THOMAS, B. The Spatial Variation of Localized Power Loss in Two Practical Transformer T-Joints. In: IEEE Transaction on Magnetics, n־4, 1973. v. MAG-9, p. 655-659.

[55] LOFFLER, F. et al. Relevance of step-lap joints for magnetic characteristics of transformer cores. In: IEE Proceedings, n6, 1995. v.142, p.371-378.

[56] BASTOS, J. P. A.; QUICHAUD, G. 3D modelling of a non-linear anisotropic lamination. In: IEEE Transaction on Magnetic, n־6, 1985. v. MAG-21, p. 2366-2369.

[57] SANDE, H. V. et al. An Effective Reluctivity Model for Nonlinear and Anisotropic Materials in Time-Harmonic Finite Element Computations. In: IEEE Transaction on Magnetic, n5, 2005. v.41, p. 1508-1511.

[58] LIN, D. A New Nonlinear Anisotropic Model for Soft Magnetic Materials. In: COMPUMAG, 2005. v.42, p.963-966.

[59] BASTOS, J. P. A.; QUICHAUD, G. 3D Modelling of a Non-Linear Anisotropic Lamination. In: IEEE Transaction on Magnetics, $n \div 6$, 1985. v. MAG-21, p.23662369.

[60] BASTOS, J. P. A.; QUICHAUD, G. Modélisation tridimensionnelle des feuilletages ferromagnétiques par élements finis. Revue des Physique Appliquée, France, v.19, p. 139-147, fev. 1984.

[61] INFOLYTICA Package for Magnetic analysis using finite elements, INFOLYTICA Co. Montreal: Canadá. Disponível em <http://www.infolytica.com> Acesso em: 15 jan. 2008.

[62] CARLSON, A. Power Transformer Design Fundamentals. Ludvika, Sweden: ABB Transformers. 1995.

[63] ABB. Distribution Transformer Handbook. Switzerland: 2003.

[64] ABB. Transformer Handbook. Switzerland: 2004. 
[65] HARLOW, James H. Electric Power Transformer Engineering.CRC Press, 2004.

[66] WINDERS JR., John J. Power Transformers: Principles and Applications. New York: Marcel Dekker, Inc, 2004.

[67] CALIL, Wílerson Venceslau; SILVA, Viviane Cristine. Determinação de Fator de Ajuste de Perdas Magnéticas em Núcleo de Transformadores de Potência pelo Método de Elementos Finitos. In: MOMAG. Florianópolis: 2008.

[68] MEURER, Evandro Jacob. Estudo das Perdas Magnéticas Interlaminares em Máquinas Elétricas. 2005. 112f. Dissertação (Mestrado) - Universidade Federal de Santa Catarina, Florianópolis.

[69] ACESITA. TAKANOHASHI, Rubens; ANDRADE, Paulo Ricardo C. de. Avaliação da qualidade e produção dos aços GO. Disponível em http://www.inmetro.gov.br/painelsetorial/palestras/PalestraTakanohashi.pdf. Acesso em: 15 jan. 2009.

[70] CZERNORUCKI, Marcos Veloso. Representação de transformadores em estudos de transitórios. 2007. 101f. Dissertação (Mestrado) - Escola Politécnica da Universidade de São Paulo, Departamento de Engenharia de Energia e Automação Elétricas, São Paulo.

[71] WINDERS JR., John J. Power Transformers: Principles and Applications.

[72] LOWTHER, D. A.; SILVESTER, P.P. Computer - Aided Design in Magnetics. Berlin: Editora: Springer-Verlag.

[73] JORDÃO, Rubens Guedes. Transformadores. Brasil: Editora Edgard Blücher Ltda., 2002. 


\section{APÊNDICE A - PROPRIEDADES DOS MATERIAIS E CONFIGURAÇÃO DO PROGRAMA}

O programa de elementos finitos utilizado neste estudo é uma ferramenta usada em simulações magnéticas e conhecido, comercialmente, como Infolytica ${ }^{\circledR}$ - Magnet 2-D Student Version.

\section{A.1 Cálculo do fator de empacotamento}

Para transformadores de potência, utiliza-se um valor típico de fator de empacotamento, também conhecido como fator de empilhamento das lâminas do núcleo. Esse valor é utilizado para descontar a quantidade da seção transversal que não é preenchida com material magnético; essa parcela restante é preenchida com a isolação entre as chapas, cuja ordem é de micrometro. Sejam os parâmetros a seguir:

- $e$ - espessura total da chapa;

- $t$ - espessura efetiva de material magnético;

- $t_{\text {isolacao }}$ - espessura da camada de isolação;

- $\varepsilon$ - fator de empilhamento.

Tem-se então:

$$
\begin{aligned}
& e=t+2 \cdot t_{\text {isolacao }} \\
& \left\{\begin{array}{l}
t=\mathcal{E} \cdot e \\
t_{\text {isolacao }}=(1-\mathcal{E}) \cdot e
\end{array}\right.
\end{aligned}
$$




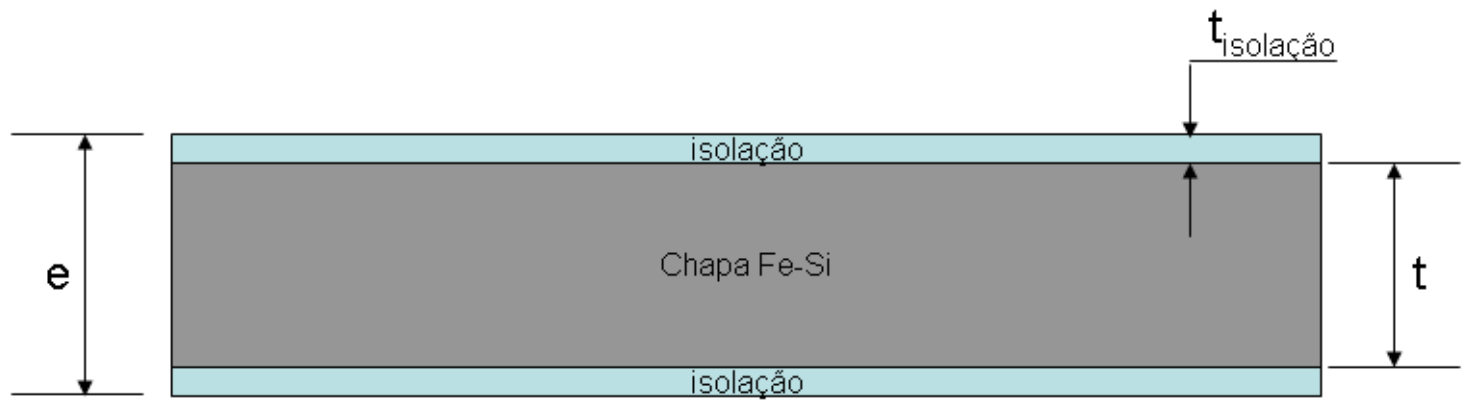

Figura A.1 - Chapa de aço-silício com isolação

Para $\varepsilon=0,96$ e $e=0,27 \mathrm{~mm}$, tem-se:

- $t=0.2592 \mathrm{~mm}$.

- $t_{\text {isolacao }}=0.0054 \mathrm{~mm}$.

Esses foram os valores utilizados na modelagem da laminação para geração do modelo de simulação do problema a ser estudado.

As chapas estudadas foram empilhadas duas a duas, pois é a formação mais usual em manufatura de transformadores de potência, podendo, também, ser analisadas para empilhamento uma a uma, três a três ou quantas chapas forem necessárias.

\section{A.2 Cálculo de profundidade de penetração de onda}

Para se dimensionar corretamente a malha de elementos finitos é importante calcular a profundidade de penetração de onda para o material a ser estudado e fornecer, como dado de entrada do programa, a maior aresta permitida para qualquer elemento da malha.

Como a malha a ser utilizada interpolação quadrática (elemento de $2^{a}$. ordem), é necessário que o maior elemento da malha tenha, no mínimo, duas vezes a profundidade de penetração.

A profundidade de penetração de onda é dada pela eq.(A.3-1), abaixo. 


$$
\delta=\frac{1}{\sqrt{2 \cdot \pi \cdot f \cdot \mu \cdot \sigma}}
$$

Para efeito de cálculo de perdas, foi considerado que a permeabilidade relativa do aço-silício no eixo de não-laminação é igual à permeabilidade relativa do ar, visto que a relação entre a permeabilidade relativa do eixo de laminação e do eixo de não-laminação é muito grande. Como a isolação entre as chapas é muito menor que o entreferro estudado, o fluxo irá comportar-se como esperado.

Tabela A.1 - Cálculo da profundidade de penetração de onda

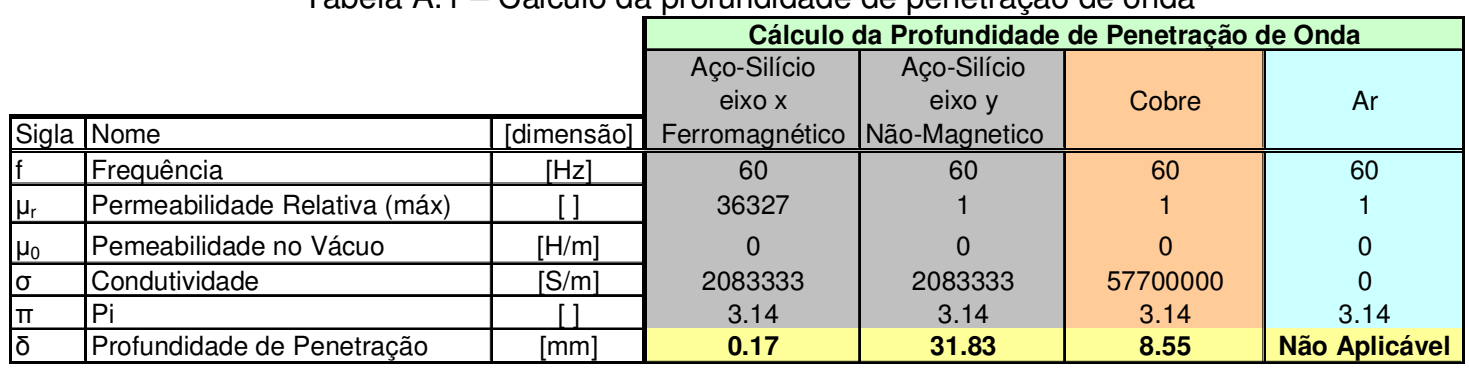

\section{A.3 Propriedade dos materiais utilizados}

Os dados dos materiais abaixo estão em condições normais e a uma temperatura de $20^{\circ} \mathrm{C}$.

\section{A.3.1 $\mathrm{Ar}$}

Permeabilidade: Linear, Isotrópica e Real $=1$.

Coercividade: $0 \mathrm{~A} / \mathrm{m}$

Condutividade Elétrica: Isotrópico $=0 \mathrm{~S} / \mathrm{m}$.

Permissividade: Isotrópico e Real $=1$.

Densidade: $1,2 \mathrm{~kg} / \mathrm{m}^{3}$.

\section{A.3.2 Cobre}


Permeabilidade: Linear, Isotrópica e Real $=1$.

Coercividade: $0 \mathrm{~A} / \mathrm{m}$.

Condutividade Elétrica: Isotrópico $=57700000 \mathrm{~S} / \mathrm{m}$.

Permissividade: Isotrópico e Real $=1$.

Densidade: $8954 \mathrm{~kg} / \mathrm{m}^{3}$.

\section{A.3.3 Aço-silício}

Permeabilidade: Não-linear, Anisotrópico e Real.

Tabela A.2 - Dados da curva B-H do material estudado - aço-silício de grão orientado (GO) na direção de laminação - ACESITA

\begin{tabular}{|c|c|}
\hline$H[A / m]$ & $B[T]$ \\
\hline 9.3 & 0.00 \\
\hline 9.3 & 0.20 \\
\hline 11.1 & 0.30 \\
\hline 12.7 & 0.40 \\
\hline 16.4 & 0.60 \\
\hline 19.5 & 0.80 \\
\hline 22.5 & 1.00 \\
\hline 26.4 & 1.20 \\
\hline 30.0 & 1.30 \\
\hline 36.2 & 1.40 \\
\hline 47.7 & 1.50 \\
\hline 73.6 & 1.60 \\
\hline 153.2 & 1.70 \\
\hline 508.7 & 1.80 \\
\hline 990.8 & 1.85 \\
\hline 1903.0 & 1.90 \\
\hline
\end{tabular}

Tabela A.3 - Curva B-H do material estudado - aço-silício de grão orientado (GO) na direção de nãolaminação - ACESITA

\begin{tabular}{|c|c|}
\hline $\mathrm{H}[\mathrm{A} / \mathrm{m}]$ & $B[\mathrm{~T}]$ \\
\hline 0,0 & 0,0 \\
\hline 1511972,0 & 1,9 \\
\hline
\end{tabular}

A tabela A.3 mostra que a permeabilidade relativa na direção normal à de orientação dos grãos é igual à permeabilidade do vácuo, ou seja, $\mu=\mu_{0}$.

Coercividade: $0 \mathrm{~A} / \mathrm{m}$

Perda a $60 \mathrm{~Hz}$. 
Tabela A.4 - Indução de pico versus perda à $60 \mathrm{~Hz}$ - ACESITA

\begin{tabular}{|c|c|}
\hline$B_{\text {pico }}[\mathrm{T}]$ & Perda $[\mathrm{W} / \mathrm{kg}]$ \\
\hline 0.00 & 0.000 \\
\hline 0.20 & 0.025 \\
\hline 0.30 & 0.047 \\
\hline 0.40 & 0.081 \\
\hline 0.60 & 0.175 \\
\hline 0.80 & 0.302 \\
\hline 1.00 & 0.462 \\
\hline 1.20 & 0.659 \\
\hline 1.30 & 0.775 \\
\hline 1.40 & 0.908 \\
\hline 1.50 & 1.066 \\
\hline 1.60 & 1.274 \\
\hline 1.70 & 1.589 \\
\hline 1.80 & 2.100 \\
\hline 1.85 & 2.381 \\
\hline 1.90 & 2.631 \\
\hline
\end{tabular}

Resistividade Elétrica: $4.8 \cdot 10^{-7} \Omega \cdot m$.

Permissividade: Isotrópico e Real = 1 .

Densidade: $7650 \mathrm{~kg} / \mathrm{m}^{3}$.

\section{A.4 Dados de entrada e configuração do programa}

Unidades:

- Comprimento: $\mu m$.

- Freqüência: $\mathrm{Hz}$.

- Tempo: ms.

- Temperatura: $\stackrel{\circ}{ } \mathrm{C}$.

Geral:

- Temperatura Inicial: $20^{\circ} \mathrm{C}$. 
- Freqüência para cálculo de perda: $60 \mathrm{~Hz}$.

Malha do aço-silício:

- Tamanho do maior elemento: $80 \mu m$.

- Opção: melhorar a qualidade da malha inicial antes da resolução ativada.

Algoritmo de Cálculo:

- Tipo de Material: Não-homogêneo.

- Método: Newton-Raphson.

- Número Máximo de Iteração de Newton: 20.

- Ordem de Polinômio: 2.

- Tolerância de Newton: 1\%.

- Gradiente Conjugado: 0,01\%.

Adaptação de Malha:

- Adaptação H: 5\%.

- Tolerância: 1\%.

- Máximo número de passos: 10. 


\section{APÊNDICE B - CÁLCULO DAS PROPRIEDADES FÍSICAS PARA NÚCLEO HOMOGÊNEO}

No modelo de núcleo homogeneizado um bloco de material laminado é substituído por um bloco equivalente não-laminado, homogêneo e anisotrópico com as propriedades $[\mu],[\sigma][59],[60],[61]$.

A figura B.1 apresenta a curva BH do material estudado e a figura B.2 apresenta a curva de intensidade de campo por permeabilidade. Quando a indução é de 1,0T, tem-se:

$\mu_{f x}=35500.4$

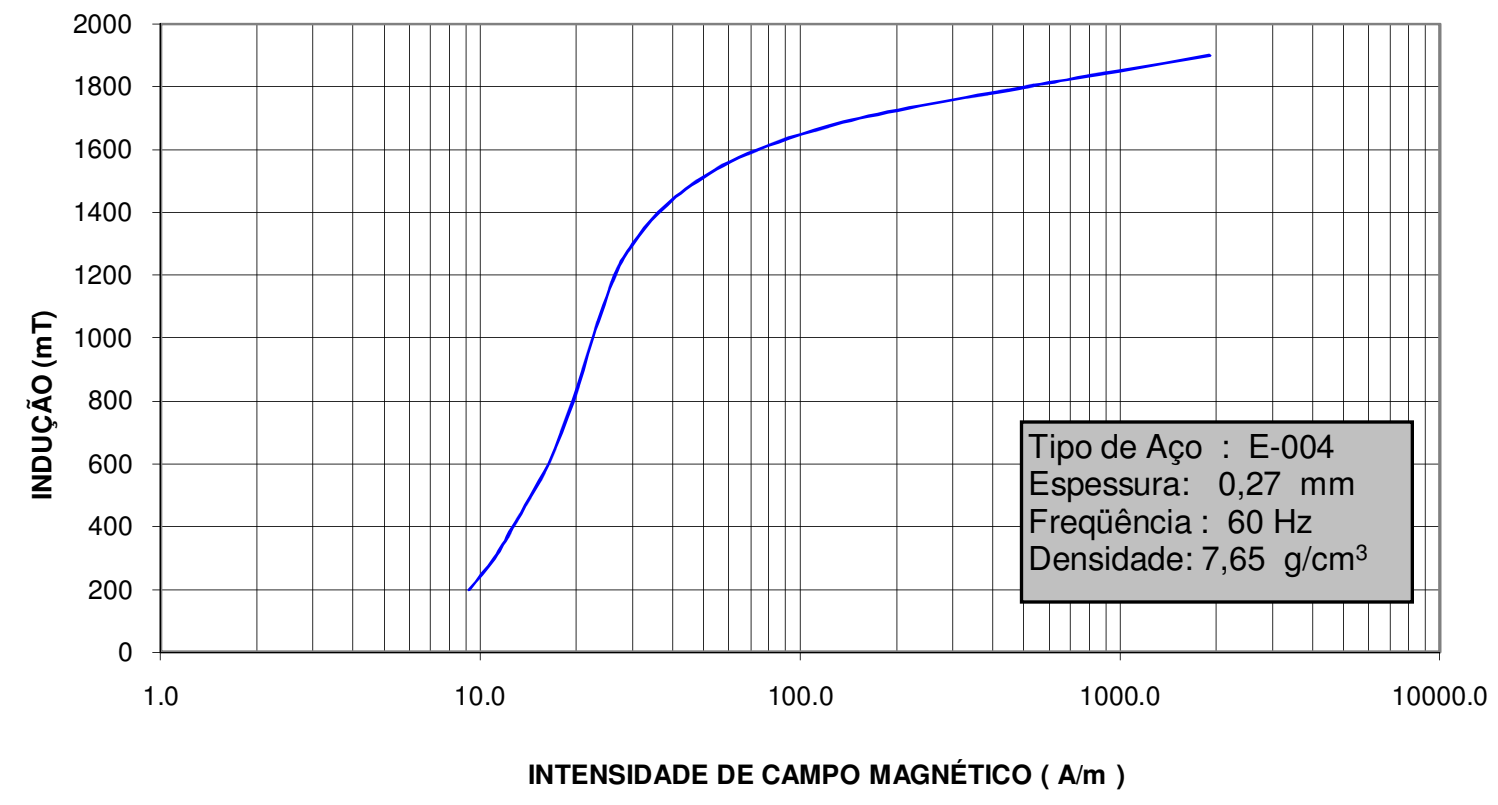

Figura B.1 - Curva de Magnetização BH do material utilizado - GO [69] 


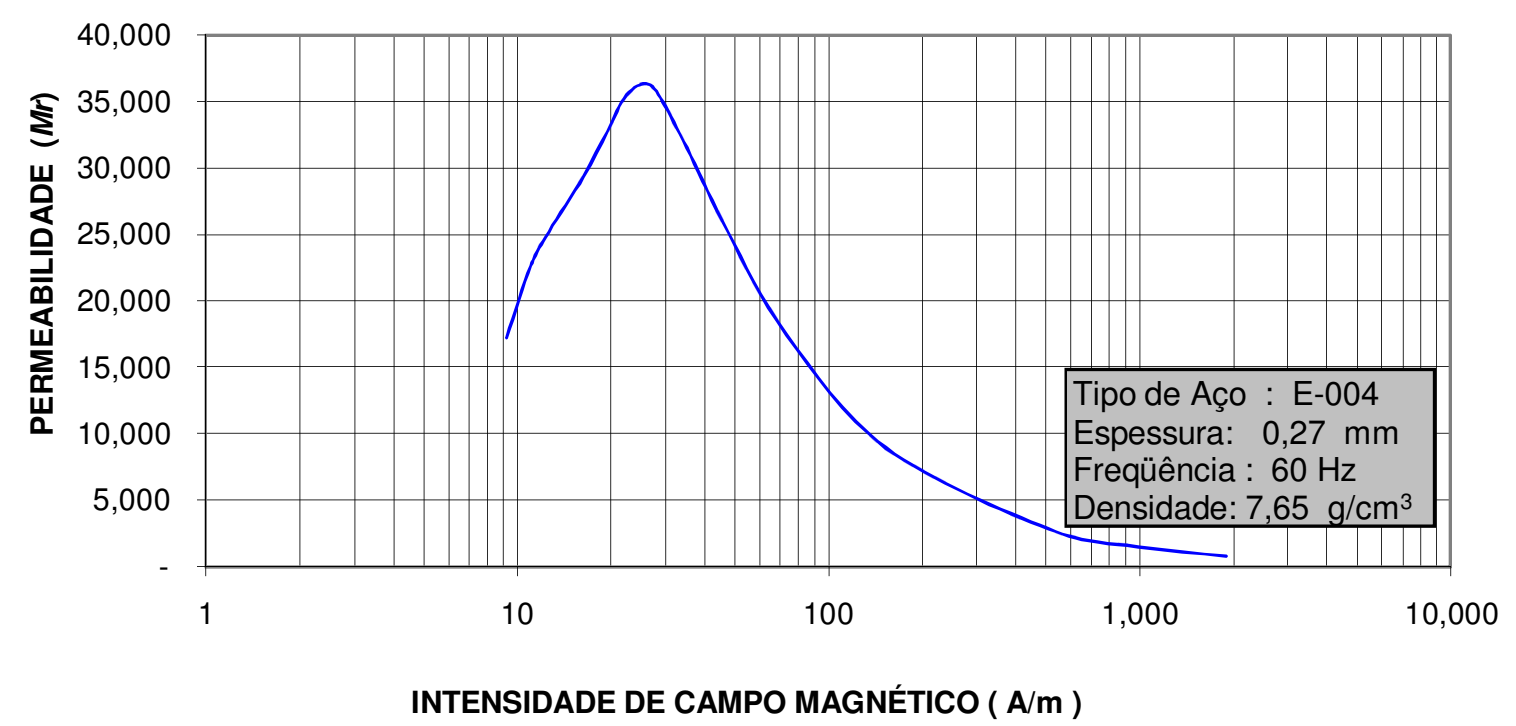

Figura B.2 - Permeabilidade relativa de pico [69]

$\sigma_{f}=2000000 S / m$

Para, fator de empilhamento $\varepsilon=0,96$, tem-se que:

$$
\mu_{t}=\varepsilon \mu_{0}+(1-\varepsilon) \mu_{f x}
$$

$\mu_{t}=0.96 \cdot 4 \pi 10^{-7}+(1-0.96) * 35500.4$

$\mu_{t}=1420.016$

$$
\frac{1}{\mu_{n}}=\frac{\varepsilon}{\mu_{0}}+\frac{(1-\varepsilon)}{\mu_{f x}}
$$

$\frac{1}{\mu_{n}}=\frac{0.96}{4 \pi 10^{-7}}+\frac{(1-0.96)}{35500.4}$

$\mu_{n}=1.309 \cdot 10^{-6}$

$$
\sigma_{t}=(1-\varepsilon) \sigma_{f x}
$$

$\sigma_{t}=(1-0.96) 2000000$

$\sigma_{t}=80000$ 


$$
\sigma_{n}=0
$$

Os tensores inseridos no programa foram:

$$
\begin{aligned}
& {[\mu]=\left[\begin{array}{cc}
\mu_{t} & 0 \\
0 & \mu_{n}
\end{array}\right]=\left[\begin{array}{cc}
1420.016 & 0 \\
0 & 1.309 \cdot 10^{-6}
\end{array}\right]} \\
& {[\sigma]=\left[\begin{array}{cc}
\sigma_{t} & 0 \\
0 & \sigma_{n}
\end{array}\right]=\left[\begin{array}{cc}
80000 & 0 \\
0 & 0
\end{array}\right]}
\end{aligned}
$$




\section{ANEXO A - CÁlCULO DE CAPITALIZAÇÃO DE PERDAS EM VAZIO}

\section{Parâmetros Relevantes}

\section{A.1 O custo da energia e amortização do custo}

O custo de energia por $\mathrm{kWh}$ é influenciado por muitos fatores, assim como o mercado do petróleo, oferta e demanda da eletricidade, taxas, inflação, situações e decisões políticas e variações climáticas. Isso pode aumentar ou diminuir a demanda de um ano para outro ou mesmo flutuar durante as 24 horas de um dia. Isso faz com que a previsão do custo da energia torne-se muito difícil. Analisando o cenário passado, é possível verificar que o custo da energia, em média, aumenta por ano. Em um modelo de cálculo de perdas capitalizadas, é possível calcular várias alternativas com taxas, a fim de verificar como o resultado final é influenciado.

O custo de energia consumida pelos equipamentos de refrigeração como bombas e ventiladores, devem ser capitalizados, pois é uma potência necessária para o sistema de refrigeração do transformador.

\section{A.2 Carregamento padrão do transformador}

O carregamento padrão de um transformador pode variar muito de um equipamento para outro, em aplicações industriais; por exemplo, para eletrólise do alumínio, esses transformadores operam continuamente com 100\% de carga nominal, exceto 
durante paradas programadas para manutenção ou por alguma razão econômica do mercado de alumínio.

Transformadores para operações em sistemas elétricos normalmente são dimensionados para trabalhar com potência inferior à potência nominal do transformador, mas isso é, apenas, por uma questão de segurança: o caso de haver necessidade de aumento da demanda de energia elétrica, que o transformador consiga operar nessa situação. Geralmente a carga inicial de um transformador é metade da carga nominal, que faz com que a perda sob carga seja um quarto menor, mas a perda sem carga sempre será constante, independentemente do carregamento do equipamento.

\section{A.3 Vida útil}

Inúmeros transformadores estão operando satisfatoriamente após mais de meio século em serviço. Para acumular uma economia considerável durante um longo período, deve-se fazer um investimento para compra de um transformador com baixas perdas, que, nesses casos, torna-se mais atrativo. $O$ montante de dinheiro que o investidor está disposto a investir por $\mathrm{kW}$ reduzido é determinado pelo número de anos $(n)$ que estará disposto a esperar para acumular os ganhos que foram investidos na compra de um transformador com baixas perdas. O valor deve ser ajustado de acordo com a taxa de inflação. Antes dos $n$ anos, não há receita líquida sobre o investimento: os ganhos virão nos anos seguintes.

Neste estudo, deve-se considerar o tempo que o transformador ficará fora do sistema para manutenção ou se ele será um transformador de reserva. 


\section{A.4 Prêmio de seguro}

O prêmio anual, normalmente, é certa porcentagem do custo de aquisição, acrescido das despesas operacionais. É ajustado de acordo com a taxa de inflação, no entanto, esse parâmetro, comumente, não tem grande influência sobre o valor de perda capitalizada e pode ser excluído.

\section{A.5 Impostos}

Impostos sobre a propriedade é uma determinada porcentagem do custo de aquisição e é acrescentado, também, o custo operacional. Regras de amortização para o equipamento variam de um país para outro. Após certo número de anos, o valor do transformador é amortizado e o imposto sobre a propriedade pode desaparecer.

\section{A.6 Capitalização}

Será desenvolvida aqui uma maneira para alcançar o valor de perdas capitalizadas.

O montante de dinheiro $X$ é o valor que o comprador está disposto a investir, de maneira a reduzir $1 \mathrm{~kW}$ de perda em vazio.

O calculo se dará pelo preço de energia em $\$ / k W h$, essa variável é $d$. Deve-se assumir, como exemplo, uma concessionária que adquire energia elétrica por um preço de $d \$ / \mathrm{kW}$. O preço $d$ é o valor da energia no local em que o transformador será instalado, já considerando as perdas desde a geração e a alimentação da rede 
de transmissão. O valor $d$ é o preço da energia durante o primeiro ano de funcionamento do transformador. O custo de energia para $1 \mathrm{~kW}$ no primeiro ano será, então, $8760 \cdot d$, desde que a potência seja consumida continuamente durante todas as 8760 horas de um ano.

Considera-se que o preço da energia aumenta a uma taxa $p \%$ ao ano, em média, para um número $n$ de anos. O custo de $1 \mathrm{~kW}$ durante o segundo ano de operação da máquina será de,

$$
8760 \cdot d \cdot\left(1+\frac{p}{100}\right)
$$

para o terceiro ano será de,

$$
8760 \cdot d \cdot\left(1+\frac{p}{100}\right)^{2}
$$

para o n-ésimo ano será de,

$$
8760 \cdot d \cdot\left(1+\frac{p}{100}\right)^{n-1}
$$

sendo,

$$
q=1+\frac{p}{100}
$$

A soma do custo de $1 \mathrm{~kW}$ consumido continuamente durante $n$ anos será então

$$
8760 \cdot d \cdot\left(1+q+q^{2}+\ldots .+q^{n-1}\right) \quad(\mathrm{A} .5-2)
$$

em que a expressão dentro dos parênteses representa uma série geométrica com o quociente $q$. A soma $s$ dessa série é a seguinte:

$$
s=\frac{q^{n}-1}{q-1}
$$

Para calcular o custo total para $1 \mathrm{~kW}$ durante $n$ anos, o custo para o primeiro ano $8760 \cdot d$ deve então ser multiplicado pelo fator $s$. A figura A.1 apresenta curvas para diferentes valores de $n$. 


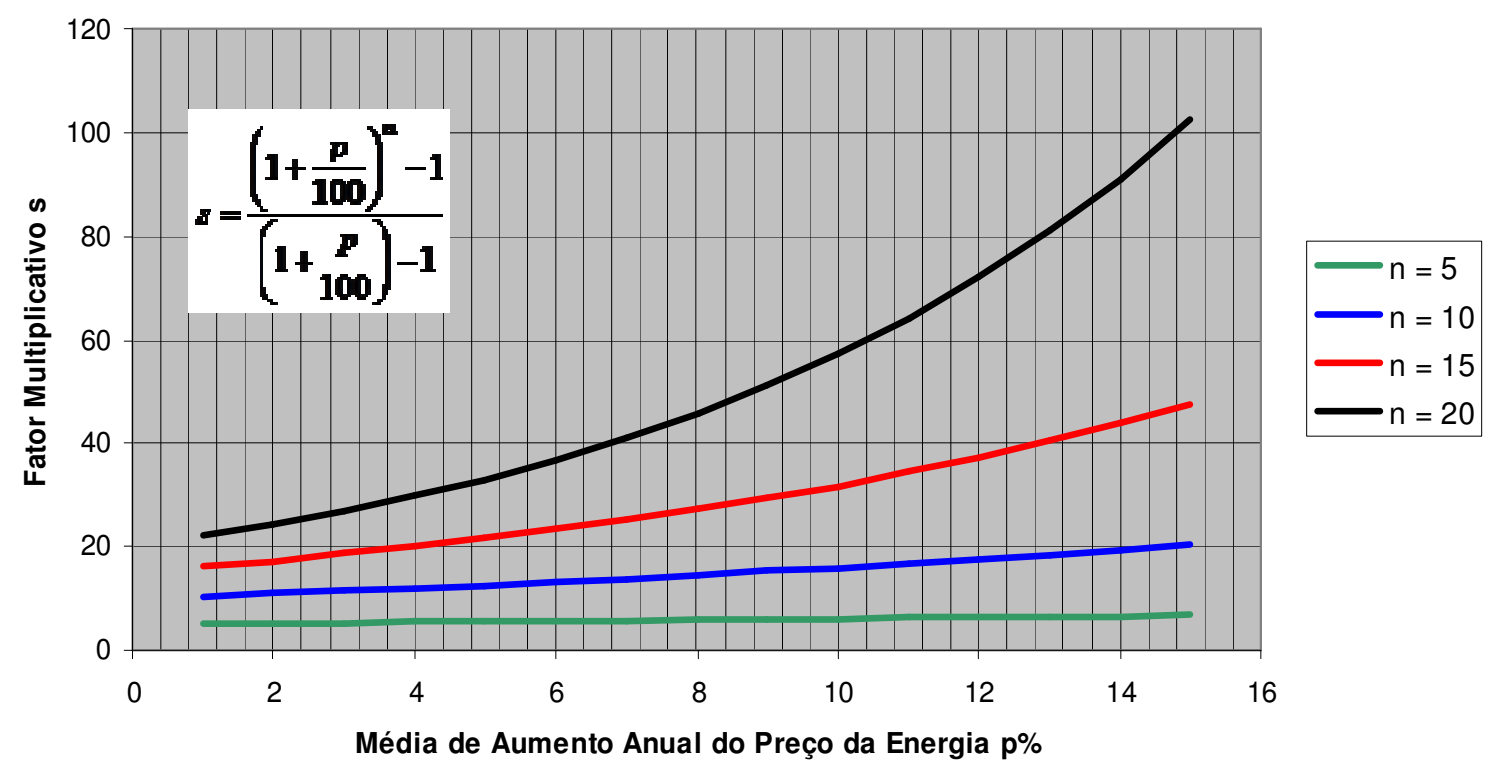

Figura A.1 - Comparativo com diversos $n$ [64]

O gráfico abaixo mostra a curva de $s$ por $p \%$ com um $n$ médio de 50 anos.

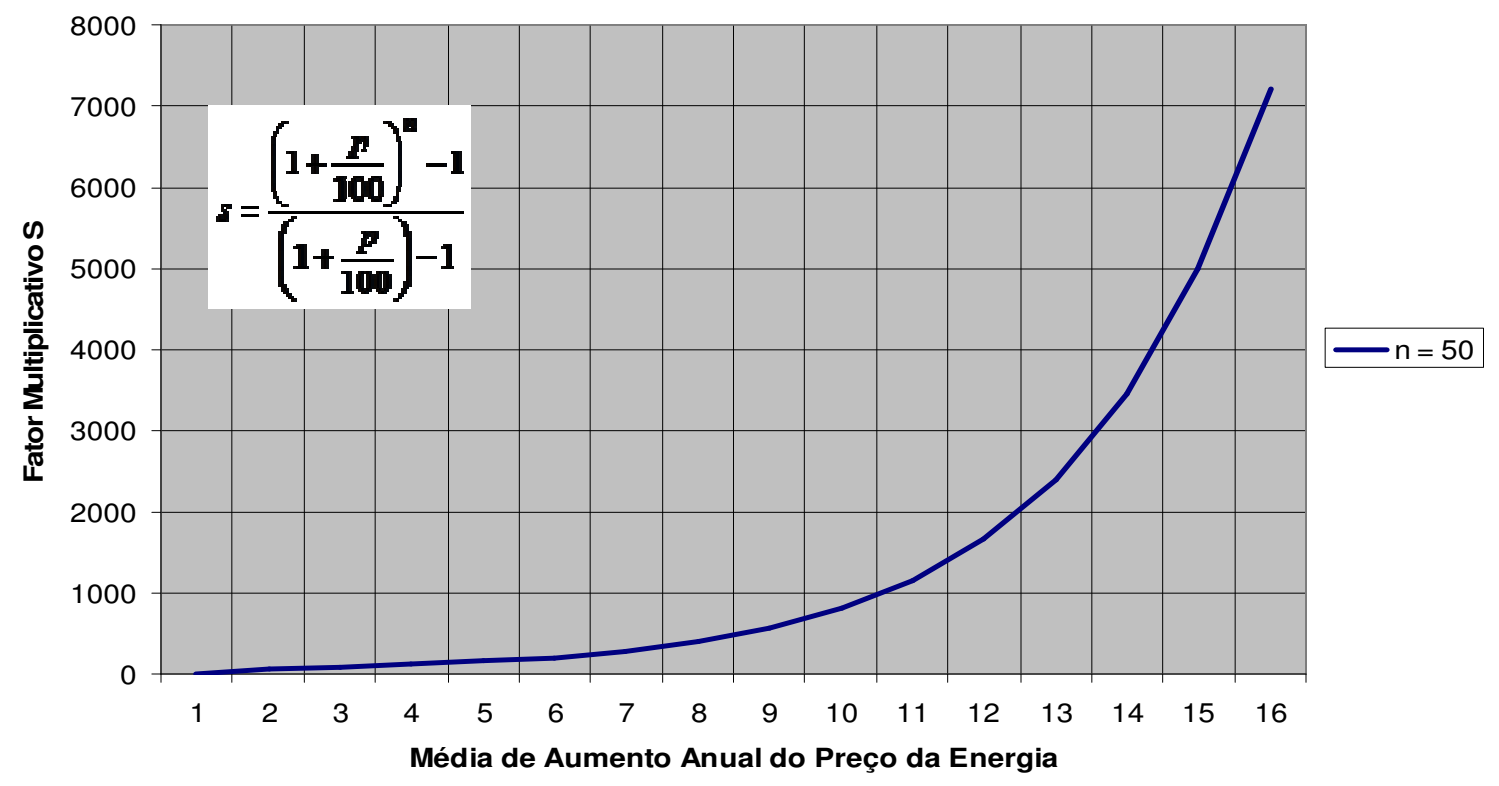

Figura A.2 - Comparativo com $n=50$ [64] 
Para saber quanto se deve investir para que haja uma redução de $1 \mathrm{~kW}$ nas perdas em vazio, considerando que o retorno dos investimentos tem a forma de evitar despesas durante os anos que o transformador estará em funcionamento, o primeiro passo é determinar quantos anos irão decorrer antes que o valor acumulado economizado retorne. Em outras palavras, deve-se decidir quantos anos $n$ é permitidos passar, antes de o investidor obter o valor investido sob forma de evitar despesas. O investidor também pode exigir que o montante investido seja ajustado para o valor passado na taxa de inflação média anual, estimada em $i \%$ durante $n$ anos.

Quando $n$ e $i$ são determinados, uma taxa de juros correspondente à média anual $a \%$ pode ser calculada como é mostrado a seguir.

O retorno anual do montante investido $X$ será:

$$
X \cdot \frac{a}{100}
$$

Para $n$ anos têm-se:

$$
n \cdot X \cdot \frac{a}{100}
$$

Com a média de taxa de inflação anual de $i \%$, o montante investido $X$ depois de $n$ anos será ajustado para

$$
X \cdot\left(1+\frac{i}{100}\right)^{n}
$$

Para manter o valor real original de $X$, pode-se escrever o seguinte:

$$
n \cdot X \cdot \frac{a}{100}=X \cdot\left(1+\frac{i}{100}\right)^{n} \quad(\mathrm{~A} .10-2) \text {. }
$$

Esta equação dá a correlação entre as três variáveis $n, i$ e $a$ :

$$
a=\frac{100}{n} \cdot\left(1+\frac{i}{100}\right)^{n}
$$

O retorno total sob o montante investido $X$ para obter $1 \mathrm{~kW}$ menos de perda em vazio deve ser igual ao custo de energia reduzido em $1 \mathrm{~kW}$ em vazio acumulada durante $n$ anos de operação, dado por: 


$$
8760 \cdot d \cdot \frac{\left(1+\frac{p}{100}\right)^{n}-1}{\left(1+\frac{p}{100}\right)-1}
$$

Chega-se então a:

$$
n \cdot X \cdot \frac{a}{100}=8760 \cdot d \cdot \frac{\left(1+\frac{p}{100}\right)^{n}-1}{\left(1+\frac{p}{100}\right)-1} \quad(\mathrm{~A} .13-2)
$$

O lado esquerdo de (A.13-2) representa o retorno sobre o investimento $X$ e o lado direito, o valor de economia de energia, resultando em:

$$
X=\frac{8760 \cdot d\left(\left(1+\frac{p}{100}\right)^{n}-1\right)}{n \cdot a \cdot p} \cdot 100 \cdot 100 \quad(\mathrm{~A} .14-2)
$$

